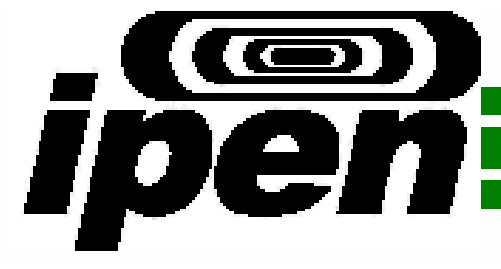

AUTARQUIA ASS OCIAD A A UIIIVRSIDADE DE SÄO PAULO

Desenvolvimento de uma metodologia para a calibração de instrumentos de medida utilizados no controle de qualidade em radiodiagnóstico intervencional

JUREMA APARECIDA DE MIRANDA

Dissertação apresentada como parte dos requisitos para obtenção do Grau de Mestre em Ciências na Área de Tecnologia Nuclear - Aplicações.

Orientadora:

Dra. Maria da Penha Albuquerque Potiens 


\section{INSTITUTO DE PESQUISAS ENERGÉTICAS E NUCLEARES}

Autarquia associada à Universidade de São Paulo

Desenvolvimento de uma metodologia para a calibração de instrumentos de medida utilizados no controle de qualidade em radiodiagnóstico intervencional

JUREMA APARECIDA DE MIRANDA

Dissertação apresentada como parte dos requisitos para obtenção do Grau de Mestre em Ciências na Área de Tecnologia Nuclear Aplicações.

Orientadora:

Dra. Maria da Penha Albuquerque

Potiens

São Paulo 


\section{DEDICATÓRIA}

Dedico este trabalho aos meus pais;

Vanderly Fátima Ribeiro Miranda e Avelino Martins de Miranda.

Que tanto lutaram para que este momento de vitória chegasse a minha vida. 


\section{AGRADECIMENTOS}

Á Dra. Maria da Penha Albuquerque Potiens, pela paciência e dedicação, durante os anos de estudo;

Ao Dr. Vitor Vivolo pelo apoio técnico;

Á Dra. Felícia Del Gallo Rocha pelo apoio e incentivo;

Ao Sr. José Carlos Sabino pela confecção dos simuladores e suportes;

Ao Sr. Marcos Xavier pelo apoio técnico;

Ao Instituto de Pesquisas Energéticas e Nucleares pela oportunidade para 0 desenvolvimento deste trabalho;

Ao Conselho Nacional de Desenvolvimento Científico e Tecnológico, CNPq, pelo suporte financeiro;

Á todos os amigos que fiz no laboratório de calibração de instrumentos, LCI, do IPEN. 


\title{
Desenvolvimento de uma metodologia para a calibração de instrumentos de medida utilizados no controle de qualidade em radiodiagnóstico intervencional
}

\begin{abstract}
RESUMO
Radiologia intervencional é a prática na qual imagens geradas por radiação-X são usadas como uma ferramenta na condução de procedimentos diagnósticos terapêuticos. Tanto nos procedimentos para diagnósticos como nos terapêuticos, os tempos de exposição são longos, podendo causar graves lesões no paciente, e contribuindo para a dose espalhada no corpo clínico. O Brasil ainda não possui regras bem definidas quanto às doses e dosimetria de feixes fluoroscópicos. Há um grande interesse no estudo destes feixes, quanto a qualidade do feixe, camada-semi-redutora, entre outros parâmetros.

Neste trabalho foi desenvolvida uma metodologia para a calibração de instrumentos de medida utilizados no controle de qualidade em radiodiagnóstico intervencional utilizando um sistema de radiação $X$ clínico Medicor Neo Diagnomax, no modo fluoroscópico. Foi utilizada uma câmara de ionização plana marca PTW como monitora. Algumas câmaras de ionização recomendadas para fluoroscopia foram avaliadas e calibradas em relação à câmara de ionização de referência do laboratório de calibração do IPEN. Foram implantadas as qualidades de radiação $R Q R 3$, RQR5 e $R Q R 7$ e as específicas para a fluoroscopia RQC3, RQC5 e RQC7 seguindo as recomendações da norma IEC 61267. Todas as características dos feixes foram determinadas. Para a realização deste trabalho foi construído um sistema de posicionamento de câmaras de ionização. Para a determinação de dose de entrada e saída do paciente e de radiação espalhada na posição do corpo clínico, foram construídos simuladores de acrílico. Os resultados obtidos mostram uma taxa de Kerma de entrada no simulador de 4,5 $\times 10^{-3}$, $1,2 \times 10^{-2}$ e $1,9 \times 10^{-2} \mathrm{~Gy} / \mathrm{min}$ para RQC 3, RQC 5, RQC 7 respectivamente. Foram realizados testes sem e com a colimação posicionada entre a câmara monitora e o simulador e os resultados encontrados mostram uma diferença de $+5,5 \%,+0,6 \%$ e +0,8 \%. Comprovando a importância da colimação nestes procedimentos intervencionistas.
\end{abstract}




\title{
Development of a calibration methodology for instruments used to interventional radiology quality control
}

\begin{abstract}
Interventional radiology is the technique where $X$ radiation images are used as a tool in the conduction of diagnostic or/and therapeutic procedures. The exposition times are long for both procedures, diagnostic and therapeutic, may cause serious injuries in the patient, and also contribute to the dose of the clinical staff. In Brazil there are not yet well established rules to determine the doses and to make the dosimetry in fluoroscopic beams. There is great interest in this study, in relation to the beam quality, the half-value-layer, and others parameters. In this work a Medicor Neo Diagnomax clinical $X$ ray generator, fluoroscopy mode, was used to develop a calibration methodology for instruments used in interventional radiology quality control. One plane parallel ionization chamber PTW was used as monitor. The ionization chambers recommended for fluoroscopy measurements had been evaluated and calibrated in relation to the IPEN Calibration Laboratory reference ionization chamber. The RQR3, RQR5 and RQR7 radiation qualities and the specific ones for fluoroscopy, RQC3, RQC5 and RQC7, were established following the norm IEC 61267. All beams characteristics were determined. Ionization chambers positioning system and the acrylic phantoms to the entrance and exit doses determination were developed and constructed. The results obtained show air kerma rates of $4.5 \times 10^{-3}, 1.2 \times 10^{-2}$ and $1.9 \times 10^{-2} \mathrm{~Gy} / \mathrm{min}$ for RQC3, RQC5 and RQC7 respectively. Tests with and without the collimation just after the monitor chamber, were carried out and the results showed a difference of $+5.5 \%,+0.6 \% \mathrm{e}$ $+0.8 \%$, confirming the importance of the collimation use in these interventionist procedures.
\end{abstract}




\section{SUMÁRIO}

DEDICATÓRIA

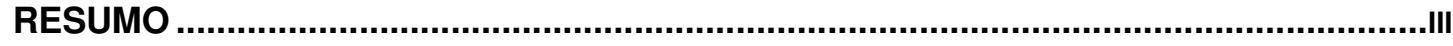

ABSTRACT

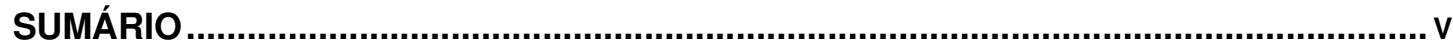

1. INTRODUÇÃO................................................................................................

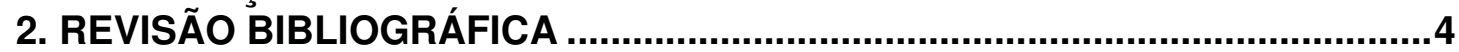

3. FUNDAMENTOS TEÓRICOS ..................................................................... 8

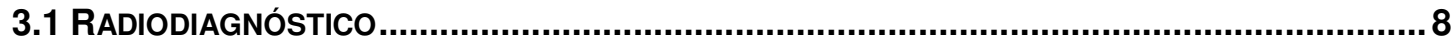

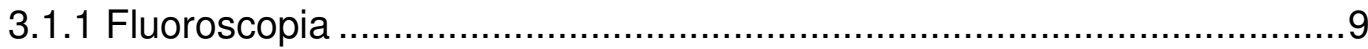

3.1.1.1 Evolução tecnológica dos equipamentos de radiodiagnóstico .............11

3.1.1.2 Radiologia intervencional ............................................................. 16

3.1.2 Controle de qualidade em equipamentos de fluoroscopia ....................17

3.1.3 Parâmetros importantes para formação da imagem em fluoroscopia....18

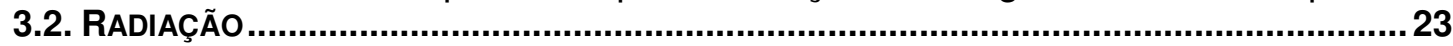

3.2.1 Interação da radiação por colisões com elétrons.................................23

3.2.2. Interações elásticas com o núcleo ..................................................24

3.2.3. Interações inelásticas com o núcleo ............................................24

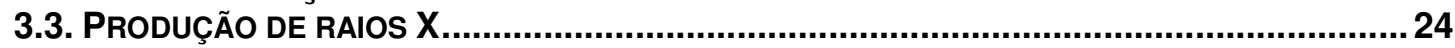

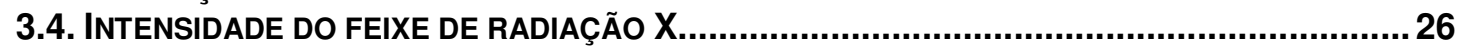

3.4.1 Fatores que modificam a intensidade do feixe..................................27

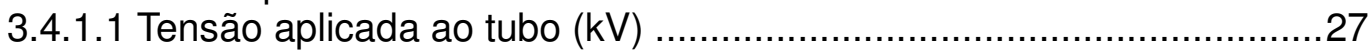

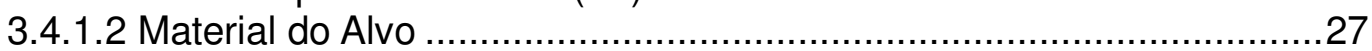

3.4.1.3 Corrente do Tubo ................................................................. 28

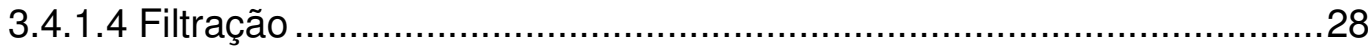

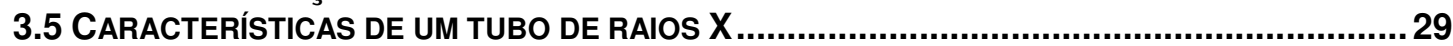

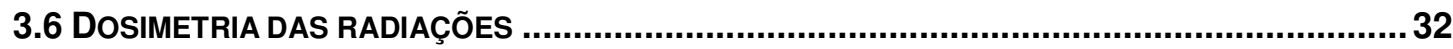

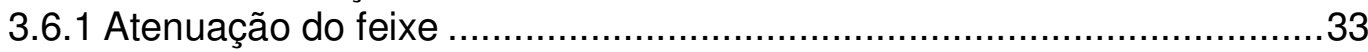

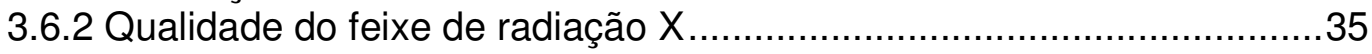

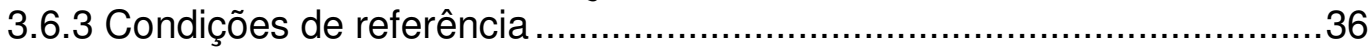

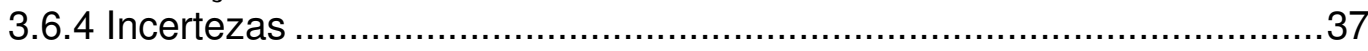

3.6.5 Princípios de proteção radiológica ..............................................38

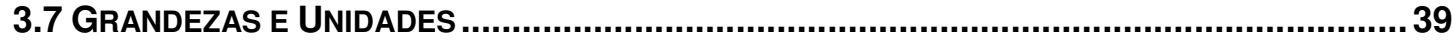

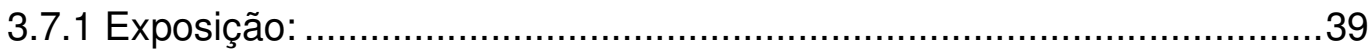

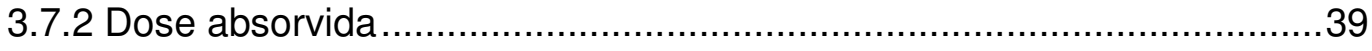

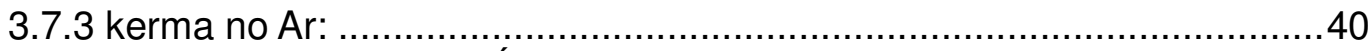

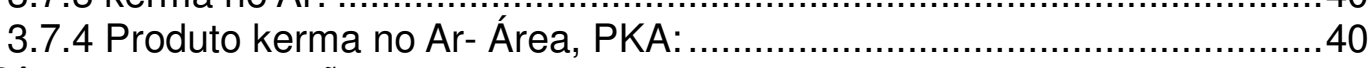

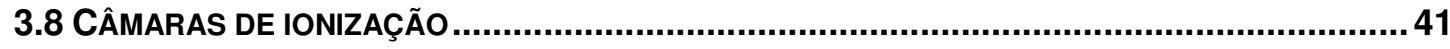

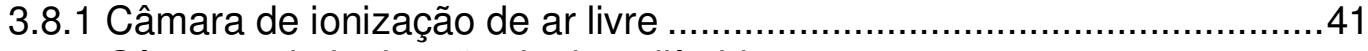

3.8.2 Câmaras de ionização do tipo cilíndrica ............................................... 42

3.8.3 Câmaras de ionização de placas paralelas ........................................43

3.8.4 Câmara de ionização para medidas de kerma no ar em fluoroscopia ...44

3.8.5 Câmara de ionização para medidas de produto kerma no ar-área, KAP.

4. MATERIAIS E MÉTODOS

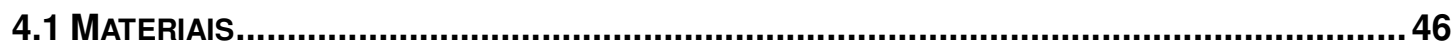

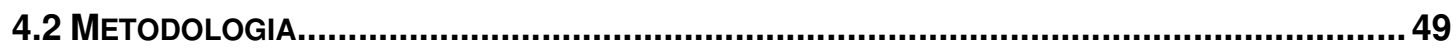

4.2.1 Método de calibração .................................................................49

4.2.2 Teste de estabilidade da câmara de referência...................................49

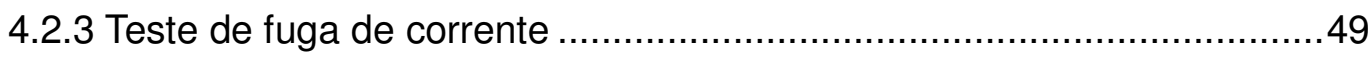


4.2.4 Sistemas de posicionamento da fonte de controle .............................50

4.2.5 Utilização de Câmara monitora...................................................... 51

4.2.6 Determinação da filtração adicional ................................................52

4.2.7 Implantação das qualidades de radiação............................................54

4.2.8 Determinação das taxas de kerma no ar .........................................54

4.2.9 Determinação da tensão ( $\mathrm{kV}$ ) aplicada aos equipamentos de radiação $X$

4.2.10 Dependência energética das câmaras de ionização utilizadas............56

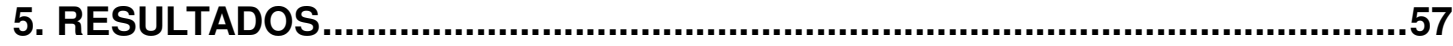

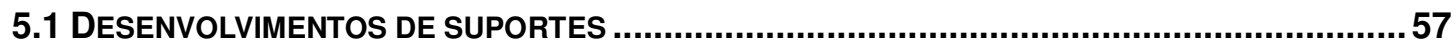

5.2 ESTUDO DO COMPORTAMENTO DAS CÂMARAS PLANAS COMO CÂMARAS MONITORAS....... 58

5.3 CONTROLE DE QUALIDADE DO SISTEMA DE RADIAÇÃO X MEDICOR..................................61

5.4 IMPLANTAÇÃO DAS QUALIDADES RQR DE ACORDO COM A REVISÃO DE NORMA IEC 61267

5.4.1 Determinação da filtração adicional ............................................64

5.4.2 Determinação das Camadas Semi-redutoras, CSR ...........................66

5.4.3 Determinação das taxas de kerma no ar ......................................68

5.5 CONTROLE DE QUALIDADE E CALIBRAÇÃo DAS CÂMARAS DE IONIZAÇÃo DE FLUOROSCOPIA

5.6 IMPLANTAÇÃO DAS QUALIDADES RQC DE ACORDO A NORMA IEC $61267^{(17)} \ldots \ldots \ldots \ldots \ldots \ldots . . . . . . . . . . .70$

5.7 DETERMINAÇÃO DA HOMOGENEIDADE DO CAMPO DE RADIAÇÃO ......................................72 5.8 DESENVOLVIMENTO E UTILIZAÇÃO DOS SIMULADORES PARA ESTIMATIVA DO KERMA DE

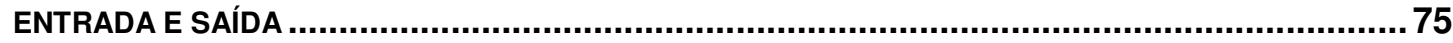

5.8.1 Determinação do kerma na superfície de entrada usando um simulador

5.8.3 Determinação das taxas de kerma na superfície de entrada simulando um paciente maior ......................................................................... 82

5.8.4 Determinação das taxas de kerma de saída simulando um paciente maior.

5.8.5 Medidas de radiação espalhada para uma situação extrema (simulador

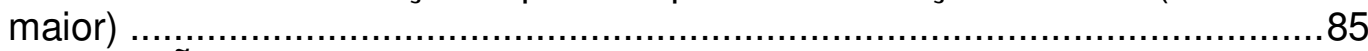

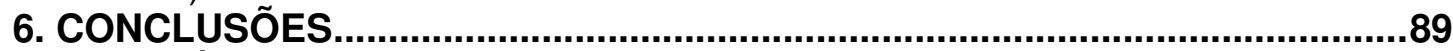

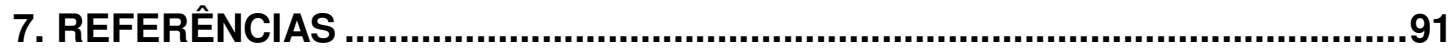




\section{INTRODUÇÃO}

A descoberta dos raios X, em 1895 pelo físico alemão e professor da Universidade de Wurzburg, Wilhelm Conrad Roentgen ${ }^{(1)}$, mudou o mundo médicocientífico e abriu as portas para o novo, útil e tão desconhecido fenômeno. Médicos puderam avaliar e diagnosticar os seus pacientes de uma forma jamais vista até o momento, visualizando o interior do corpo humano sem a necessidade de abrí-lo ou dissecá-lo. Órgãos, músculos e ossos vistos de uma forma diferente: de fora para dentro. Com esta possibilidade ao alcance de muitos médicos e cientistas, a prática tornou-se a principal ferramenta para diagnosticar além de uma fonte de estudos. Embora os mistérios que cercavam os raios $\mathrm{X}$ fossem imensos, não sabendo exatamente quais eram os seus riscos, o seu uso disseminou-se e tornou-se de grande valia para a população. A curiosidade sobre o assunto explodiu na sociedade da época ${ }^{(2)}$.

Os cientistas da época tiveram grande interesse na descoberta de Roentgen. Entre eles, Thomas Edison elaborou um aparelho que permitia a visualização das estruturas internas do corpo humano(2). A evolução dos sistemas de radiação $X$ foi rápida e não demorou muito para que novos equipamentos fossem inventados, técnicas aperfeiçoadas e maiores esforços para entender o mecanismo do processo fossem realizados. Com a evolução rápida das máquinas e dos procedimentos, tanto médicos quanto científicos, surgiram também vários problemas, como por exemplo, epilação dos membros superiores, eritemas e até sérias queimaduras. Com o agravamento dos problemas relacionados com a radiação X, criou-se em 1923 o primeiro Comitê Internacional de Proteção Radiológica ${ }^{(3)}$. Foram criados alguns regulamentos e normas para a utilização das radiações ionizantes, embora pouco se soubesse das suas propriedades danosas $^{(1,2,3)}$.

O radiodiagnóstico é a prática na qual um feixe de radiação, geralmente radiação $X$ é usado para produzir uma imagem com o propósito de se obter um diagnóstico, que irá excluir ou avaliar o desenvolvimento de uma condição patológica. Radiologia Intervencional é a prática nas quais imagens geradas por radiação $X$ são usadas como uma ferramenta na condução de procedimentos 
terapêuticos. Neste último caso devem ser utilizados sistemas de radiação $X$ específicos, que utilizem acessórios visando à otimização das doses ao paciente, assim como uma manutenção adequada e um controle de qualidade apropriado $^{(4,5)}$.

As técnicas fluoroscópicas e as cinefluoroscópicas são as bases para procedimentos cardiovasculares. Importantes realizações diagnósticas e terapêuticas como cateterismo, angiografias cardíacas e vasculares, estudos eletrofisiológicos, pacemakers permanentes ou temporários estão entre os procedimentos que requerem ou são facilitados pelas imagens radiográficas ${ }^{(5,6)}$.

Nos recentes anos a capacidade e a complexidade dos procedimentos cardiovasculares vêm aumentando substancialmente. Certamente vários destes procedimentos, tantos diagnósticos quanto terapêuticos, podem levar um longo tempo de exposição, causando um dano considerável ao paciente.

$\mathrm{Na}$ radiologia intervencional instrumentos medidores de radiação são utilizados tanto para a dosimetria do paciente como para técnicas de programas de controle de qualidade, incluindo a qualidade da imagem. Ainda não existem níveis de referência bem estabelecidos para a dose dos pacientes nesta área. Vários estudos vêm sendo realizados com este propósito, tanto no exterior ${ }^{(7,8,9)}$ como no Brasil( ${ }^{(10,11,12,13)}$. Os fatores de retro-espalhamento foram estimados por vários autores utilizando métodos diferentes, como câmaras de ionização, dosímetros termoluminescentes e o método de Monte Carlo ${ }^{(14,15,16)}$. Embora as qualidades de radiação para calibração dos instrumentos utilizados em radiodiagnóstico já estejam bem definidas na norma IEC 61267 em sua última revisão ${ }^{(17)}$, ainda não existe um método específico para a calibração das câmaras de ionização utilizadas na dosimetria dos sistemas de radiologia intervencional, que leve em consideração os fatores de retroespalhamento.

O Laboratório de Calibração de Instrumentos do IPEN (LCI) realiza, há mais de 30 anos, calibração de instrumentos medidores de radiação, que são empregados em medidas de radioproteção, radiodiagnóstico e radioterapia. Este serviço é prestado a hospitais, indústrias, clínicas e outros usuários localizados em todo o Brasil. O aumento do número de equipamentos testados anualmente faz necessário o desenvolvimento contínuo de novos projetos para o aperfeiçoamento e a implementação dos métodos já existentes, bem como o estabelecimento de 
novas técnicas e a conseqüente ampliação dos serviços de calibração prestados $^{(18)}$.

Em 2007 a Agência Internacional de Energia Atômica (AIEA) publicou um código de prática, que destina técnicas especiais para os procedimentos de calibração dos instrumentos para fluoroscopia em Laboratório de Referência. Tais procedimentos são importantes para a padronização dos métodos e avaliação dos instrumentos clínicos. Para isso o laboratório deverá estabelecer pelo menos 3 qualidades de radiação recomendadas por este documento ${ }^{(4)}$.

O objetivo deste trabalho é o desenvolvimento de uma metodologia para o controle de qualidade de instrumentos de medida utilizados em radiodiagnóstico intervencional, considerando as especificidades destas medidas, visando uma melhoria na qualidade da imagem radiológica e a diminuição da dose no paciente e no corpo clínico. Tal procedimento será aplicado aos instrumentos encaminhados ao LCI para calibração periódica. 


\section{REVISÃO BIBLIOGRÁFICA}

Um equipamento de radiação $X$ médico é um sistema complexo, e para a sua utilização há a necessidade do conhecimento prévio do seu funcionamento e das aplicações técnicas específicas. Um sistema de radiação $X$ é composto por:

- Cabeçote $\rightarrow$ Ampola de vidro, Catodo, Anodo (giratório ou fixo), copo de foco e filamento;

- Geradores de alta tensão (primário e secundário);

- Mesa de comando.

A partir do aquecimento do filamento, para a geração da nuvem de elétrons, inicia-se o processo de geração da radiação $X$, aplica-se a diferença de potencial (DDP), onde os elétrons serão acelerados e freados bruscamente contra o material do anodo. O produto final da interação dos elétrons com a matéria (Tungstênio para a radiologia convencional e fluoroscopia e Molibdênio e o Ródio para a mamografia) é a radiação eletromagnética ${ }^{(4)}$.

Por serem ionizantes as radiações $\mathrm{X}$, gama e as partículas carregadas, se mal utilizadas podem provocar danos a saúde do trabalhador e do paciente. Segundo $\mathrm{Okuno}^{(3)}$ a partir de 1924 iniciou-se uma preocupação com as radiações ionizantes em relação à proteção radiológica. O primeiro Congresso Internacional de Radiologia foi realizado em Londres, onde foram discutidas as unidades e normas de trabalho com radiação X. O National Council on Radiation Protection and Measurements (NCRP), nos Estados Unidos, apresentou suas primeiras recomendações de segurança em $1947^{(3)}$, período pós segunda guerra mundial quando a preocupação com a proteção radiológica para baixas doses fez com que uma série de estudos fossem iniciados, além da elaboração de documentos orientativos para a padronização dos procedimentos radiológicos ${ }^{(3)}$. Além disso, a utilização de equipamento de radiodiagnóstico por um laboratório de calibração também requer a padronização dos métodos aplicados, norteando-se pelas normas estabelecidas por órgãos nacionais e internacionais ${ }^{(4,5,17)}$.

Cronologicamente pode se destacar algumas publicações, do Brasil e no exterior, que foram muito importantes para o estabelecimento de métodos e padronização de técnicas aplicadas com radiação $X$ levando-se em conta os princípios de proteção radiológica: 
$\rightarrow$ Em 1978, em São Paulo, foi publicado um decreto lei estadual (n.ำ 12.342, Livro V), que diz respeito aos procedimentos médicos e odontológicos que empregam radiação ionizante, com o objetivo de implementar a proteção radiológica ${ }^{(19)}$;

$\rightarrow$ A International Commission on Radiological Protection (ICRP) publicou em 1985 (ICRP 45), um importante documento para prevenção de danos causados pelas radiações em procedimentos intervencionistas ${ }^{(20)}$;

$\rightarrow$ Em 14 de dezembro de 1994 a Secretária de Saúde do Estado de São Paulo publicou a resolução SS 625. Este documento expressa a preocupação com os procedimentos radiológicos médicos e odontológicos, que devem considerar a justificativa, limites de doses e otimização na utilização das radiações ionizantes ${ }^{(21)}$;

$\rightarrow$ Em 1994 foi publicada a primeira versão da norma IEC 1267, que recomenda qualidades de radiação $X$ para serem empregadas na calibração de instrumentos medidores de radiação utilizados em radiodiagnóstico ${ }^{(22)}$;

$\rightarrow$ A Comunidade Européia publicou em 1996 o documento UR 16260 EN entitulado: European Guidelines on Quality Criteria for Diagnostic Radiographic Images. Este documento estabelece parâmetros para a qualidade da imagem em radiodiagnóstico convencional, contrastado , Tomografia Computadorizada (CT), Mamografia e Fluoroscopia ${ }^{(23)}$;

$\rightarrow$ O Ministério da Saúde Brasileiro, no ano de 1998, por meio da Agência Nacional de Vigilância Sanitária (ANVISA), estabeleceu requisitos para a utilização da radiação $X$ para diagnóstico por profissionais nas áreas clínicas, legislando, fiscalizando e autuando os estabelecimentos clínicos. Este documento (portaria 453) apresenta estes requisitos, desde a documentação para 0 alvará de funcionamento, responsabilidades técnicas, atuação dos profissionais, disposição dos equipamentos, blindagens, controle de qualidade até a desativação da clinica ou centro de radiodiagnóstico ${ }^{(5)}$;

$\rightarrow$ Em outubro de 1998 a American Association of Physicists in Medicine (AAPM) publicou o report. no. 58, orientando instituições hospitalares a 
melhorarem a qualidade do trabalho utilizando equipamentos de fluoroscopia ${ }^{(24)}$;

$\rightarrow$ Em 1999, o laboratório de calibração do IPEN iniciou o trabalho de calibração de equipamentos em radiodiagnóstico, implementando os métodos $e$ as qualidades de radiações recomendadas internacionalmente pela norma IEC 1267 publicada em 1994 ${ }^{(18)}$;

$\rightarrow$ Para auxiliar a compreensão de determinados termos específicos, foi publicado em 2000 o Guia Regulador de Segurança Radiológica para a prática de Raios X Diagnósticos (convencional e fluoroscopia) desenvolvido pelo Acordo Regional de Cooperação para a promoção da Ciência e Tecnologia Nucleares na América Latina (ARCAL) ${ }^{(25)}$;

$\rightarrow$ Em 2001 foi desenvolvido um programa de Controle de Qualidade em Equipamentos de Angiografia por Subtração Digital, como parte de uma dissertação de mestrado. Neste trabalho foram apresentados testes específicos para equipamentos de fluoroscopia ${ }^{(26)}$;

$\rightarrow$ Em 2002 foi publicado a primeira revisão do Protocolo Espanhol para o controle de qualidade em radiodiagnóstico médico ${ }^{(27)}$, que complementa os aspectos do controle de qualidade para diversas aplicações da radiação $X$, incluindo a fluoroscopia;

$\rightarrow$ Em 2003, a ANVISA publicou a Resolução - RE no, 64, um documento que revisa e complementa a Portaria 453/98. Com o título "Guia de Procedimentos para Segurança e Qualidade de Imagem em Radiodiagnóstico Médico", apresentando procedimentos específicos a serem aplicados no controle de qualidade em Radiodiagnóstico para as diversas técnicas utilizadas ${ }^{(28)}$. Esta resolução foi revogada em 2006, sendo substituída pela Resolução 1016 que aprovou o guia "Radiodiagnóstico Médico - Segurança e Desempenho de Equipamentos"(29);

$\rightarrow$ A Associação Brasileira de Normas Técnicas (ABNT) publicou uma norma em 2004 para equipamentos eletromédicos estabelecendo requisitos particulares para a segurança de equipamento de raios $X$ utilizados em procedimentos intervencionistas. A elaboração deste 
projeto foi importante porque determinou parâmetros significativos para o equipamento Intervencionista (desde riscos físicos até o cuidado com o paciente quanto às lesões) ${ }^{(30)}$.

$\rightarrow$ A International Eletroctechnical Commission (IEC) publicou em 2005 a revisão da norma 61267, que estabelece qualidades de radiação $X$, nível diagnóstico. Esta norma estabelece qualidades de radiação para diversas modalidades de exames, padronizando os procedimentos de calibração. Este documento recomenda qualidades específicas para fluoroscopia, baseadas em uma filtração adicional de cobre ${ }^{(17)}$.

$\rightarrow$ O Código de Prática publicado pela Agência Internacional de Energia Atômica (AIEA) $2007^{(4)}$ recomenda procedimentos que devem ser estabelecidos em laboratórios de calibração e dosimetria na área de radiodiagnóstico. Este documento apresenta técnicas que podem ser aplicadas tanto em clínicas de radiodiagnóstico como em laboratórios de calibração e dosimetria (SSDL), apresentando modalidades específicas de qualidades para exames diagnósticos específicos e técnicas terapêuticas específicas utilizando a radiação $X$, incluindo a radiologia odontológica e a proteção radiológica. Este documento também recomenda métodos de calibração específicos para fluoroscopia.

Neste trabalho, pretende-se estabelecer uma metodologia de calibração de instrumentos específicos para fluoroscopia, de acordo com a norma IEC $61267^{(17)}$ e com o TRS-457 ${ }^{(4)}$, incluindo a determinação das grandezas kerma de entrada e kerma incidente utilizando-se simuladores. 


\section{FUNDAMENTOS TEÓRICOS}

\subsection{Radiodiagnóstico}

Todas as intervenções médicas que utilizam a radiação $X$ para obter um diagnóstico, são chamadas de radiodiagnóstico. A especialidade médica que estuda a radiologia possui várias áreas de aplicação, como pode ser visto no organograma da FIG. 1.

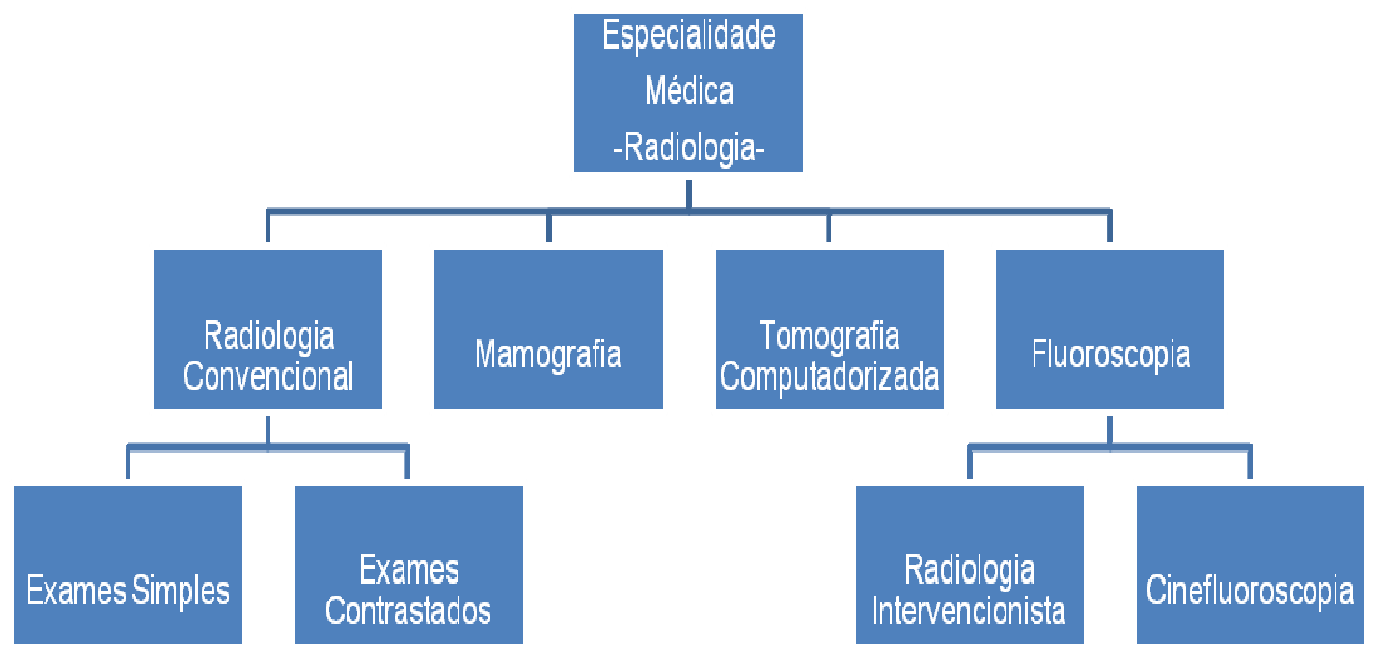

FIGURA 1: Organograma das principais especialidades radiodiagnósticas.

Existem modalidades específicas para determinados objetivos, por exemplo, a radiologia convencional pode utilizar a técnica simples ou a contrastada (utilização de contraste: bário ou iodo) para exames mais detalhados das estruturas tubulares com o auxilio da radiação $X$ e utiliza filmes de vários tamanhos. A mamografia, radiodiagnóstico específico para as mamas (feminina e masculina), utiliza técnicas, sistema de radiação, material do anodo e as qualidades do feixe diferentes da convencional. Já a técnica da tomografia computadorizada possui um aparelho que utiliza vários sensores e feixes estreitíssimos onde é possível a visualização da imagem radiografada por planos transversais e reconstruções destes planos. E, por fim, a fluoroscopia (feixe contínuo) obtém as imagens geradas em tempo real que são visualizadas pelo médico através de um monitor, podendo ser gravadas e avaliadas posteriormente. As técnicas são diferentes e muito utilizadas para as práticas terapêuticas. Devido 
ao longo tempo de exposição, exige dos médicos, auxiliares e pacientes maiores cuidados com a proteção radiológica.

Além destas modalidades da radiologia que utilizam radiação eletromagnética, existem outros exames que não utilizam radiação $X$, mas são tratadas dentro da especialidade radiológica, como por exemplo:

- Medicina Nuclear

- Ressonância Nuclear Magnética

- Ultra-Som

Estas especialidades são amplamente utilizadas com o objetivo de se obter um diagnóstico mais seguro e uma tomada de decisão correta. A radiologia é uma das especialidades médicas de grande procura, só em São Paulo são 2,1\% de profissionais da saúde atuando nesta área, e há grande procura da especialidade no meio acadêmico ${ }^{(31,32)}$.

\subsubsection{Fluoroscopia}

O grande inventor e cientista americano Thomas Alva Edison (1847-1931) interessou-se pelos raios $X$ logo após a sua descoberta, e aplicou seu extraordinário gênio inventivo ao seu aperfeiçoamento e popularização. Entre outras coisas, ele desenvolveu um fluoroscópio portátil em 1896, que consistia de uma tela fluorescente sensível aos raios $X$, que podia mostrar a imagem sem necessidade de radiografar fotograficamente. Edison pesquisou 8.000 compostos até determinar que o tungstato de cálcio, era o melhor agente fluorescente, e passou a comercializar o Vitascope Fluoroscopy Unit ${ }^{(2)}$ demonstrado na FIG. 2 e que se tornou grandemente popular, com demonstrações públicas. Embora, no mesmo ano Enrico Salvioni, um físico italiano, tenha inventado o primeiro "Fluoroscópio", foi Thomas Edison que o nomeou. O fluoroscópio logo mostrou sua utilidade na medicina, ao permitir a observação de imagens internas do corpo em movimento, como o coração, o aparelho fonador, etc. No mesmo ano de 1896, Michael Pupin desenvolveu um método de obter radiografias usando filmes fotográficos impressionados diretamente pelo fluoroscópio de Edison, reduzindo assim dramaticamente o tempo de exposição ${ }^{(1,2)}$. 
"A fotografia do invisível"
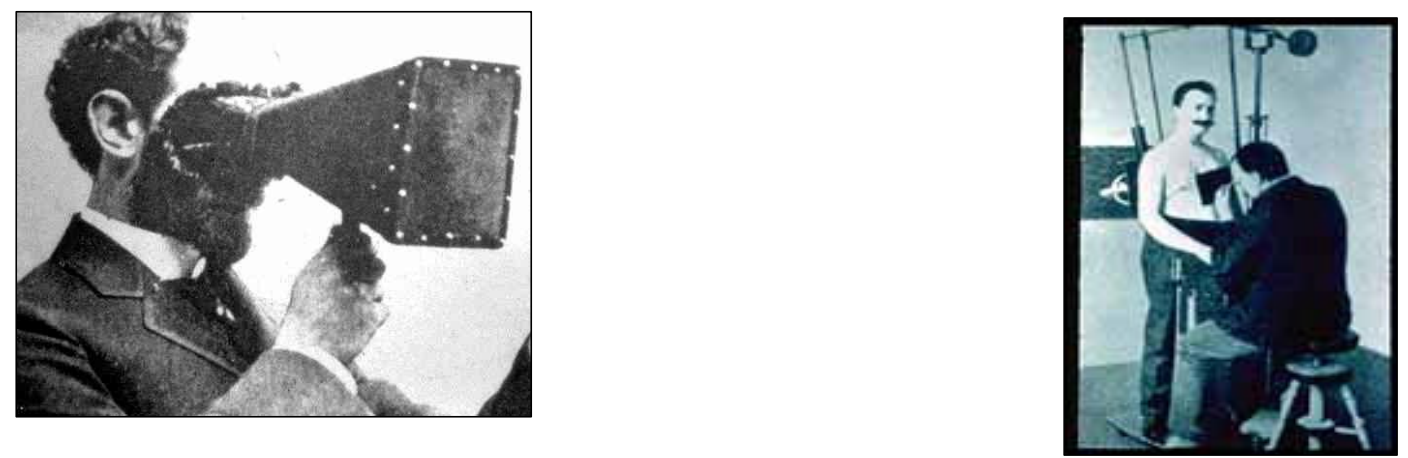

FIGURA 2: Invento de Thomas A. Edison: o Vitascope Fluoroscopy Unit ${ }^{(4)}$

No início do século $X X$ muitos médicos e cientistas deduziram que a fluoroscopia iria substituir a radiografia convencional pela fácil visualização dos órgãos em movimento, mas como a radiografia tinha qualidade superior, a dedução não se concretizou.

Com o pouco conhecimento dos efeitos prejudiciais das radiações ionizantes na época, muitos médicos e cientistas sofreram com queimaduras e lesões graves.

A fluoroscopia é o estudo das estruturas corporais em movimento. Um feixe de raios $X$ contínuo é transmitido através da parte do corpo a ser examinada, e esta imagem é transmitida para um monitor de TV, assim o médico pode avaliar as estruturas internas com detalhes e em tempo real ${ }^{(33)}$.

A técnica fluoroscópica é uma ferramenta importante para a medicina atual e foi de grande valia para os tempos remotos, permitindo que o médico avaliasse estruturas como o sistema digestivo, urinário, respiratório, reprodutivo e a estrutura esquelética e ou outras partes de interesse do médico como comumente é utilizado no Brasil (artéria e veias cardíacas).

A fluoroscopia pode ser utilizada sozinha como procedimento de diagnóstico ou associada a outras técnicas como o ultra-som, radiografia simples 
ou contrastada, tomografia ou ressonância nuclear magnética.

Utilizando contraste (bário), o médico pode fazer avaliações do tubo digestivo, e verificar se há obstruções ou desvios anormais enquanto o contraste desloca-se pelo tubo digestivo. A fluoroscopia é indispensável para a realização do cateterismo; exame que permite a avaliação do fluxo sangüíneo através das artérias coronárias, para avaliar a presença de obstruções arteriais. Com a inserção de cateter venoso, a fluoroscopia auxilia a orientação do médico a avaliar o sistema periférico do paciente ${ }^{(33)}$.

\section{radiodiagnóstico}

\subsubsection{Evolução tecnológica dos equipamentos de}

Neste capítulo será demonstrada a evolução tecnológica dos equipamentos de radiodiagnóstico, com destaque aos de fluoroscopia ao longo do século $X X$.

O primeiro fluoroscópio consistia de um tubo de raios $X$ e uma tela fluorescente. O radiologista ficava exatamente em frente à janela do aparelho, cujas imagens amarelo-esverdeadas eram reveladas e os órgãos de interesses eram estudados em tempo real, algo extraordinário na época.

Em 1920, avanços significativos foram vistos na radiologia convencional e fluoroscópica. O avanço deu-se principalmente pelas necessidades médicas e evidencias de danos físicos ocorridos após a utilização indiscriminada da radiação X. Foram desenvolvidos pela empresa Cleyde Snook's Victor Electronic Co, interruptores e transformadores de corrente alternada com retificadores mecânicos ${ }^{(34)}$.

Em 1926 a Engeln Electric Company, de Cleveland, Ohio, lançou o "Duplex", uma combinação de radiografia e fluoroscopia, ilustrado na FIG.3. Enquanto na Alemanha em 1929, a Siemens produzia a primeira unidade trifásica, que poderia operar com 2000 mA e 80 kVp, uma revolução na época. Neste mesmo ano foi lançado o primeiro tubo de raios $X$ com 0 anodo giratório 0 "Rotalix" da Philips. Por causa do seu tubo de radiação $X$ ter um formato modificado, uma simples exposição era feita em segundos, muito mais eficiente que os aparelhos da época. 


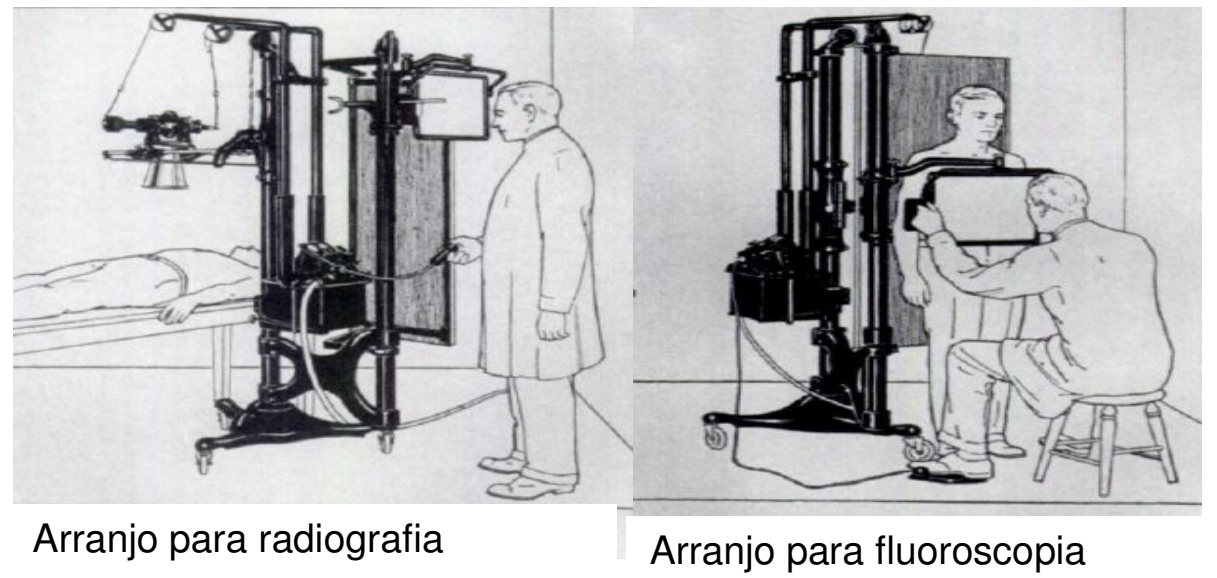

FIGURA 3: "Duplex", o primeiro aparelho que poderia ser usado no modo radioscopia e fluoroscopia ${ }^{(5)}$.

A partir de 1929 foram desenvolvidos aparelhos com tempos de exposição cada vez mais rápidos, como por exemplo, o "Micronex", desenvolvido e fabricado pela Westinghouse X Ray Company. E em 1934, foi desenvolvido pela Picker a primeira unidade de fluoroscopia bi plano ${ }^{(34,35)}$, ilustrado na FIG. 4.

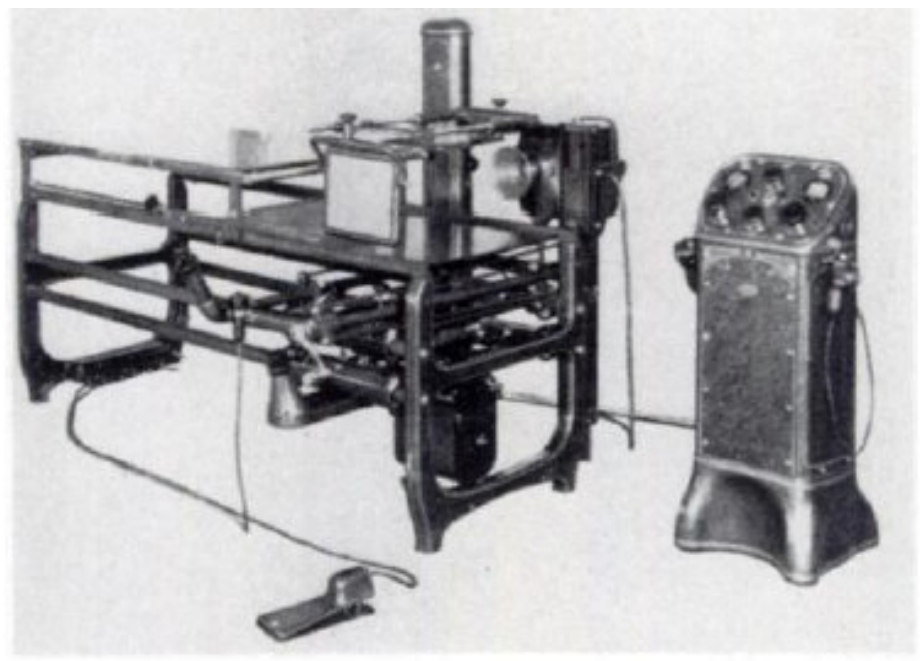

FIGURA 4: Primeiro aparelho de fluoroscopia bi plano, construído pela Picker ${ }^{(5)}$.

As empresas Westinghouse e Continental lançaram no mercado, em 1936, as primeiras unidades portáteis de fluoroscopia. E, em 1937, a General Electric construiu o primeiro tubo de raio $\mathrm{X}$ com anodo giratório imerso em óleo e com 
disco de Tungstênio sólido.

Com o inicio da nova década, novos equipamentos foram lançados no mercado como o Double Fulcrum Fluoroscopic Table desenvolvido e construído pelo Dr. John Camp's, e novos estudos sobre um novo equipamento de fluoroscopia multiplanos (W.E. Chamberlain e G. Henny), fervilharam a época. Avanços importantes nas tecnologias dos anos 40 aconteceram na época da segunda grande guerra, pois buscando suprir as necessidades dos campos de batalhas, foram desenvolvidos vários equipamentos que atendessem aos soldados feridos sem a necessidade de remoção para outros hospitais mais distantes. Outro avanço importante foi a construção do intensificador de imagem desenvolvido por J.W. Coltman da Westinghouse, com grande utilidade na área clinica.

A era Pós - Guerra chegou e jovens cientistas que ajudaram no período de guerra ajudaram também no desenvolvimento de novas tecnologias dos anos 50 , com os seguintes desafios a serem alcançados:

- Tempos de exposição aos pacientes mais curtos;

- Procedimento utilizando fluoroscopia com técnicas mais fáceis e avaliação mais detalhada dos tecidos moles;

- Exatidão e melhoria do feixe de radiação $\mathrm{X}$ na radiografia;

- Tempos de exposição menores e maior recuperação de informações nos procedimentos complexos de fluoroscopia como a angiografia e o cateterismo cardíaco; entre outras necessidades.

Em 1952 a General Electric lança o "Imperial", FIG. 5, um equipamento que poderia ser utilizado tanto no modo radioscopia como em fluoroscopia, com um diferencial que era a mesa, cujo movimento chegava a uma rotação 360 graus. 


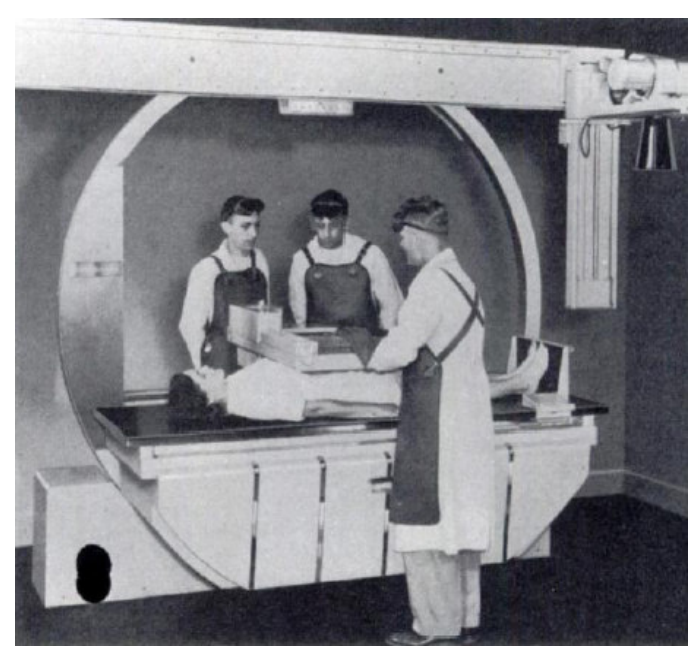

FIGURA 5: O Imperial (G.E) com rotação de 360 graus da mesa de exame ${ }^{(5)}$.

$\mathrm{Na}$ década de 60 foram introduzidos no mercado equipamentos mais potentes. Em 1962 foi lançado pela X-Ray Manufacturing Corporation of American o primeiro mamógrafo. Na mesma época foram lançados pela G.E e Picker os controles remotos para fluoroscopia, junto com o monitor de TV, facilitando o trabalho dos radiologistas. A General Electric mudou a configuração da unidade de fluoroscopia, colocando o tubo de raios $X$ embaixo da mesa de exame, e o intensificador de imagem em cima da mesa, com esta mudança foi possível aumentar a distância foco-objeto e melhorar a qualidade da imagem. Dois outros avanços dentro das novas técnicas da radiologia foram a xeroradiografia nos estudos da mamografia, e a utilização do fósforo de terras raras, melhorando as imagens radiográficas.

Nos anos 70, aconteceu a revolução das técnicas de obtenção de imagem, com a Tomografia Computadorizada e a Ressonância Nuclear Magnética. No campo da fluoroscopia também houve grandes avanços. Na Universidade de Wisconsin, Mistretta et. al. ${ }^{(36)}$, introduziram aparatos computadorizados na fluoroscopia. As imagens são gravadas em uma câmara de vídeo e um processador digital de imagem, como mostra a FIG. 6. 


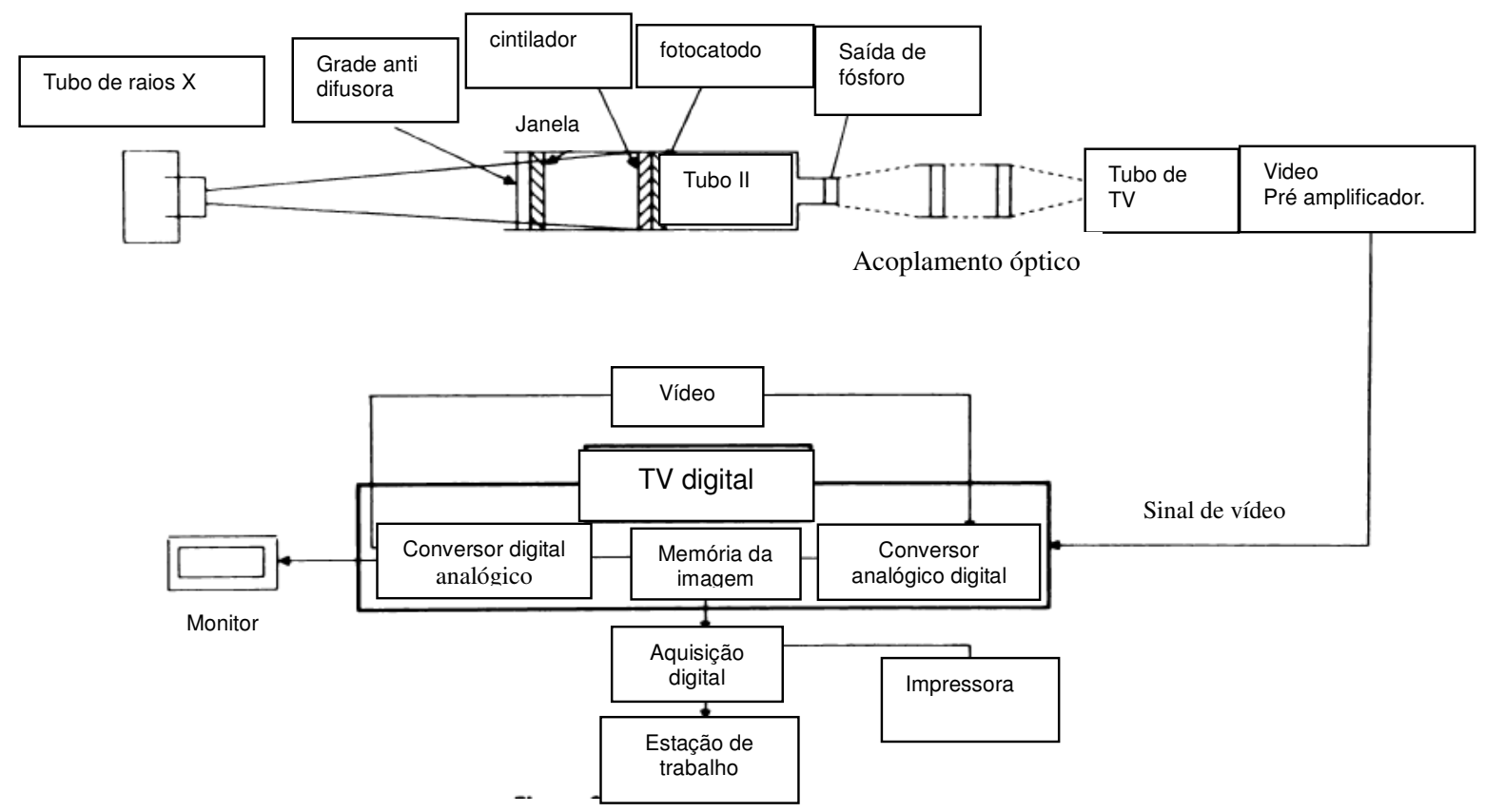

FIGURA 6: Sistema de aquisição de imagem digital em fluoroscopia utilizada na década de $70^{(35)}$.

Um fato que também foi importante na década de 70 foi a construção de novas ampolas de radiação $X$ com pequeno ponto focal $(0,1 \mathrm{~mm}$ a $0,3 \mathrm{~mm})$, utilizados nas técnicas de magnificação da imagem.

A década de 80 foi a era da digitalização para a imagem em radiologia convencional e para as imagens geradas através da fluoroscopia. Surgiram também as novas técnicas de aquisição de imagens para a Ressonância Nuclear Magnética, Tomografia computadorizada e varreduras a laser. A FIG. 7 mostra um intensificador de imagem que utiliza um processador de imagem digital.

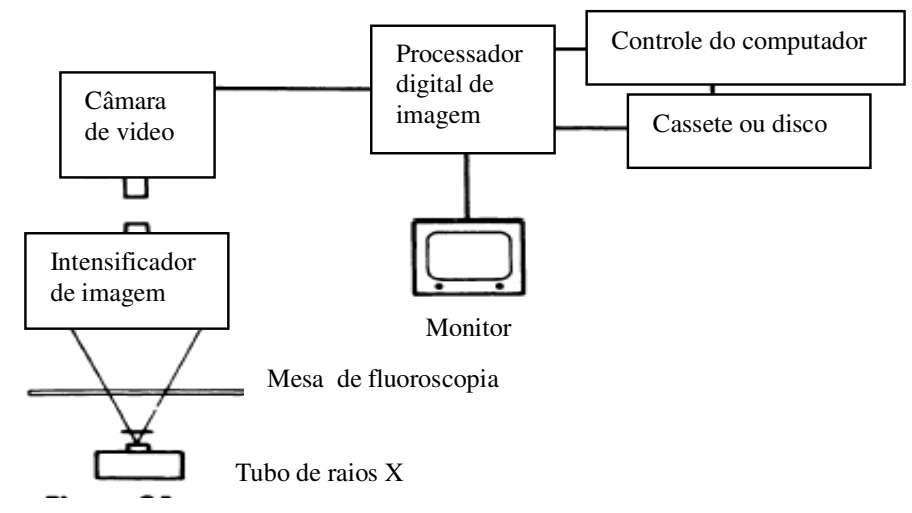

FIGURA 7: Intensificador de imagem utilizando um processador digital de imagem $^{(35)}$. 


\subsubsection{Radiologia intervencional}

A radiologia intervencionista ou intervencional é composta por métodos diagnósticos e terapêuticos de algumas doenças do sistema circulatório, e pode ser realizado através da utilização de radiação $X$ de feixe pulsado (CINE) ou contínuo (CONVENCIONAL), onde são realizadas em grande parte dos hospitais públicos e particulares. Algumas ferramentas utilizadas são complexas, tais como, guias, cateteres, filtros e stents inseridos dentro do corpo humano e guiados utilizando os raios $X$. Outras técnicas de imagens, tais como: Tomografia Computadorizada, Ressonância Nuclear Magnética, Ultra-Som podem ser associados para o melhor diagnóstico e segurança para o médico e o paciente. A Radiologia Intervencional oferece uma alternativa para o tratamento cirúrgico de muitas condições e pode eliminar a necessidade de hospitalização, em alguns casos. A utilização da radiologia intervencional em diversos casos médicos são mostrados na TAB. $1^{(25)}$.

TABELA 1: Técnicas de Diagnósticos e tratamentos utilizando a radiologia intervencional.

Técnica

\begin{tabular}{|c|c|}
\hline Angiografia & $\begin{array}{l}\text { Radiografia das artérias e veias para detectar obstruções e } \\
\text { estreitamento das mesmas. A radiologia intervencional utiliza cateteres } \\
\text { e guias para a desobstrução com a colocação de stent ou insuflando } \\
\text { um pequeno balão. }\end{array}$ \\
\hline Angioplastia & Desobstrução da veia através da insuflação de um pequeno balão \\
\hline Embolização & $\begin{array}{l}\text { É a inserção de um cateter com substâncias coagulantes no interior } \\
\text { dos vasos sangüíneos para estancar uma hemorragia. }\end{array}$ \\
\hline Gastrectomia & $\begin{array}{l}\text { Inserção de um cateter especial para alimentação do paciente, } \\
\text { quando ele é impossibilitado de se alimentar pela boca. }\end{array}$ \\
\hline $\begin{array}{l}\text { Ultra-som } \\
\text { intravascular }\end{array}$ & Auxilio com guia na ultra-sonografia intravenoso \\
\hline $\begin{array}{l}\text { Colocação de } \\
\text { stent }\end{array}$ & $\begin{array}{l}\text { O stent é uma pequena mola de metal, inserida e guiada para dentro } \\
\text { dos vasos sanguíneos, recuperando o lúmen do vaso e garantindo } \\
\text { maior fluidez do sangue. }\end{array}$ \\
\hline $\begin{array}{l}\text { Injeções de } \\
\text { anticoagulantes }\end{array}$ & Inserções de substâncias anticoagulantes \\
\hline $\begin{array}{l}\text { Colocação de } \\
\text { filtros sangüíneos }\end{array}$ & $\begin{array}{l}\text { Inserções de pequenos filtros para evitar pequenos coágulos nos } \\
\text { vasos sangüíneos. }\end{array}$ \\
\hline $\begin{array}{l}\text { Inserções de } \\
\text { cateteres }\end{array}$ & $\begin{array}{l}\text { Inserções de cateteres para levar medicamentos em tratamentos de } \\
\text { tumores malignos e nos casos de transplantes de medula e } \\
\text { hemodiálises }\end{array}$ \\
\hline
\end{tabular}




\subsubsection{Controle de qualidade em equipamentos de fluoroscopia}

No ano de 2003, a Agência Nacional de Vigilância Sanitária (ANVISA), publicou uma resolução com um guia de procedimentos para segurança e qualidade de imagem em radiodiagnóstico médico, considerando a preocupação com a saúde, a segurança radiológica e o bom funcionamento dos equipamentos de raios $X$ médicos ${ }^{(28)}$. Este documento, na sua parte 3, fornece procedimentos específicos para equipamentos de raios $\mathrm{x}$ com fluoroscopia. Alguns destes procedimentos são citados a seguir:

\section{a. Teste de controle de reprodutibilidade e exatidão da tensão do tubo}

- Objetivo: avaliar a exatidão e a reprodutibilidade da tensão de pico do tubo de raios $X$.

- Freqüência: Anual ou após o reparo.

b. Determinação da camada semi-redutora (CSR)

- Objetivo: Verificar a qualidade do feixe de raios $X$.

- Freqüência: Mínima Anual.

- Excepcionalmente: Após reparos

c. Taxa de kerma no ar típica e taxa máxima de kerma no ar na entrada da pele do paciente

- Objetivo: Determinar a taxa de dose típica e a taxa máxima de kerma no ar na entrada da pele do paciente. A taxa de Kerma no ar em fluoroscopia deve ser menor que $50 \mathrm{mGy} / \mathrm{min}$, na menor distância focopele. No mínimo a uma distância de $18 \mathrm{~cm}$ para tensão menor ou igual a $60 \mathrm{kVp}, 20 \mathrm{~cm}$ para valores de tensão entre 60 e $70 \mathrm{kVp}$ e $24 \mathrm{~cm}$ para valores de tensão acima de $70 \mathrm{kVp} .{ }^{(5)}$

- Freqüência: Mínima Anual.

- Excepcionalmente: Após reparos. 


\subsubsection{Parâmetros importantes para formação da imagem em}

\section{fluoroscopia}

\section{a. Manutenção do equipamento radiação $X$}

O profissional deve fazer periodicamente uma verificação do equipamento, utilizando instrumentos calibrados. Para garantir que a dose submetida ao paciente seja tão baixo quanto possível, mantendo uma imagem com alta qualidade ${ }^{(23)}$, um bom programa de controle de qualidade deve ser estabelecido, que inclua uma avaliação periódica desta dose.

Os operadores devem ser capazes de reconhecer que se há um aumento da dose para garantir uma boa qualidade de imagem, pode haver problemas no intensificador de imagem e o mesmo deve ser trocado ${ }^{(23)}$.

\section{b. Poder de penetração do feixe da radiação $X$}

A tensão aplicada ao tubo é responsável pelo poder de penetração do feixe. Com o aumento da tensão há uma menor interação desta radiação com a pele do paciente. Portanto, a escolha do $k V p$ requerido para a formação da imagem deve ser balanceada entre a dose no paciente, o contraste da imagem e $o$ poder de penetração do $\mathrm{kVp}{ }^{(42)}$.

Um aumento dos números de elétrons (corrente aplicada em $\mathrm{mA}$ ) aplicados no tubo sem a mudança do $\mathrm{kVp}$, também pode aumentar a quantidade de fótons no feixe, esta estratégia também pode garantir um contraste ideal para a imagem, mas o custo é a maior dose no paciente ${ }^{(24)}$.

\section{c. Filtração}

Devido aos fótons de baixa energia produzidos pelos raios $\mathrm{X}$, e ao poder de penetração limitado, as interações dos fótons de baixa energia se depositam na pele do paciente, causando lesões e queimaduras sem a contribuição na formação da imagem. É desejável a utilização dos filtros de alumínio, para remover estes fótons de baixa energia do feixe de radiação X. Nos sistemas de fluoroscopia, no qual a energia dos fótons é maior, a filtração é feita através de filtros de cobre, que absorve mais fótons e garante um feixe mais "duro", sem a perda do contraste e a qualidade da imagem. 


\section{d. Radiação espalhada}

A radiação espalhada é produzida quando o feixe primário interage com o corpo do paciente. A radiação espalhada alcança o receptor de imagem, causando ruído e baixo contraste. É a principal fonte de dose extra no paciente (irradiando partes do corpo fora do campo de radiação primário) e também para o corpo clinico. O aumento do tamanho do campo (colimadores), mantendo a mesma distância, aumenta visivelmente a dose espalhada pela sala de exame ou laboratório. A redução do tamanho do campo, ou seja, limitando os colimadores e reduzindo o tamanho de campo apenas à área de interesse, diminui a dose no paciente e a radiação espalhada para o corpo clínico. Esta afirmação pode ser comprovada nas FIG. 8 e FIG. $9^{(6)}$.

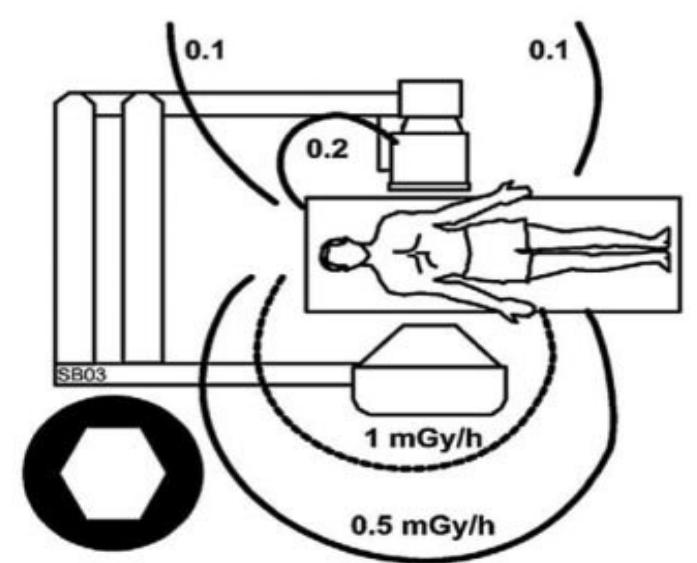

$50 \%$ FOV

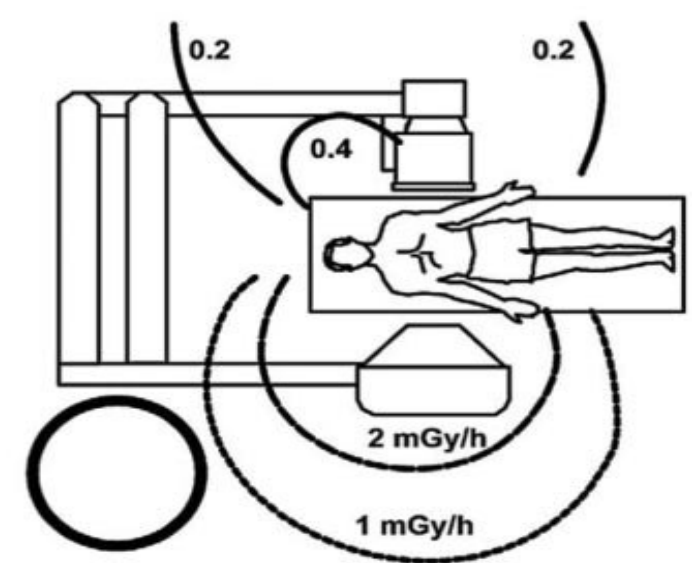

$100 \%$ FOV

FIGURA 8: A influência da colimação correta na diminuição da radiação espalhada e a diminuição da dose. FOV (Field of vision): campo de visão(6) 

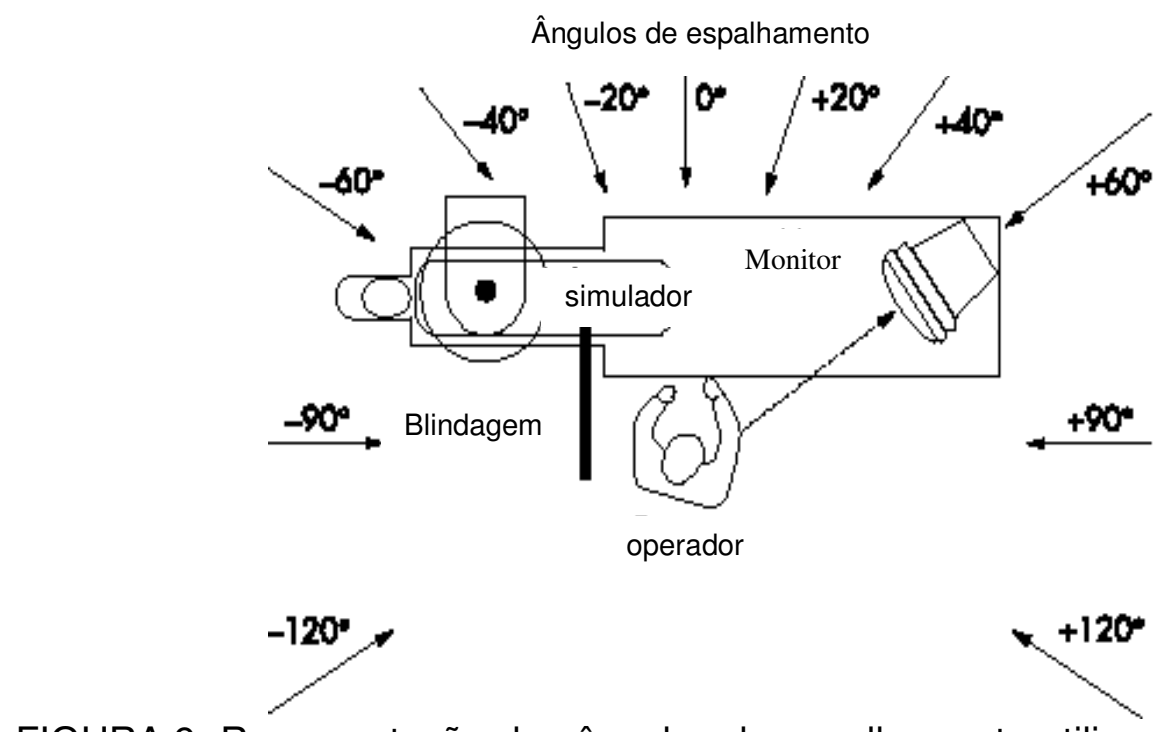

FIGURA 9: Representação dos ângulos de espalhamento utilizando um simulador como paciente, e a exposição do operador ${ }^{(6)}$. 


\section{e. Captura da imagem}

Normalmente as clínicas utilizam duas maneiras para se obter a captura de imagem em um sistema de fluoroscopia ${ }^{(6)}$ :

\section{Intensificador de imagem e sistema de câmara de vídeo}

O intensificador de imagem é um tubo a vácuo que converte a imagem da radiação $X$ em imagem visível. $A$ imagem gerada pelos raios $X$ interage com a janela de entrada do intensificador, a luz visível emitida na saída do intensificador é transmitida para uma câmara de vídeo digital e finalmente é mostrada no monitor e gravada. O intensificador está ilustrado na FIG.10.
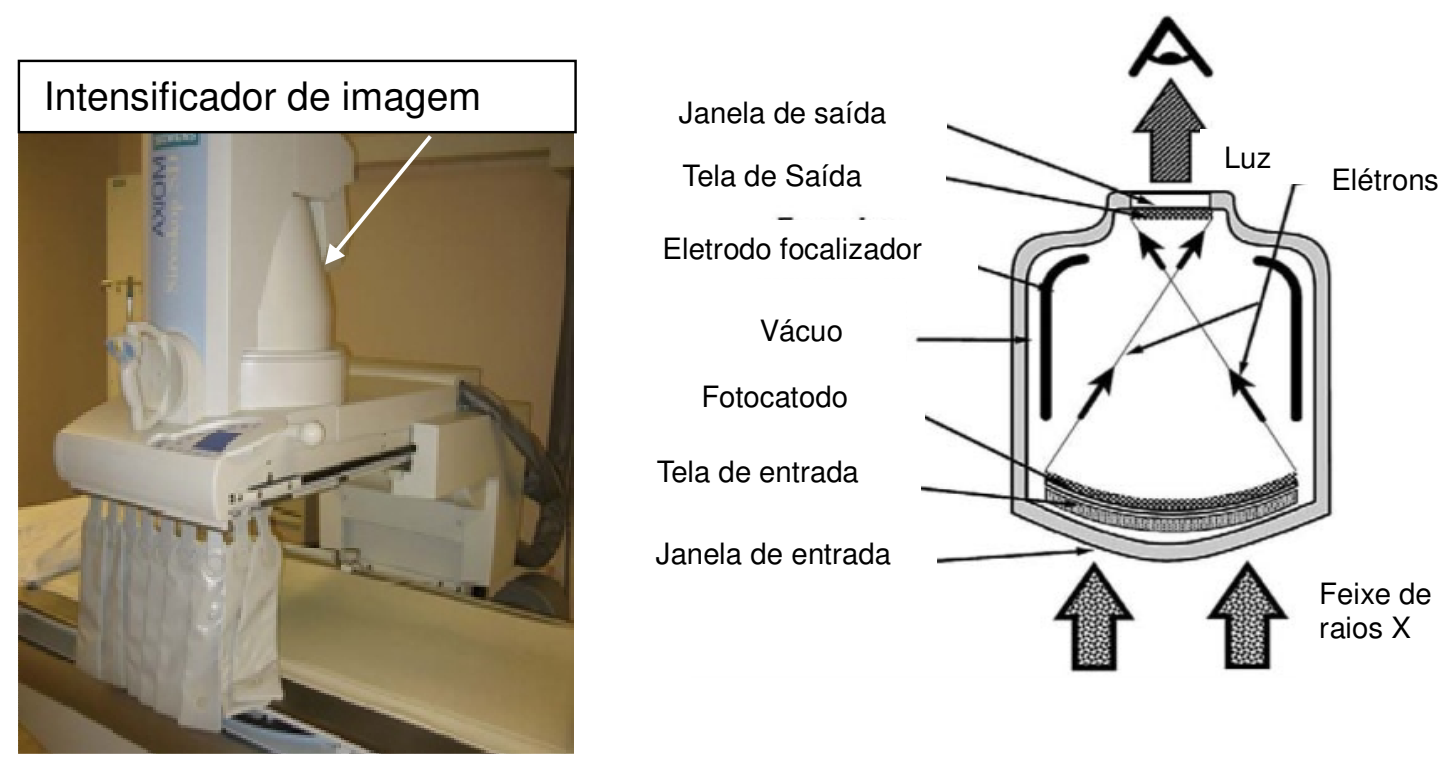

FIGURA 10: Representação esquemática de um Intensificador de Imagem e a multiplicação dos elétrons. 


\section{Painel de detecção plano}

O painel de detecção plano vem a cada dia mais substituindo o intensificador de imagens. A radiação $\mathrm{X}$ proveniente do paciente interage diretamente com o detector plano sem a intervenção do intensificador de imagem. Os raios $\mathrm{X}$ interagem com o cristal de iodeto de césio, liberando os elétrons fracamente ligados em seus orbitais. Os elétrons livres serão acumulados no fotodiodo de silício, este através das forças de repulsão abrirá uma lacuna no cristal, na camada de condução espacial, que funcionará como um volume sensível encontrado nas câmaras de ionização. Os elétrons livres ionizam o meio e o sinal será enviado para o leitor eletrônico. Este detector pode ser visualizado no esquema da FIG. 11.
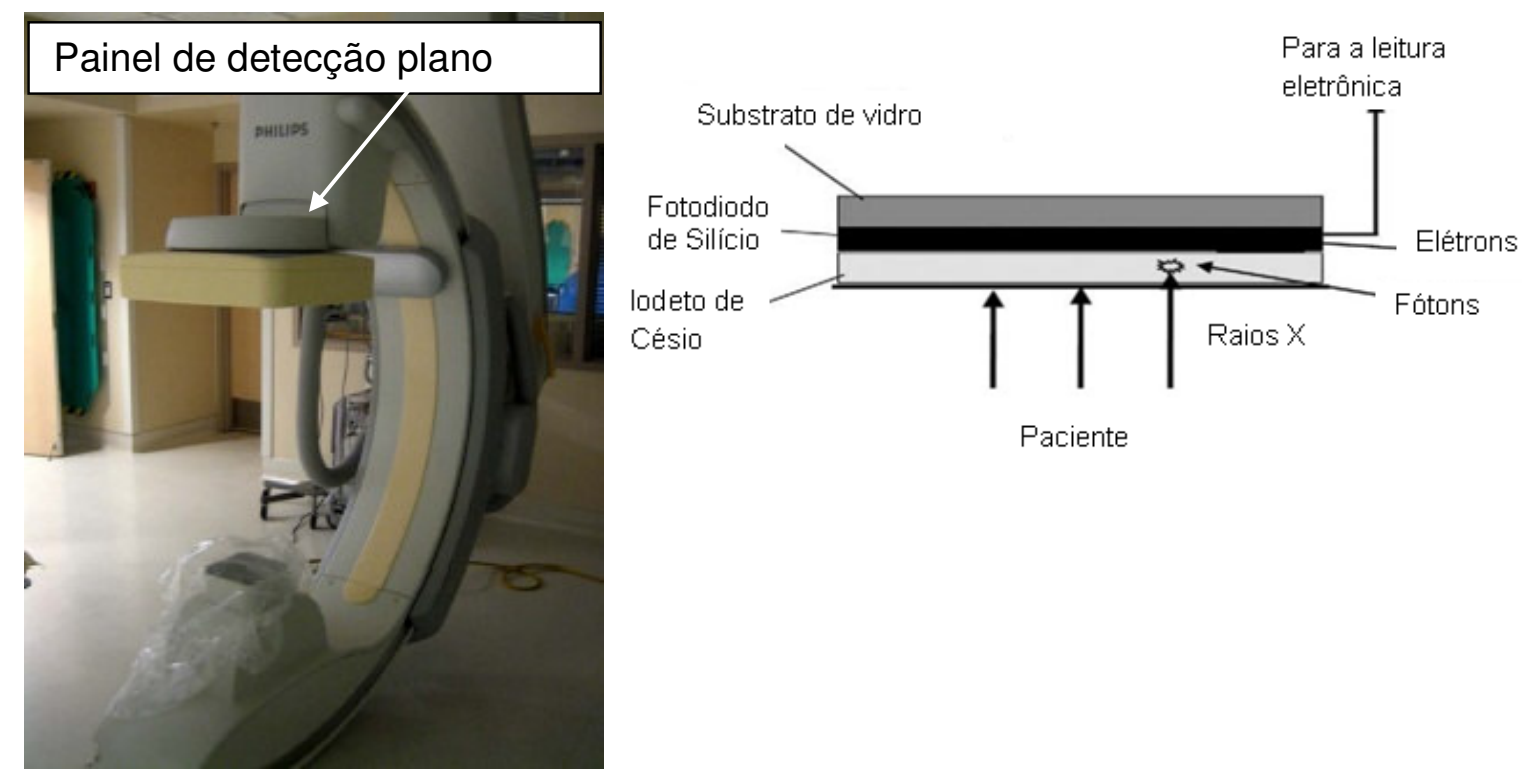

FIGURA 11: Representação de um painel de detecção plano em plano coronal e seus componentes. 


\subsection{Radiação}

A radiação é qualquer forma de emissão de energia que se propaga através do espaço em forma de oscilações ondulatórias ou em forma de partículas carregadas ou não carregadas interagindo com a matéria. A radiação pode ser encontrada na natureza de duas formas:

- Radiações Não-lonizantes: São radiações que não tem o poder de arrancar elétrons dos orbitais dos átomos.

- Radiações lonizantes: Radiação cuja energia é superior à energia de ligação dos elétrons de um átomo com o seu núcleo, sendo suficiente para arrancar elétrons de seus orbitais.

A interação das radiações ionizantes com a matéria é um processo que se passa em nível atômico. Quando as partículas carregadas perdem energia por interação com os elétrons orbitais ocorrem à excitação e a ionização. A excitação é a transferência da fração de energia da partícula incidente para o elétron no material absorvedor, causando a elevação aos orbitais do elétron mais distante do núcleo ${ }^{(37)}$. Caso a energia transferida seja superior à energia de ligação do elétron com o restante da estrutura atômica, este é ejetado de sua órbita. O átomo é momentaneamente transformado em um íon positivo. O elétron arrancado (íon negativo) desloca-se no meio, impulsionado pela energia cinética adquirida neste processo. Esta energia é dissipada através da interação do elétron com elétrons e núcleos de outros átomos, eventualmente encontrados em sua trajetória. Novos íons podem, assim, serem introduzidos na matéria. O processo é interrompido quando, tendo sua energia dissipada em interações (choques), os elétrons (e suas cargas negativas) acabam capturados por moléculas do meio. A introdução de pares de íons (positivo e negativo) na matéria recebe o nome de ionização ${ }^{(38,39)}$.

\subsubsection{Interação da radiação por colisões com elétrons}

O elétron pode, ao receber energia, ser ejetado do átomo. Somente quando o elétron é fracamente ligado ao átomo e sua energia de ligação é desprezível quando comparada à energia recebida na colisão com o elétron incidente, 
podemos considerá-la uma colisão elástica entre partículas livres. A probabilidade de espalhamento dos elétrons é proporcional ao número atômico do elemento e inversamente proporcional a energia cinética da partícula incidente. A freqüência de interações diminui rapidamente com o aumento da energia cinética da partícula incidente.

\subsubsection{Interações elásticas com o núcleo}

A probabilidade da interação com o núcleo varia com $Z^{2}$ e 1/E, na qual $E$ é a energia cinética do elétron incidente $\mathrm{e} Z$, é o número atômico do elemento alvo. A probabilidade de interação elástica com o núcleo é levemente menor para os pósitrons com a mesma energia cinética dos elétrons.

\subsubsection{Interações inelásticas com o núcleo}

Os elétrons ou pósitrons próximos ao núcleo podem ser defletidos com a velocidade reduzida. A interação é inelástica se a energia é liberada com radiação eletromagnética ou se a perda de energia cinética do elétron se dá por radiação de freamento ou bremsstrahlung. A probabilidade cresce com o aumento do número atômico e da energia do elétron incidente.

Independentemente do processo, a quantidade de energia cedida por unidade de trajetória por uma partícula incidente no meio pode ser representada pela razão $\mathrm{dE} / \mathrm{dx}$. A razão entre os dois tipos de perda de energia dos elétrons, isso é, perda de energia por ionização $(-\mathrm{dE} / \mathrm{dx})_{\text {ion }}$ e perda de energia por radiação $(-\mathrm{dE} / \mathrm{dx})^{\mathrm{rad}}$, é independente da energia do elétron e do meio e é dada por ${ }^{(37)}$ :

$$
(-d E / d x)_{\text {ion }} /(-d E / d x)^{\text {rad }}=Z \cdot T / 800
$$

Onde T é a energia cinética máxima do elétron.

\subsection{Produção de raios $X$}

A emissão de fótons característicos é um processo natural que permite a liberação do excesso de energia de um átomo durante a transição dos elétrons para suas camadas mais internas. Uma única transição de elétrons pode provocar transições de elétrons em cascata, com fótons característicos de uma faixa de 
energia $^{(38,39)}$, como mostra a FIG. 12.

Formaçào de Raios- $X$ característico, a) Ejecăo de elétron ortital. b) e c) Enissóes de ráios $X$ Caraterííicos.
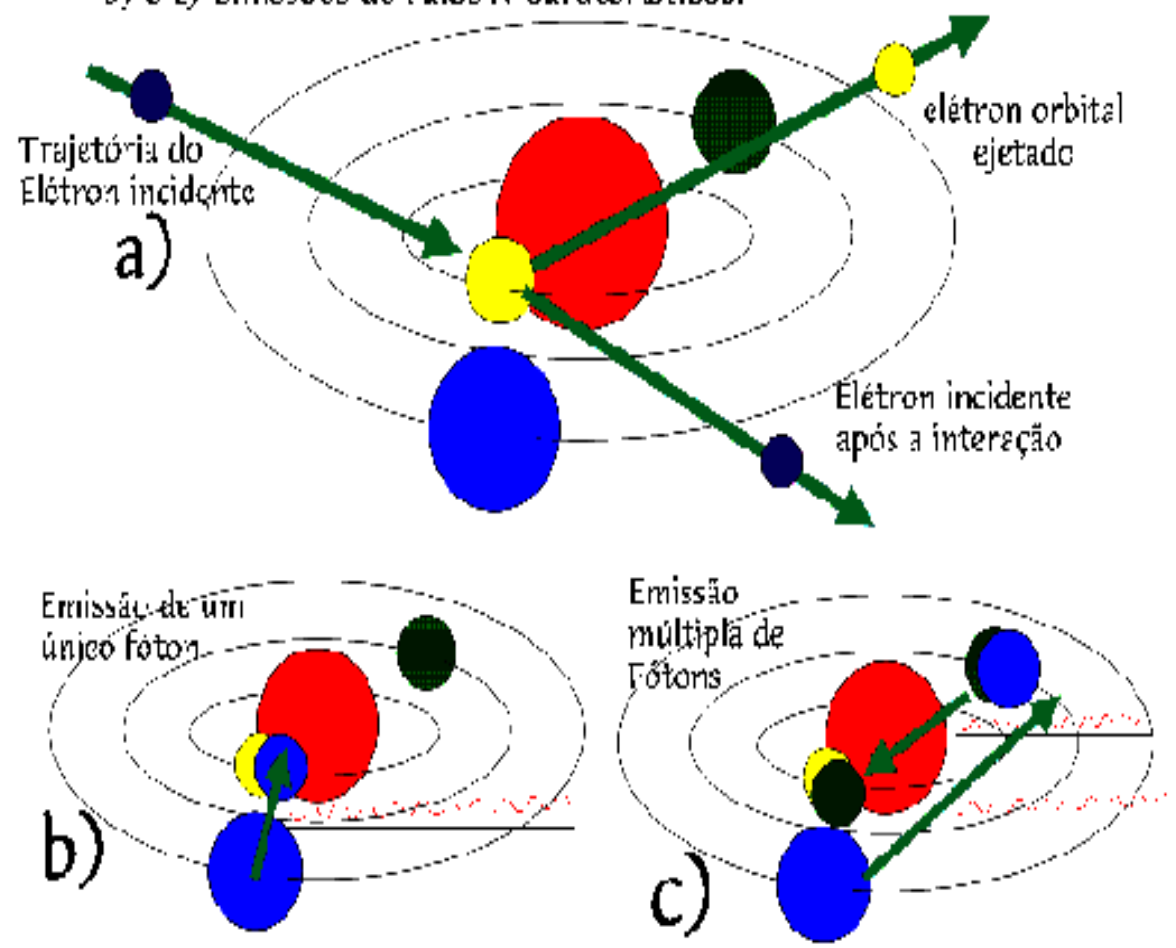

FIGURA 12: Representação dos raios $X$ característicos $^{(40)}$

O processo de ionização é uma forma de gerar fótons ou raios $X$ característicos por meio de transformação de energia cinética de elétrons acelerados na forma de radiação eletromagnética. São denominados característicos por serem únicos de um dado elemento utilizado no alvo de interação para os elétrons ${ }^{(38,39)}$.

No caso do tungstênio, material utilizado como alvo na maioria dos equipamentos de radiodiagnóstico convencional, quando um elétron acelerado interage com o material do alvo, arranca um elétron da camada $\mathrm{K}$ e ioniza o meio, possibilita que um dos elétrons da camada $L$ ocupe a vacância da camada $K$, ocorrendo assim a emissão de um fóton de raios $X$ de energia igual a $59 \mathrm{keV}$, valor igual à diferença de energia de ligação dos elétrons (K: 69,9 keV e L: 11,5 keV), característicos do tungstênio.

Nos equipamentos de radiação $X$, a desaceleração de elétrons pode 
ocorrer principalmente no campo elétrico dos núcleos dos átomos que constituem o elemento alvo, devido à atração coulombiana, desta maneira os elétrons transformam a sua energia cinética em radiação eletromagnética (raios $\mathrm{X}$ ) por interação no campo nuclear. Este processo é chamado perda de energia por freamento ou bremsstrahlung, e resulta na produção de fótons de alta energia.

Quanto mais próximo do campo nuclear o elétron passar, maior será a probabilidade de emitir fótons de alta energia. Podemos ver a representação da radiação de freamento na FIG. 13.

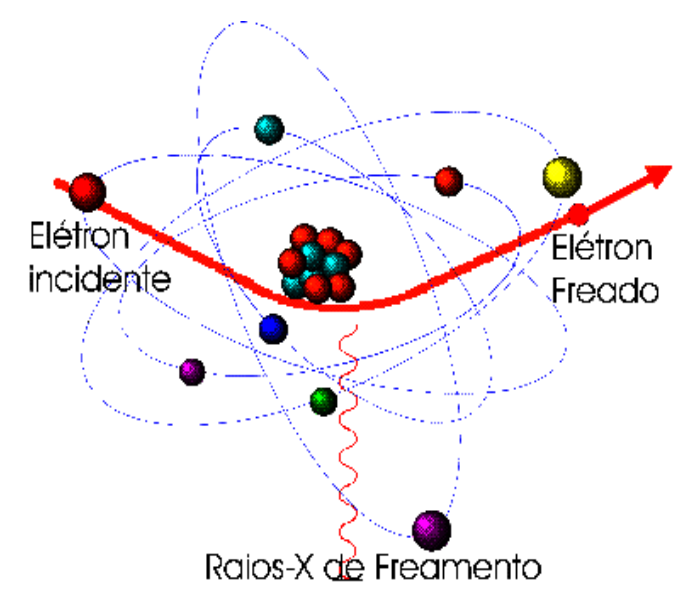

FIGURA 13: Representação da radiação de freamento ${ }^{(40)}$.

A radiação máxima é alcançada quando os elétrons interagem com o núcleo convertendo toda a sua energia cinética $(E c)$ em um único fóton de alta energia.

\subsection{Intensidade do feixe de radiação $X$}

A taxa de kerma no ar proveniente de um feixe de raios $X$ não é prontamente calculável devido às características de espectro largo gerado pelos equipamentos como conseqüência da conversão da energia cinética em radiação eletromagnética. Além disso, a filtração pode variar e modificar estas características. Pode-se expressar como rendimento do tubo a medida de taxa de Kerma no ar por unidade de carga transportada, medida a um metro de distância do foco, cujos valores típicos variam em função do tipo de gerador de tensão. Os valores são geralmente superiores a $1 \mu \mathrm{C} / \mathrm{mAs}$ para geradores monofásicos e para 
geradores trifásicos $1,5 \mu \mathrm{C} / \mathrm{mAs}^{(39)}$.

\subsubsection{Fatores que modificam a intensidade do feixe}

$A$ intensidade de um feixe de raios $X$ é função do número total de fótons de raios $\mathrm{X}$ e da energia que os mesmos transportam. A energia dos fótons emitidos pelos equipamentos de radiação $X$ é resultante da desaceleração dos elétrons e dependerá da distância entre o elétron e o núcleo, da sua energia e da carga do núcleo. Assim serão quatro os fatores que influenciam a qualidade do feixe. São eles:

- Tensão aplicada ao tubo (kV)

- Material do Alvo

- Corrente do Tubo (mA)

- Filtração

\subsubsection{Tensão aplicada ao tubo (kV)}

A energia dos fótons está diretamente ligada à força de bombeamento dos elétrons ao alvo. Quanto maior a diferença de potencial utilizada para acelerar os elétrons em direção ao alvo, maior será a probabilidade do elétron ser desacelerado no campo nuclear, propiciando a produção de mais fótons de energia média ou maior.

\subsubsection{Material do Alvo}

Quanto maior o número atômico $(Z)$ do elemento utilizado como alvo, maior será a probabilidade do elétron perder sua energia no processo de interação por bremsstrahlung, tornando mais intenso o feixe de raios $\mathrm{X}$, devido ao maior número de fótons. Além disso, o número atômico também determina a qualidade dos fótons gerados a partir das interações dos elétrons por colisões. Por exemplo, o tungstênio tem $Z=74$ e além de fótons característicos de $59 \mathrm{keV}$ são gerados fótons com cerca de $9 \mathrm{keV}$, correspondente à diferença das energias de ligação 
das camadas L com 11,5 keV e M com 2,5 keV. A relação entre a energia perdida por radiação e por colisão está descrita na equação abaixo.

$$
(d E / d x)_{\mathrm{rad}} /(d E / d x)_{\text {col }}=E c . Z^{2}
$$

\subsubsection{Corrente do Tubo}

O número de elétrons é controlado pela temperatura (grau de incandescimento) do filamento do cátodo. O controle é feito através do ajuste da corrente do filamento com seu próprio circuito elétrico de baixa voltagem. Quanto mais quente for o filamento, maior o número de elétrons disponível para formar a corrente de elétron; quer dizer, a corrente do tubo do raio X. Por exemplo, se o número de elétrons por segundo dobra, a corrente (em $\mathrm{mA}$ ) também dobra, e por sua vez a intensidade de raios $X$ também dobra. Ajustar a máquina de raios $X$ uma corrente específica significa, na verdade ajustar a temperatura do filamento para produzir a corrente indicada.

\subsubsection{Filtração}

Os filtros modificam o espectro da radiação quando adicionados na saída do tubo de raios $X$, e, portanto modificam também a intensidade da radiação. Filtros adicionais de alumínio, $Z=13$, e cobre $Z=29$, geralmente são utilizados em equipamentos convencionais, com o objetivo de absorver os fótons de menor energia presentes no feixe de raios $X$ e minimizar a quantidade de fótons absorvidos na superfície da pele. O cobre geralmente é usado em combinação com o alumínio como filtro composto para absorção de fótons de maior energia. Neste caso os fótons são mais absorvidos nos filtros de cobre. O alumínio é utilizado para absorver a radiação característica de aproximadamente $8 \mathrm{keV}$, produzida por interação dos fótons no cobre que, se não fossem atenuados, aumentariam a dose na pele do paciente. Já as radiações características do alumínio são absorvidas pelo ar entre o filtro e o paciente.

Este processo é conhecido como endurecer ou modificar o feixe originalmente gerado transformando uma energia média, em uma energia maior e por conseqüência, mais penetrante. Além do mais os fótons de baixa energia 
também são barrados pela filtração inerente.

A filtração inerente são todos os componentes do tubo de radiação $X$ que possam atenuar ou barrar estes fótons de energia baixa como, por exemplo: a ampola, o cabeçote, a janela de berílio e o óleo de refrigeração.

O aumento excessivo da filtração não contribui para o aumento da qualidade da imagem, e sim diminuirá a intensidade do feixe, que resultará em uma má qualidade da imagem ou o aumento de dose no paciente proporcionado pelo tempo de exposição prolongado ${ }^{(39)}$.

\subsection{Características de um tubo de raios $\mathrm{X}$}

Os raios $X$ são produzidos por um mecanismo de conversão de energia, quando um feixe de elétrons de alta velocidade é desacelerado em um alvo de metal existente no interior do tubo de raios $\mathrm{X}$, cujas principais características podem ser observadas na FIG. 14.

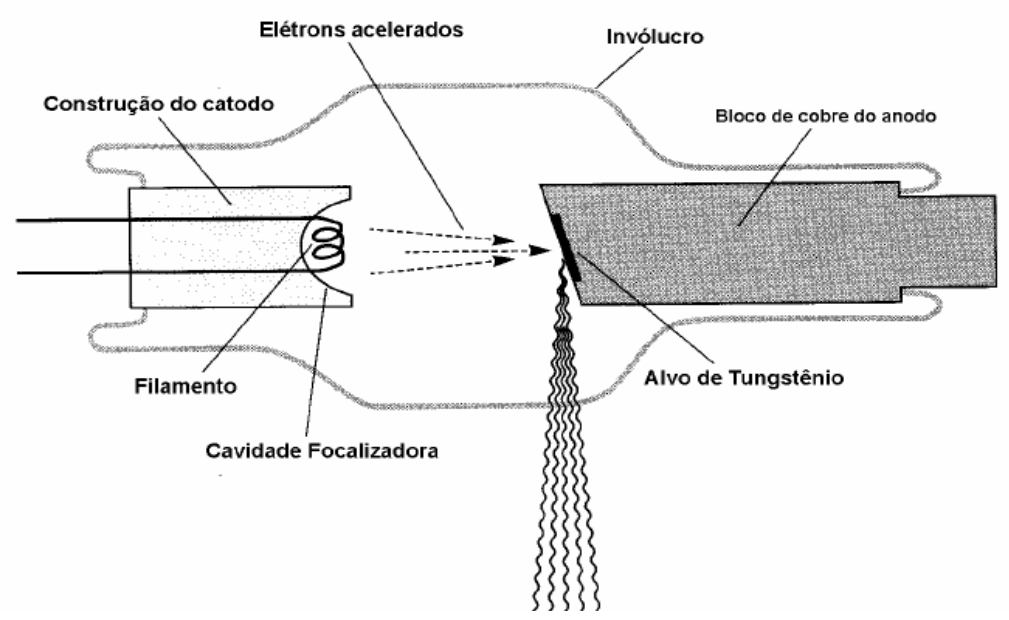

FIGURA 14: Representação esquemática de um tubo de raios $X^{(41)}$.

Ampola: A ampola é construída por um invólucro de vidro temperado (para suportar altas temperaturas) desprovida de ar (vácuo), para garantir que não haverá interação dos elétrons com o meio e manter o máximo de elétrons interagindo com o alvo. 
Anodo: É chamado por muitos de dispositivo positivo (+) da ampola. O seu material tem que suportar altas temperaturas, portanto, ele pode ser fabricado com alguns materiais mais resistentes, tais como, o Tungstênio, o Molibdênio, ou o Grafite unido a uma liga de Tungstênio e Rênio. Também é chamado de alvo. $\mathrm{O}$ anodo pode ser encontrado em dois modos de funcionamento, o fixo e o giratório.

O anodo giratório tem uma maior durabilidade, tem uma área maior para a interação dos elétrons incidentes, maior poder de dissipar o calor. Também há diferenças na angulação do anodo, que conseqüentemente irá aumentar ou diminuir o tamanho do campo. Os equipamentos de anodo fixo têm uma durabilidade de funcionamento muito menor e má dissipação do calor, porque oferece menor espaço para interação dos elétrons e aumentam as chances de ruptura na estrutura do anodo, por excessivas colisões dos elétrons.

Apesar de toda a energia liberada durante o processo apenas $1 \%$ é transformada em radiação X, e 99\% é transformada em calor, sendo necessária a utilização de materiais com alto ponto de fusão (como o tungstênio cujo ponto fusão é igual a $3380^{\circ} \mathrm{C}$ ). Geralmente estes processos de geração de radiação $X$ chegam a $3.000^{\circ} \mathrm{C}^{(38)}$.

Catodo: Também conhecido como eletrodo negativo do tubo, é formado por um bloco de material resistente com formato de um pequeno "L“. A parte inferior é conhecida como "copo de foco", e em seu interior estão os filamentos. O filamento possui um formato semelhante ao do filamento de uma lâmpada incandescente. $O$ material da sua fabricação é o tungstênio para agüentar as altas temperaturas provocadas pelos elétrons no processo da produção de raios $X$, que ocorre no alvo. A sua função é dar passagem para a corrente elétrica em ampères $(A)$ gerada por um gerador de baixa tensão, liberando elétrons das camadas mais distantes do núcleo. Este processo é chamado de emissão termiônica. O tamanho do filamento helicoidal, a forma do copo de foco, o diâmetro do filamento, a tensão aplicada são alguns dos fatores que afetam o tamanho focal real no qual os elétrons irão se chocar contra o alvo. A temperatura do filamento ou a corrente do filamento controlará a quantidade de elétrons emitidos contra o alvo, também sendo responsável pela qualidade da imagem radiográfica. Nos sistemas de radiação $X$ há dois tamanhos de filamentos, sendo possível a escolha do mesmo na hora do exame, dependendo da técnica a ser aplicada e podem ser acionados 
ou selecionados através da mesa de comando ou console. Na prática o mais utilizado é do foco grosso, pois possui maior área de dissipação, maior resistência a exposições mais prolongadas e uma maior quantidade de elétrons circulantes.

Angulação do anodo: A próxima etapa da formação dos raios $X$ é o ponto efetivo aonde os elétrons irão se chocar. $O$ anodo tem um formato de disco em seu todo, mas ao final deste disco há uma angulação que pode variar de acordo com o fabricante ou sua utilização. Geralmente nos sistemas de radiodiagnósticos as angulações não passam de $15^{\circ}$. Esta angulação influencia na qualidade da imagem radiográfica. Quanto menor a angulação, menor será o ponto focal.

Devido à angulação do alvo e ao fato de a interação dos elétrons ocorrem em diferentes profundidades dos elétrons, a intensidade do feixe de raios $X$ produzida não é uniforme em seu plano transversal. Esse efeito é denominado "efeito anódico", ou seja, a intensidade do feixe é menor do lado do anodo e mais intenso no lado do catodo, o que é explicado pelo resultado da interação e absorção dos fótons pelo próprio alvo, e a forma de leque assimétrico ao longo do eixo transversal faz do efeito a sua principal característica, como pode ser verificado na FIG. $15^{(41)}$.

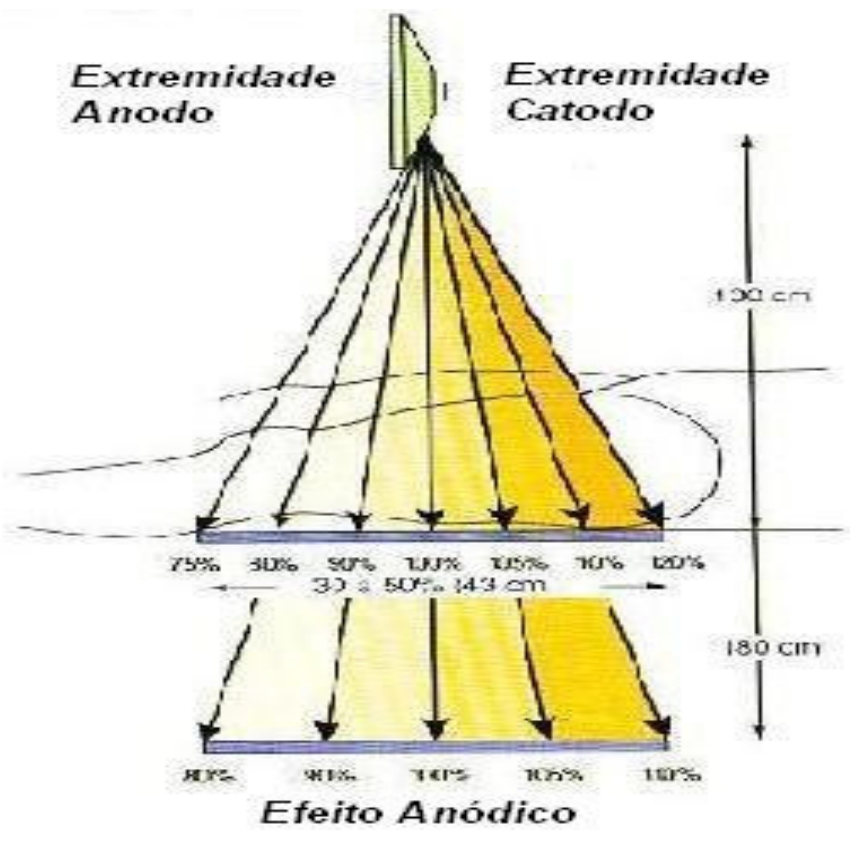

FIGURA 15: Representação do efeito Anódico ${ }^{(41)}$ 
Um gerador de raios $X$ pode ser do tipo monofásico, trifásico, de potencial constante ou gerador de alta e média freqüência. Entre os demais componentes de um sistema de radiação $X$, pode-se citar:

- Retificadores: responsáveis pela polaridade correta na alimentação da tensão do tubo, corrigem a passagem da corrente alternada originária do transformador de alta tensão, permitindo um único caminho para a passagem dos elétrons ou corrente do tubo, garantindo 0 bom funcionamento do sistema (tensão no ciclo invertido).

- Transformadores: permitem elevar ou diminuir a tensão no circuito, por meio de bobinas (enrolamentos de fio de cobre) existentes no circuito primário e secundário do transformador.

- Seletores operacionais do console

- Controle de exposições automática, entre outros.

\subsection{Dosimetria das radiações}

Sabemos que as radiações ionizantes podem ser largamente utilizadas em vários seguimentos, como na medicina e na indústria, entre outros, embora, as mesmas possam ser altamente prejudiciais a saúde, se não utilizadas adequadamente. Um dos meios de se garantir o seu emprego seguro é a dosimetria. $\mathrm{O}$ termo dose para física médica quer dizer exposição à radiação ou taxa de dose de exposição à radiação por um determinado intervalo de tempo em um determinado ponto de um ambiente ou meio. A abrangência da dosimetria inclui a calibração de instrumentos; dosimetria interna e externa; pesquisa e ensino; planejamento das aplicações radiodiagnósticas e radioterapêutica; proteção radiológica e higiene das radiações. De acordo com as recomendações da Organização Mundial de Saúde $(\mathrm{OMS})^{(42)}$, esta responsabilidade é do profissional da área (Unidades Hospitalares) ou do responsável técnico (Indústrias e outras instalações). 


\subsubsection{Atenuação do feixe}

Sendo a radiação ionizante um fenômeno natural, com modos e origens diferentes (corpusculares e eletromagnéticas), a interação da radiação com o meio também ocorre com trajetórias diferentes. A radiação eletromagnética não tem massa, e não é afetada por outro campo elétrico ou magnético e tem uma velocidade constante em um determinado meio. A radiação eletromagnética é caracterizada pelo comprimento de onda $(\lambda)$, freqüência $(v)$ e energia por fóton. Comumente utilizadas no diagnóstico por imagem. A radiação gama é resultante da mudança na energia do núcleo do átomo radioativo. Usa-se como blindagem o chumbo e paredes de concreto $^{(37)}$.

Conhecendo o comportamento das radiações, e sabendo suas trajetórias pode-se avaliar a qualidade da radiação, utilizar equipamentos adequados para a dosimetria com os conhecimentos técnicos apropriados.

Quando ocorre a produção de radiação $\mathrm{X}$, a interação dos elétrons com o anodo, pode ocorrer em diversas profundidades, com isso, os fótons gerados não terão as mesmas energias, sendo assim, o feixe gerado será heterogêneo e não homogêneo.

O conhecimento do espectro de raios $\mathrm{X}$, que é definido como sendo a distribuição de energia da radiação produzida em um feixe de raios $X$, é necessário para se entender os vários estágios da produção de uma imagem diagnóstica. As técnicas para a determinação precisa e direta de espectros de raios $X$ são os detectores de Germânio e os detectores de estado sólido. $O$ espectro de raios $X$ é formado de duas partes distintas e superpostas: uma contínua e outra em linhas discretas. Sendo que a parte contínua deve-se aos raios $\mathrm{X}$ de bremsstrahlung e vai de energias muito baixas até uma energia máxima, numericamente igual à diferença de potencial aplicada ao tubo, e as linhas discretas são em decorrência dos raios $X$ característicos. A filtração inerente e adicional elimina as energias baixas que podem ser absorvidas pelo paciente. Um espectro teórico de radiação X pode ser visto na FIG. 16. 


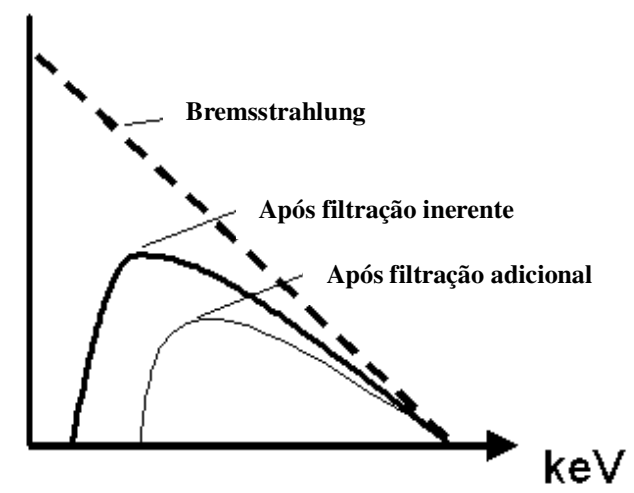

FIGURA 16: Espectro da radiação X; bremsstrahlung (sem filtração); com filtração inerente e com filtração total.

A quantidade de raios $X$ gerados é proporcional ao número atômico $(Z)$ do material do alvo, ao quadrado do valor da tensão $(k V p)^{2}$, e à corrente aplicada ao tubo (mA), e a sua energia depende, portanto principalmente do potencial $(k V p)$ aplicado ao tubo.

A norma IEC $61267^{(17)}$ recomenda para cada qualidade de radiação uma determinada espessura de filtração adicional. Estas espessuras podem variar conforme o fabricante do sistema de radiação $X$, o tempo de uso da maquina, $e$ outros parâmetros do equipamento. A FIG. 17 ilustra um feixe de radiação passando pelos colimadores e pelo anteparo.

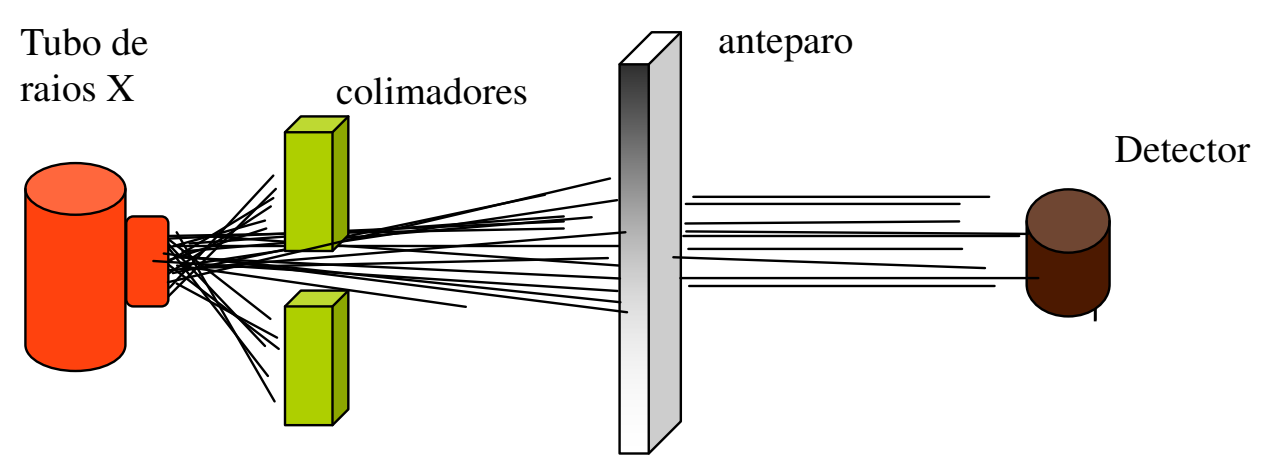

FIGURA 17: Simulação de um feixe de radiação $X$ sendo colimado e atenuado pelo anteparo.

A intensidade da radiação $(\mathrm{I} x)$ transferida para uma espessura de material $\mathrm{x}$ 
é dada pela fórmula:

$$
I(x)=I_{0} \cdot e^{-\mu x}
$$

onde $\mathrm{I}_{0}$ é a intensidade da radiação incidente no absorvedor, $\mu$ é chamado de coeficiente de atenuação linear e sua unidade é dada $\mathrm{em}^{-1}$. No geral, este coeficiente depende na energia do fóton e da natureza do material (água, gordura, alumínio, etc.).

A camada semi-redutora (CSR) é definida como a espessura de um absorvedor capaz de reduzir a intensidade do feixe de radiação pela metade (50\%) do valor original. A equação que representa esta afirmação é:

$$
\mathrm{CSR}=0,693 / \mu
$$

A atenuação exponencial intrínseca aplicada para um feixe monoenergético, cuja curva atenuada é a base do cálculo para encontrarmos a $1^{\text {a }}$ e a $2^{\text {a }}$ camadas semi-redutora. Quando se aumenta a espessura do filtro, a energia média do feixe transmitida também aumenta isso quer dizer; quando os fótons de várias energias interagem com os filtros, os fótons com energias baixas são absorvidos, e assim sucessivamente, até este feixe tornar-se mais "duro", em outras palavras, só atravessam os atenuadores com maior espessura os fótons com as energias maiores, tornando os feixes mais monoenergéticos ${ }^{(38)}$.

\subsubsection{Qualidade do feixe de radiação X}

A qualidade dos feixes de radiação $X$ é definida como "a habilidade de penetração em materiais conhecidos".

Um meio ideal para descrever as qualidades do feixe de raios $X$ são as medidas realizadas através da distribuição espectral. Pode-se avaliar a qualidade do feixe utilizando um meio mais fácil e barato: determinação da filtração adicional, da CSR e da energia efetiva.

A camada semi redutora qualifica o feixe de raios $\mathrm{X}$ e pode ser relacionada com a energia do espectro para um feixe primário e colimado. A determinação do

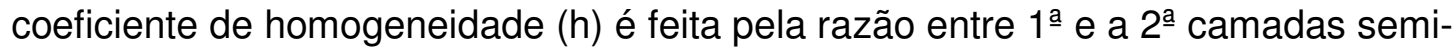


redutoras. A energia efetiva ou equivalente do feixe é a energia dos fótons monoenergéticos e é determinada pela curva de atenuação para um dado material, e é caracterizada pelo grau de inclinação ou pelo coeficiente de atenuação linear $(\mu)$.

\subsubsection{Condições de referência}

As condições de referência representam um conjunto de valores (valores de referência) que influenciam a qualidade para qual o coeficiente de calibração é válido sem demais correções. Exemplos de fatores de influência para a calibração em termos de kerma no ar são a qualidade do feixe de radiação $X$ ou gama, $a$ temperatura do ambiente, a pressão atmosférica, a umidade relativa do ar, a direção da incidência da radiação, etc. As condições de referência são definidas não como subjetivas da medida, mas ainda podem ter uma influência no resultado da medida. Eles podem ser de diferentes naturezas como, por exemplo, pressão do ambiente e temperatura, elas podem vir do eletrômetro (fuga, aquecimento, etc.), ou podem ser relacionados com o campo de radiação (qualidade do feixe, taxa de dose, tamanho do campo, presença de radiação de fuga). A influência destes fatores pode ter diferentes efeitos nos eletrômetros. Como por exemplo, a resposta de um eletrômetro com um dosímetro semicondutor não é influenciada pelas mudanças atmosféricas, mas as câmaras de ionização são influenciadas por estas mudanças $^{(17)}$. Durante as medidas, algumas destas influências não podem ser controladas, como por exemplo, a pressão. É possível aplicar um fator de correção para ter uma maior precisão dos valores obtidos. 


\subsubsection{Incertezas}

É importante reconhecer que qualquer medida está sujeita a erros. Tanto no valor medido como no valor real. A diferença entre estes valores é a medição do erro. Infortunadamente saber precisamente o valor real é difícil e envolve vários parâmetros ${ }^{(43)}$.

De acordo com o Vocabulário Internacional de Termos Fundamentais e Gerais de Metrologia a incerteza de medição é definida como sendo um parâmetro, associado ao resultado de uma medição que caracteriza a dispersão dos valores que podem ser fundamentadamente atribuídos a um mensurando(44). Os parâmetros envolvidos podem ser organizados conforme a necessidade do laboratório ou estabelecimento que fazem uso das mesmas.

Tipos de erros:

- Erros grosseiros: O esquecimento de anotar os fatores ambientais, posicionamento do equipamento manualmente, ou a adição de um material que não era o adequado (filtro). Estes infortúnios são definidos como erros grosseiros.

- Erros sistemáticos: São erros que afetam sempre na mesma direção, ou seja, para mais ou para menos. Como por exemplo, erros dos aparelhos de medição, posicionamento automático de uma câmara, etc.

Utilizando um recurso mais simples da estatística pode-se avaliar algumas flutuações, assim os erros nos valores são amenizados. Tais recursos podem ser a média, desvio do valor médio e desvio padrão e variância.

A avaliação das incertezas é caracterizada por:

- Incerteza do tipo A: A incerteza do tipo A tem como base os parâmetros estatísticos, ou seja, sistemáticos como a média e os seus desvios.

- Incertezas do tipo B: A incerteza do tipo B tem como base os parâmetros não estatísticos, tais como, informações anteriores, certificado de calibração, especificações dos instrumentos, manuais 
técnicos, e outras bases com informações prévias.

- Incertezas expandidas: A incerteza combinada é estimada por uma equação, que reflete a ação combinada das várias fontes de erros considerados. O valor obtido representa uma faixa de valores em torno de um valor médio, onde se espera encontrar o erro da medição. A equação da incerteza combinada é:

$$
\mathrm{u}_{\mathrm{c}}=\sqrt{u_{1}^{2}+u_{2}^{2}+\ldots .+u_{n}^{2}}
$$

O valor de $u_{c}$ é a somatória do quadrado de todas as incertezas (tipo A e Tipo B).

\subsubsection{Princípios de proteção radiológica}

A principal finalidade da proteção radiológica é proteger os indivíduos dos efeitos danosos das radiações ionizantes permitindo o trabalho seguro com as atividades utilizando radiação. Os princípios de proteção radiológica são:

- Justificação: Nenhuma prática envolvendo o uso de radiação ionizante deve ser autorizada a menos que produza benefício para o indivíduo exposto ou para a sociedade de modo a compensar o prejuízo que possa ser causado;

- Otimização: As instalações e práticas devem ser planejadas, implantadas e executadas de modo que a magnitude das doses individuais, o número de pessoas expostas e a probabilidade de exposições acidentais sejam tão baixos quanto razoavelmente exeqüíveis/praticáveis, levando-se em conta fatores sociais e econômicos (Princípio ALARA/ALARP);

- Limites de Dose: Valores de dose efetiva (anual, corpo inteiro), estabelecidos para exposição ocupacional (trabalhadores com radiação) e exposição do público, decorrentes de práticas controladas, cujas magnitudes não devem ser excedidas, são: $20 \mathrm{mSv}$ para trabalhadores, média ponderada em 5 anos consecutivos, desde que não exceda $50 \mathrm{mSv}$ em qualquer ano. Para o indivíduo do público este limite é de $1 \mathrm{mSv} / \mathrm{ano}^{(45)}$. 


\subsection{Grandezas e Unidades}

3.7.1 Exposição: É o quociente entre $d Q$ por $d m$, onde $d Q$ é o valor absoluto da carga total de íons de um dado sinal, produzidos no ar, quando todos os elétrons (negativos e positivos) liberados pelos fótons no ar, em uma massa $\mathrm{dm}$, são completamente freados no ar. Esta grandeza é válida para a radiação $X$ e radiação gama

$$
X=\frac{d Q}{d m}
$$

A sua unidade especial é o Röentgen $(R)$ e no Sistema Internacional é representada por coulomb/kilograma e $1 \mathrm{R}=2,58 \times 10^{-4} \mathrm{C} / \mathrm{kg}^{(46,47)}$.

3.7.2 Dose absorvida: Em 1950, foi introduzida a dose absorvida, que é a energia média cedida pela radiação ionizante à matéria por unidade de massa dessa matéria. Essa grandeza é definida para qualquer tipo de radiação ionizante e para qualquer meio, ao contrário da exposição. Sua unidade especial é o Gray (Gy) e no Sistema Internacional $1 \mathrm{~Gy}=1 \mathrm{~J} / \mathrm{kg}^{(46,47)}$

A relação entre a energia média cedida $d \varepsilon$ numa massa $d m$ constitui a dose absorvida $D$ :

$$
D=\frac{d \bar{\varepsilon}}{d m}
$$

Quando ocorre um balanço entre as partículas carregadas entrando e saindo do volume onde são detectadas, diz-se que há equilíbrio eletrônico. Sob essa e mais algumas condições (em que as energias de ligação e de perdas por radiação podem ser desprezadas), o kerma e a dose absorvida são praticamente iguais. 
3.7.3 kerma no Ar: Para radiações indiretamente ionizantes (fótons ou partículas não carregadas), define-se o kerma ${ }_{2} K$, como a relação entre a energia cinética $\mathrm{d} E_{t r}$ de todas as partículas carregadas liberadas numa massa $\mathrm{d} m^{(46)}$ :

$$
K=\frac{\mathrm{d} E_{t r}}{\mathrm{~d} m}
$$

A unidade correspondente, o joule/kilograma $(\mathrm{J} / \mathrm{kg})$, recebe também o nome especial de Gray (Gy).

A taxa de kerma expressa a variação do kerma ao longo de um intervalo de tempo $\mathrm{d} t$ :

$$
\dot{K}=\frac{\mathrm{d} K}{\mathrm{~d} t}
$$

A unidade da taxa de kerma é o Gray/segundo (Gy/s), que corresponde a $J \cdot \mathrm{kg}^{-1} \cdot \mathrm{s}^{-1}$.

O kerma no ar é a grandeza física diretamente medida mais utilizada em todos os laboratórios de calibração ${ }^{(4)}$. Ao contrário da dose absorvida, pode ser prontamente determinada, e diretamente aplicada. Pode ainda ser diretamente relacionada com a grandeza exposição, ainda utilizada em muitos instrumentos.

Valores de exposição expressos em Röentgen (R) podem ser prontamente convertidos em Gray (Gy) ${ }^{(47)}$.

$$
1 \mathrm{R}=0,876 \times 10^{-2} \mathrm{~Gy}
$$

Essa relação é válida para a grandeza kerma no $\operatorname{ar}^{(48)}$.

3.7.4 Produto kerma no Ar- Área, PKA: É a integral do produto kerma no ar livre no ar numa área $A$ do feixe de raios $\mathrm{X}$ em um plano perpendicular ao seu eixo, pela área do feixe no mesmo plano, em unidades de $\mathrm{Gy} . \mathrm{cm}^{2}(\mathrm{SI})$, dado por:

$$
P K A=\int_{A} K_{a r}(A) d A
$$

A radiação espalhada pelo paciente é excluída nesta definição ${ }^{(49)}$. 
Para uso específico em radiodiagnóstico são propostas mais algumas grandezas: kerma incidente, kerma na superfície de entrada, produto kermacomprimento (em todos os casos, kerma no ar) e, no caso de tomografia computadorizada, os índices CTDI ("Computed Tomography Dose Index") e CTKI ("Computed Tomography Kerma Index") A saída ou rendimento do tubo de raios $X$ é definida como:

$$
Y(d)=\frac{K(d)}{P_{l t}}
$$

Onde $K(d)$ é o kerma no ar medido a uma distância $d$ do ponto focal do tubo (distância focal), e $P_{l t}$ o produto corrente $(I)$ tempo de exposição $(t)$.

\subsection{Câmaras de ionização}

\subsubsection{Câmara de ionização de ar livre}

Para medir exposição de acordo com sua definição, foi projetada por Perrin $1896{ }^{(50)}$ uma câmara de ionização, denominada câmara de ar livre. Atualmente este instrumento é a referência para a grandeza kerma no $\mathrm{ar}^{(51)}$. Esta câmara possui um colimador que delimita uma certa área do feixe de radiação que passa centralmente pelas placas paralelas; uma delas é circundada por placas de guarda definindo o volume de coleta de íons (volume ativo) na direção axial das linhas de força do campo elétrico entre as placas. A medida do kerma no ar com a câmara de ionização de ar livre está diretamente relacionada ao principio do equilíbrio eletrônico. À medida que a energia dos fótons aumenta, é necessário que as dimensões da câmara aumentem consideravelmente, a fim de que os critérios especiais para a medida operacional da grandeza sejam obedecidos. Desta forma, surgem diversos problemas técnicos diretamente relacionados com as dimensões físicas, nas medidas de fótons com energia acima de $300 \mathrm{keV}$, quando os fatores de correção se tornam elevados, determinando um limite de energia da radiação para a utilização da câmara de ar livre como um padrão primário à pressão atmosférica. $O$ desenho esquematizado da câmara de ar livre é representado pela FIG. 18. 


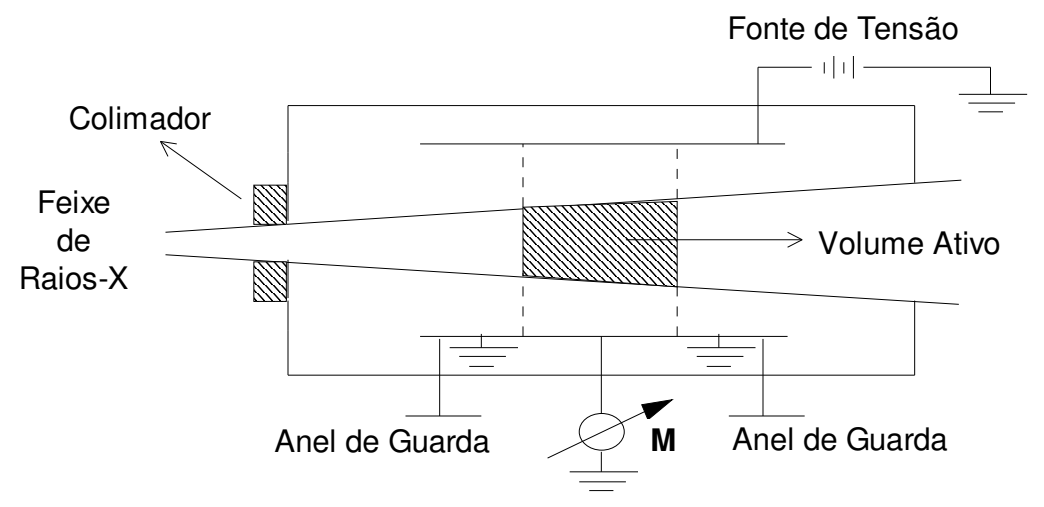

FIGURA 18: Representação esquematizada da câmara de ar livre ${ }^{(50)}$

\subsubsection{Câmaras de ionização do tipo cilíndrica}

Em medidas dosimétricas rotineiras, faz-se uso de câmaras do tipo cilíndrica, que são de fácil manuseio e transporte, versáteis e cujo projeto possibilita seu uso em simuladores. Estas câmaras não são padrões primários, isto é, não medem a grandeza segundo sua definição física, pois apresentam, entre outros fatores, dependência energética ${ }^{(52)}$. Entretanto, por meio de calibrações, podem ser padronizadas em intervalos de energia em relação às câmaras padrões.

A câmara de ionização cilíndrica consiste num instrumento de pequenas dimensões com uma parede sólida condutora que delimita um certo volume de ar. Neste volume está inserido, no centro, um eletrodo para a coleta dos íons formados no ar. A parede tem uma espessura sempre maior que o alcance máximo dos elétrons secundários gerados fora da câmara; isso significa que a transferência de energia dos elétrons secundários (gerados na parede) para o volume ativo de ar é igual à dos elétrons (gerados no volume de ar) para a parede da câmara. Este sistema, portanto constitui um detector de fótons ${ }^{(53)}$. A FIG. 19 mostra o esquema estrutural da câmara de ionização tipo cilíndrica. 


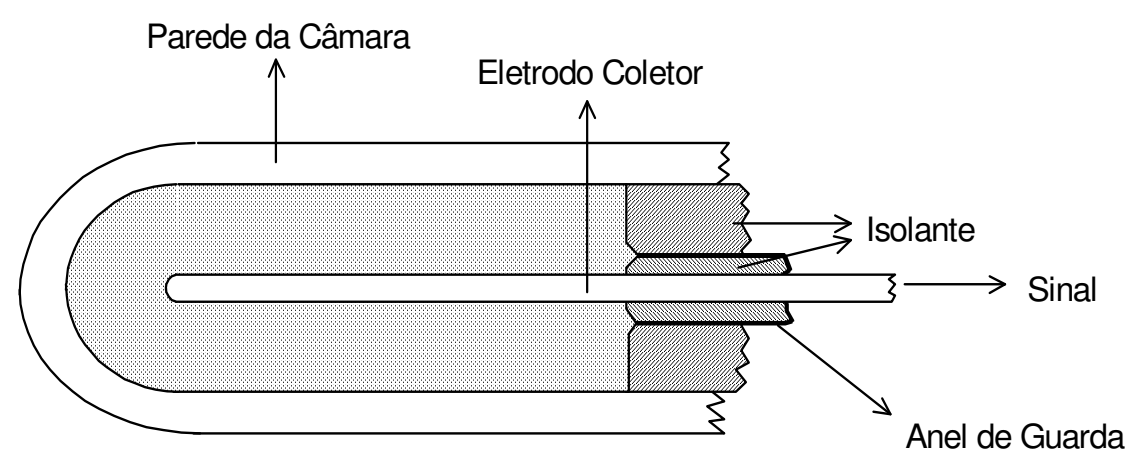

FIGURA 19: Representação esquematizada da câmara de ionização do tipo cilíndrica ${ }^{(53)}$..

\subsubsection{Câmaras de ionização de placas paralelas}

A dosimetria da radiação $\mathrm{X}$ gerada a valores baixos de potencial apresenta dificuldades especiais devido à absorção considerável desta radiação pela matéria mesmo quando se utiliza paredes finas de material equivalente ao ar.

Neste caso, são utilizadas câmaras de ionização de placas paralelas, também denominadas superficiais, para a determinação de taxas de kerma no ar e de taxas de dose absorvida deste tipo de radiação, como padrão secundário e também medidas rotineiras.

Devido à pequena profundidade da câmara, a taxa de kerma no ar varia pouco com o volume de medida e a dependência com a energia é fraca. A parede dianteira (janela de entrada) deste tipo de câmara pode ser tão fina quanto a matéria de camada atrás da qual se deseja determinar a taxa de kerma no ar ou a dose absorvida, consistindo de uma membrana ou de uma malha através da qual a radiação passa para atingir o volume ativo.

As câmaras de ionização de placas paralelas também são recomendadas para a detecção de elétrons com energias mais baixas que $10 \mathrm{MeV}$, devendo ser necessariamente utilizadas nas medidas em feixes de elétrons com energia mais baixas que $5 \mathrm{MeV}{ }^{(54,55)}$. A representação da câmara de ionização de placas paralelas desenvolvida no LCI / IPEN, pode ser vista na FIG. 20. 


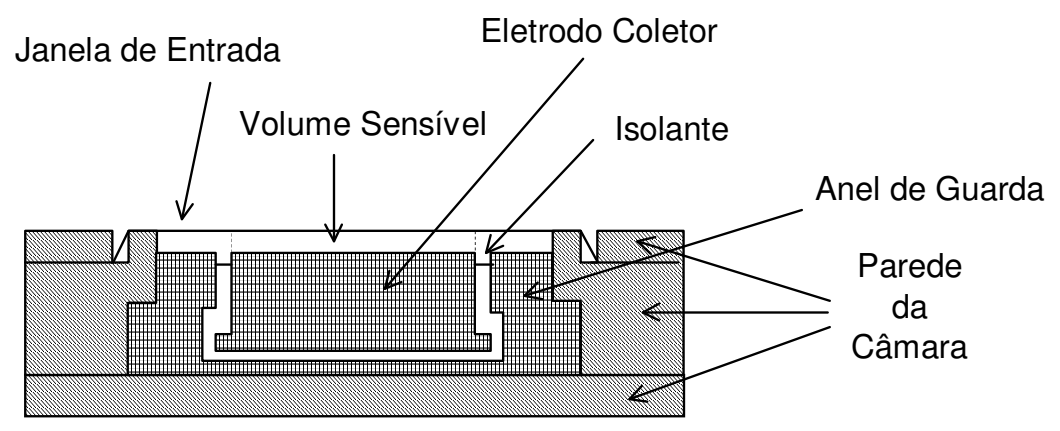

FIGURA 20: Representação da câmara de ionização de placas paralelas ${ }^{(18)}$.

\subsubsection{Câmara de ionização para medidas de kerma no ar em}

\section{fluoroscopia}

Para ser utilizada em medidas de kerma no ar em fluoroscopia, uma câmara de ionização dever ter um intervalo dinâmico de utilização e ser fina o suficiente para medir tanto as baixas doses de entrada na posição do receptor de imagem assim como as altas doses normalmente encontradas em fluoroscopia. A câmara mais utilizada nestas medidas, é uma câmara não selada, com placas paralelas e volume de $60 \mathrm{~cm}^{3}$. Possui anel de guarda, paredes de policarbonato, no interior e no exterior da sua parede possuem uma camada de grafite condutora. São fabricadas pela empresa americana Radcal, e o seu modelo é 10 x 5-60. Suas principais características estão relacionadas na TAB. 2.

TABELA 2: Principais características da câmara de ionização $10 \times 5-60^{(56)}$

Dependência com a Taxa de kerma:

Dependência energética:

Tensão de polarização:

Corrente de Fuga:

$$
<5 \% \text { para } 30 \mathrm{mGy} / \mathrm{s}
$$$$
\pm 5 \% \text {, de } 30 \mathrm{keV} \text { até } 1,3 \mathrm{MeV}
$$

(com equilíbrio eletrônico)

Nominal +300 VDC $(\max +600$ VDC)

$<5$ e-15 A com +300 VDC bias

Pode-se verificar uma representação esquematizada da câmara 10x5 - 60 na FIG. 21. 


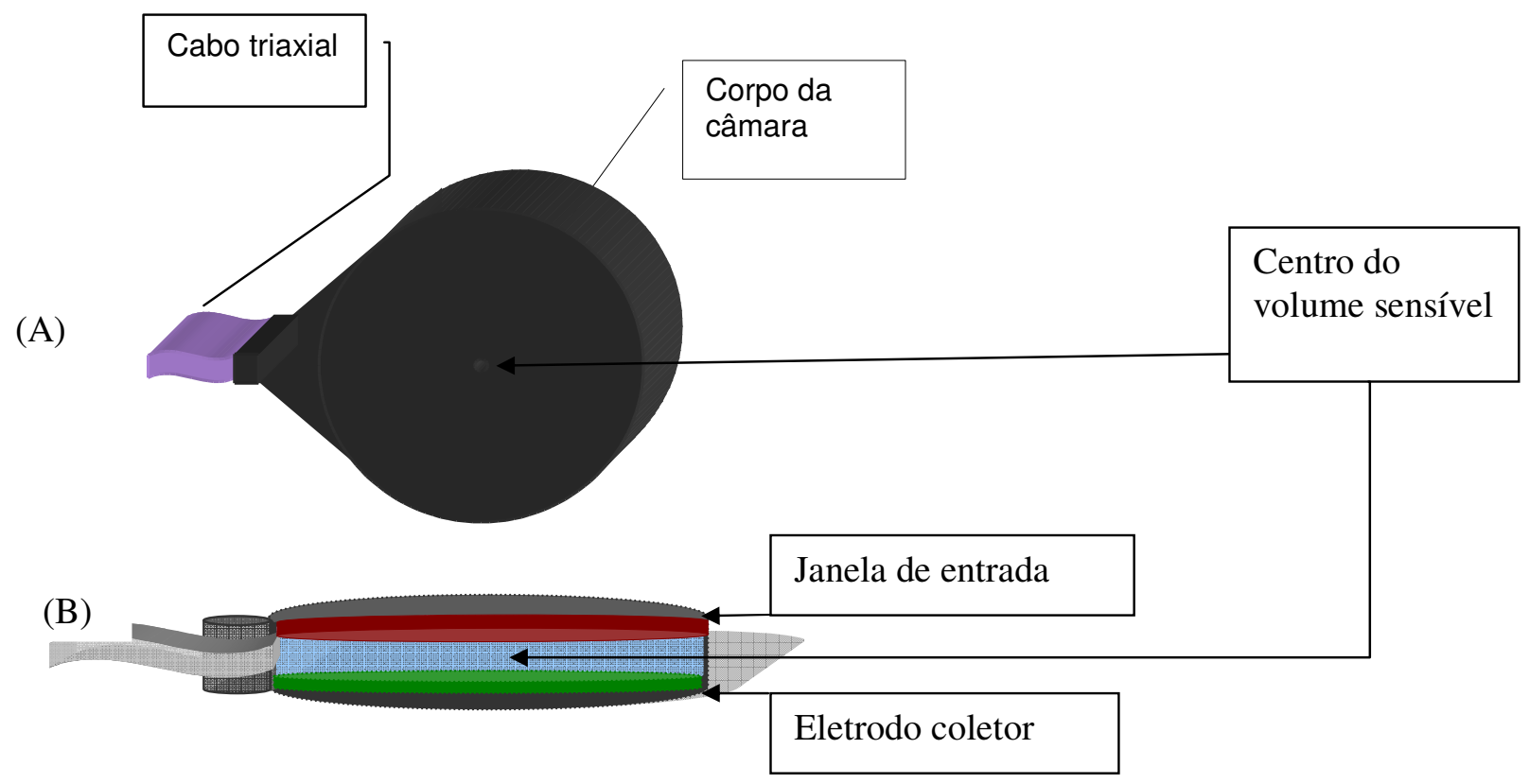

FIGURA 21: Representação esquematizada da câmara de ionização para fluoroscopia. A) Vista frontal e b) Vista lateral. ${ }^{*}$

ar-área, KAP.

\subsubsection{Câmara de ionização para medidas de produto kerma no}

O instrumento adequado para a medida da grandeza produto kerma no arárea, KAP, é uma câmara de ionização de transmissão de placas paralelas montada no colimador de saída e cobrindo todo o feixe de raios $X^{(57,58)}$. Medidores de KAP diferem das câmaras de ionização comuns em dois aspectos. Primeiro, seu volume sensível é irradiado apenas parcialmente e, segundo, este medidores usados em medidas clínicas devem ser calibrados para indicar o produto kerma no ar-área de saída para se obter a ligação entre a energia da radiação incidente no paciente com o risco ao paciente. O coeficiente de calibração, $\mathrm{k}$, é definido como: $k=K A P / Q_{K A P}$, onde $Q_{K A P}$ é a carga elétrica coletada pelo medidor de KAP e KAP é o produto kerma no ar-área para uma dada área de integração. $A$, num plano de referência, $r$, perpendicular ao eixo do feixe e transversal aos fótons que atravessam o medidor ${ }^{(59)}$.

\footnotetext{
* As cores dos eletrodos são meramente ilustrativas.

Esta representação foi baseada em informações fornecidas pelo fabricante, Radcal.
} 


\section{MATERIAIS E MÉTODOS}

Neste capítulo serão apresentados os principais equipamentos e as técnicas utilizadas no laboratório de calibração do IPEN para a realização deste trabalho.

\subsection{Materiais}

1. Sistema de radiação X, marca Medicor Mövek Röntgengyara, Hungria, modelo Neo-Diagnomax, monofásico e com retificação de onda completa e foco com potência de $50 \mathrm{~kW}$. A filtração inerente do tubo é de 0,8 mmAl. Este gerador pode ser utilizado tanto no modo radiográfico como fluoroscópico. O tubo foi posicionado de modo que o feixe incida horizontalmente em relação aos sistemas de medidas que serão posicionados em um banco óptico com 3 metros de comprimento. As características deste sistema de radiação estão representadas na TAB. 3. Todas as medidas foram realizadas no modo fluoroscópico ${ }^{(18)}$.

TABELA 3: Características do sistema de radiação $X$ Medicor Mövek Röntgengyara.

\begin{tabular}{ccc}
\hline & Modo Radiográfico & Modo Fluoroscópico \\
\hline Tensão de Operação & 40 a $125 \mathrm{kV}$ & 45 a $100 \mathrm{kV}$ \\
Tempo de Exposição & 0,04 a 5 segundos & - \\
Corrente do tubo & $500 \mathrm{~mA}$ para $90 \mathrm{kV}$ & 1 até $5 \mathrm{~mA}$ \\
Rendimento & $315 \mathrm{~mA}$ para $125 \mathrm{kV}$ & - \\
\hline
\end{tabular}

2. Como sistema de referência foi utilizado uma câmara de ionização de placas paralelas padrão secundário, com volume de $1 \mathrm{~cm}^{3}$ da marca PTW, modelo 77334 , série 2052, calibrada pelo Laboratório Padrão Primário PTB, Alemanha, e acoplada a um eletrômetro PTW modelo Unidos, 10001, série 10474. 
3. Conjunto de câmaras de ionização marca Radcal específicas para fluoroscopia, sendo duas de modelo 10x5-60, séries 9017 e 9785 e uma modelo 10x5-60 E, série 24931. A câmara número de série 9785 será utilizada como referência para fluoroscopia neste trabalho.

4. Sistema de monitoração de tensão de equipamentos de raios $X$ invasivo, modelo Dynaliser III, marca Radcal. Suas características estão demonstradas na TAB. 4.

TABELA 4: Limites de operação do sistema de monitoração invasivo Dynaliser III/Radcal.

Limites de operação

\begin{tabular}{cc}
\hline Tensão de pico & 20 a $150 \mathrm{kVp}$ \\
Corrente & 0,1 a $9999 \mathrm{~mA}$ \\
Tempo de exposição & 0,7 a $9999 \mathrm{~ms}$ \\
Exposição & 0,1 a $9999 \mathrm{mR}$ \\
Taxa de exposição & 0,1 a $9999 \mathrm{mR} / \mathrm{s}$ \\
\hline
\end{tabular}

5. Medidor de tensão não-invasivo, modelo Diavolt RAD/FLU, marca PTW ํo de série 1000. Grandezas disponíveis: Practical Peak Voltage ${ }^{\dagger}(\mathrm{PPV}) ; \mathrm{kV}_{\mathrm{p}} ; \mathrm{kV}_{\mathrm{m}}$; Dose; Tempo de Exposição. O seu modo de funcionamento está na TAB. 5.

\footnotetext{
${ }^{\dagger}$ O Potencial de Pico Prático (PPV) é definido pela derivada do Potencial Equivalente em Contraste (PEC), que por sua vez, é obtido através da comparação entre o contraste de kerma no ar produzido por um determinado sistema de potencial constante e um sistema clínico arbitrário para uma configuração de contraste específica.
} 
TABELA 5: Sistema de Monitoração não-invasivo Diavolt.

\begin{tabular}{cc}
\hline & Modo de operação \\
\hline Voltagem do tubo & $22 \mathrm{kV}$ a 150kV \\
Modelo & $\mathrm{RAD} / \mathrm{FLU}$ \\
Anodo/filtro & $\mathrm{W} / 1.5 \mathrm{Al} \mathrm{a} \mathrm{W} / 5.0 \mathrm{Al}$ \\
Modo & $\mathrm{kVmax} / \mathrm{kVmean} \mathrm{/} \mathrm{PPV}$ \\
Tempo de exposição & $0,3 \mathrm{~ms}$ a 999 s \\
\hline
\end{tabular}

6. Filtros de alta pureza, termômetros, barômetros, higrômetros, desumidificadores e ar condicionado.

7. Sistema de colimadores e filtros, formados por 3 placas de alumínio, dois colimadores de chumbo um de $4 \mathrm{~cm}$ e outro de $4,8 \mathrm{~cm}$ de diâmetro.

8. Duas fontes de controle, sendo uma de ${ }^{14} \mathrm{C}$ da PTW, modelo 894, série DK405, com atividade de 3,7 MBq (1993), acoplada à fonte por um suporte da PTW e uma de ${ }^{90} \mathrm{Sr}+{ }^{90} \mathrm{Y}$, da PTW, Alemanha, modelo 8921, série 1269, com atividade de 33,3 MBq (1990).

9 Para o desenvolvimento dos dois simuladores de acrílico, o maior com dimensões de $300 \times 300 \times 200 \mathrm{~mm}$ e o menor com dimensões iguais a $300 \times$ $300 \times 200 \mathrm{~mm}$, foram utilizadas placas de acrílico comerciais com espessura de $10 \mathrm{~mm}$. 


\subsection{Metodologia}

\subsubsection{Método de calibração}

O método de calibração utilizado no trabalho é o de substituição, que sempre utiliza a câmara de referência durante o procedimento de calibração. A técnica consiste em posicionar a câmara de referência PTW 77334, com volume sensível de $1 \mathrm{~cm}^{3}$ no feixe de radiação $X$, para a determinação da grandeza de referência (kerma no ar). Na seqüência, a câmara em calibração é colocada na mesma posição para a determinação do seu coeficiente de calibração. Todas as leituras foram corrigidas para as condições ambientais.

\subsubsection{Teste de estabilidade da câmara de referência}

Para maior confiabilidade nas medidas com a câmara de ionização PTW 77334 , foram realizados os testes de estabilidade da sua resposta a curto e a longo prazo. Este teste consiste na verificação de dez medidas consecutivas de 1 minuto cada, analisando-se a sua repetibilidade, em termos da dispersão de suas medidas. Esta verificação ao longo do tempo consiste no teste de reprodutibilidade. De acordo com normas internacionais as variações percentuais das respostas não devem exceder $0,3 \%$ para câmaras de referência e 0,5\% para os instrumentos de campo ${ }^{(60)}$.

\subsubsection{Teste de fuga de corrente}

Para se determinar a corrente de fuga foi realizado o teste de fuga, que consiste em coletar diversas medidas consecutivas em certo tempo e após este tempo analisar o comportamento da câmara de ionização após a irradiação, ou seja, a sua capacidade de agregar ou perder sinal (cargas geradas no volume sensível) sem a presença de radiação ionizante. Para a realização deste teste a câmara foi irradiada com a fonte controle de ${ }^{14} \mathrm{C}$, descrita no item 4.1, como mostra a FIG. 22, para se obter certa indicação no eletrômetro, e em seguida a fonte foi retirada da posição e sua resposta foi analisada por 20 minutos. 


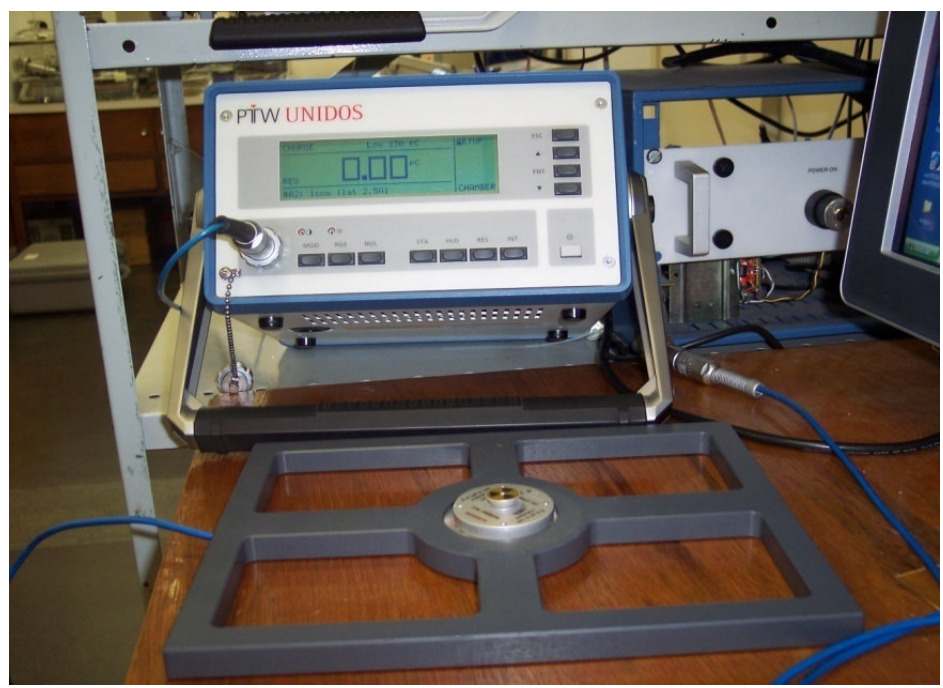

FIGURA 22: Câmara de ionização PTW 77334, conectada ao eletrômetro UNIDOS e a fonte de controle de ${ }^{14} \mathrm{C}$ posicionada sobre a câmara.

\subsubsection{Sistemas de posicionamento da fonte de controle}

Os sistemas de detecção de radiação (câmaras de ionização) utilizados em fluoroscopia têm um desenho especial (formato de gota), diferentemente da câmara de ionização plana que tem um formato circular. Portanto, para a realização das medidas do controle de estabilidade e o teste de fuga, que são realizados com uma fonte controle de ${ }^{14} \mathrm{C}$ e ${ }^{90} \mathrm{Sr}+{ }^{90} \mathrm{Y}$, foram desenvolvidos $\mathrm{e}$ confeccionados sistemas especiais de posicionamento para garantir a geometria e a reprodutibilidade das medidas para estas câmaras. Os sistemas de posicionamento. Estes suportes foram desenvolvidos em acrílico e possuem um encaixe para a fonte de controle. Para a câmara de ionização plana o suporte possui geometria circular com diâmetro de $19 \mathrm{~cm}$, com duas metades que se encaixam, acomodando a câmara de ionização no seu interior. A metade superior possui uma abertura na dimensão da fonte de ${ }^{14} \mathrm{C}$. A FIG. 23a, ilustra a câmara de ionização posicionada no suporte com a sua respectiva fonte. Para a câmara de ionização para fluoroscopia o suporte possui geometria retangular, com dimensões de $11,0 \times 12,7 \mathrm{~cm}$, também possui duas metades que se encaixam e na sua parte superior existe uma abertura na dimensão da fonte de ${ }^{90} \mathrm{Sr}+{ }^{90} \mathrm{Y}$. Na FIG. 23b pode-se ver a câmara posicionada no suporte sem a fonte de controle. 


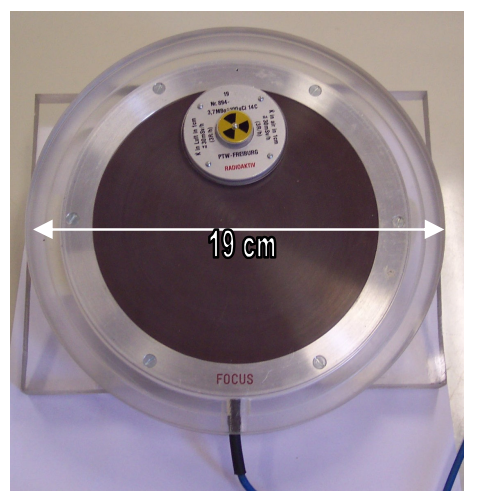

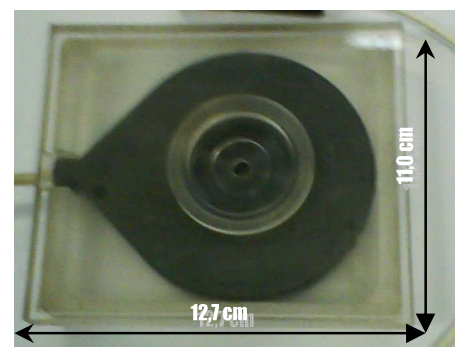

(b)

(a)

FIGURA 23: (a) Suporte para a câmara de ionização plana com a fonte de

${ }^{14} \mathrm{C}$ posicionada. (b) Suporte para a câmara de ionização para fluoroscopia sem a fonte de controle.

\subsubsection{Utilização de Câmara monitora}

O Código de Prática da Agência Internacional de Energia Atômica,TRS $457^{(4)}$, recomenda que os sistemas de radiação $X$ para laboratórios de calibração de instrumentos utilizem uma câmara de transmissão (monitora), para identificar qualquer alteração na emissão do feixe de radiação $X$. A câmara monitora deve ser posicionada na saída do feixe primário e próxima a janela do tubo de raios X. A câmara deve ser aberta e o material da janela deve ser transparente para os raios $X$, de modo que não atenue nem interfira no feixe, ser grande o suficiente para permitir a passagem integral do feixe, ser eficiente na coleção dos íons (99\%) e apresentar uma fuga de corrente menor que $2 \%$. O posicionamento da câmara monitora no feixe de radiação está representado na FIG.24. 


\section{Janela do tubo}

de raios $X$

D

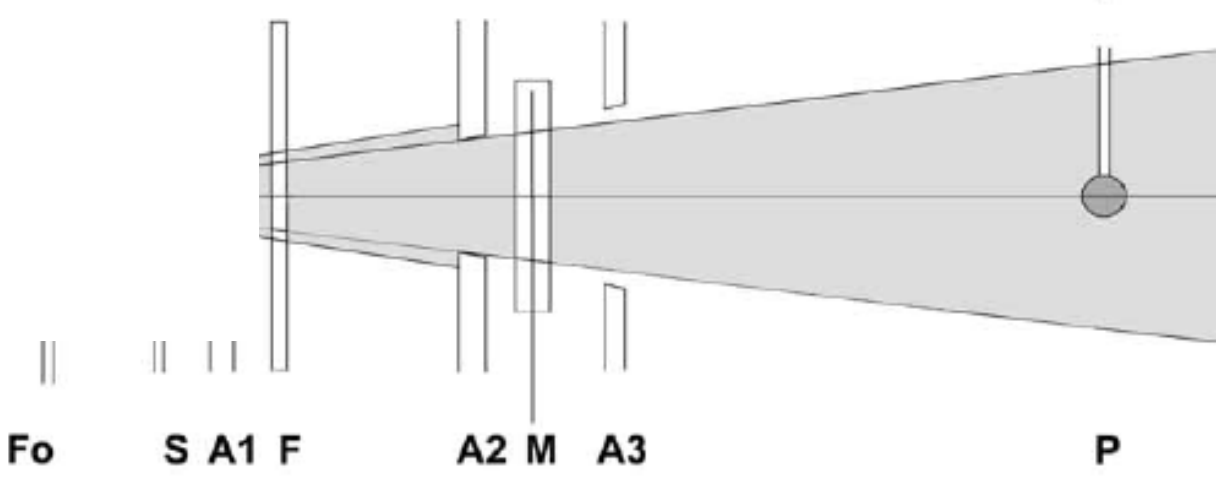

FIGURA 24: posicionamento da câmara monitora no feixe de radiação $\mathrm{X}$. Fo= foco; $S=$ obturador; $A 1$, A2 e A3 = colimadores; $F$ = filtração adicional; $M$ = câmara monitora; $\mathrm{P}$ = distância de calibração e $\mathrm{D}=$ detector.

\subsubsection{Determinação da filtração adicional}

A Norma IEC $61627^{(17)}$ estabelece para a determinação das qualidades dos feixes em fluoroscopia, que sejam utilizados filtros com espessura e material específicos. A TAB. 6 mostra os valores de filtração para cada qualidade.

$R Q R \rightarrow$ Qualidade da radiação utilizando filtros de alumínio

$R Q C \rightarrow$ Qualidade da radiação utilizando filtros de cobre (fluoroscopia)

TABELA 6: Filtração para cada qualidade de radiação conforme a IEC 61267.

\begin{tabular}{ccc|cc}
\hline $\begin{array}{c}\text { Tensão } \\
\text { aplicada } \\
(\mathrm{kV})\end{array}$ & $\mathrm{RQR}$ & $\begin{array}{c}\text { Filtração adicional } \\
(\mathrm{mm} \mathrm{Al})\end{array}$ & $\mathrm{RQC}$ & $\begin{array}{c}\text { Filtração adicional } \\
(\mathrm{mm} \mathrm{Cu})\end{array}$ \\
\hline 50 & $\mathrm{RQR} \mathrm{3}$ & 1,78 & $\mathrm{RQC} \mathrm{3}$ & 0,5 \\
70 & $\mathrm{RQR} \mathrm{5}$ & 2,58 & $\mathrm{RQC} \mathrm{5}$ & 1,5 \\
90 & $\mathrm{RQR} \mathrm{7}$ & 3,48 & $\mathrm{RQC} \mathrm{7/8}$ & 2,0 \\
\hline
\end{tabular}


O método utilizado na determinação da filtração adicional está descrito tanto na norma IEC 61267, como no protocolo da IAEA, o TRS $457^{(4)}$ :

1) Foi feita uma curva de atenuação para cada qualidade, usando a escala linear para o eixo $\mathrm{X}$ e logarítmica para o eixo $\mathrm{Y}$. A escala linear $(X)$ é utilizada para a espessura do atenuador (filtros), e a escala $(\mathrm{Y})$ utilizada para o fator de atenuação. 2) Foi preparado um retângulo de material transparente (plástico mais resistente), cuja altura e comprimento, ambos nas respectivas unidades da curva de atenuação, são dados por um fator de quatro e pela primeira camada semiredutora da qualidade da radiação padrão para ser realizada multiplicando por $(1+1 / h)$, respectivamente, onde $\circ \mathrm{h}$ é $\mathrm{o}$ coeficiente de homogeneidade da qualidade de radiação.

3) Em seguida uma linha horizontal auxiliar no retângulo (plástico) foi feita, dividindo a sua parte interior em duas partes de iguais tamanhos e outra linha auxiliar na vertical na distância para a borda esquerda do retângulo correspondendo a primeira camada semi-redutora.

4) Foi posicionado o retângulo sobre a curva de atenuação de modo que as bordas fiquem paralelas com os eixos do gráfico e que o canto superior esquerdo e o ponto de intersecção das duas linhas coincidam com os pontos na curva de atenuação. A diferença entre a posição da borda esquerda do retângulo e a coordenada forneceu a soma total da filtração adicional requerida para a qualidade da radiação padrão, como demonstra o exemplo da FIG. 25.

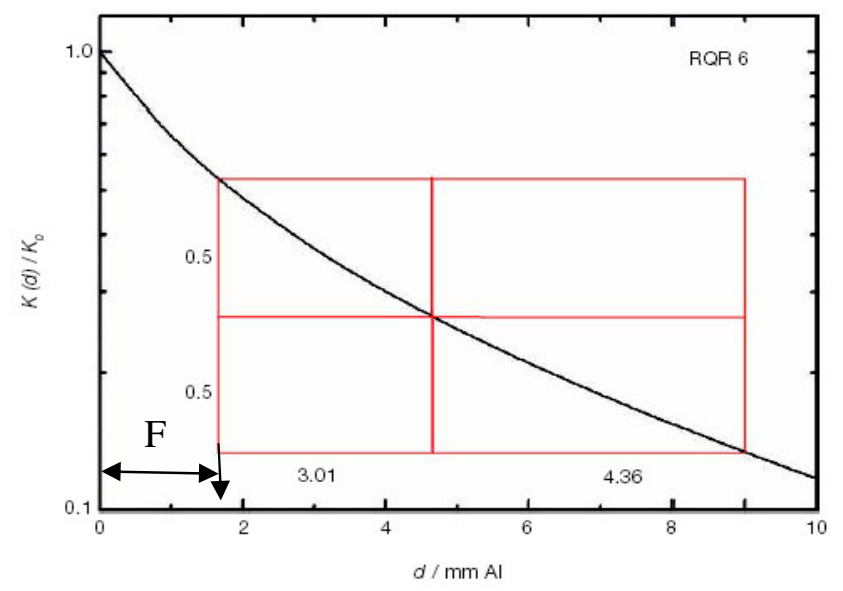

FIGURA 25: Exemplo da curva de atenuação e o modelo (retângulo) para encontrar a filtração adicional. $\mathrm{F}=$ =espessura da filtração adicional necessária. 


\subsubsection{Implantação das qualidades de radiação}

O próximo passo após a determinação da filtração adicional foi buscar o valor da camada semi-redutora, já com a filtração adicional posicionada. Foram realizadas as seguintes etapas:

$\rightarrow$ Medidas de carga com a câmara de ionização de referência, $K_{0}$, sem adição de material atenuador.

$\rightarrow$ Medidas de carga com a câmara de ionização de referência, $K$, após acrescentar a espessura de material atenuador ( $\mathrm{mmAl}$ ) recomendado pela norma IEC 61267, como CSR para cada qualidade.

$\rightarrow$ Se a razão entre os valores encontrados na segunda e na primeira e situação,K/K $\mathrm{K}_{0}$ estiver entre de 0,485 e 0,515, a qualidade da radiação foi estabelecida.

\subsubsection{Determinação das taxas de kerma no ar}

As taxas de kerma no ar $\dot{K}_{a r}$, em Gy/min, para cada qualidade de feixe estabelecida foi determinada pela formula:

$$
\dot{K}_{\text {ar }}=\mathrm{N}_{\mathrm{K}} \mathrm{Kq} \mathrm{M}
$$

Onde,

$M=$ leitura obtida com o instrumento de referência $(\mathrm{C} / \mathrm{min})$

$\mathrm{Nk}=$ coeficiente de calibração fornecido por um laboratório padrão $(\mathrm{Gy} / \mathrm{C})$

$\mathrm{Kq}=$ fator de correção para cada qualidade de radiação

A câmara de ionização de referência para radiodiagnostico do LCI /IPEN possui rastreabilidade ao Laboratório Primário Alemão, PTB. Utilizando as taxas de kerma no ar encontradas para cada qualidade, foi realizada a calibração das câmaras de ionização planas e da câmara especifica para fluoroscopia, determinando os seus respectivos coeficientes de calibração, pela seguinte fórmula:

$$
\mathrm{N}_{\mathrm{k}}=\bar{K}_{\mathrm{ar}} / \mathrm{M}
$$

Onde, 
$\mathrm{K}_{\mathrm{ar}}=$ Taxa de kerma no ar determinado com a câmara de referência

$M=$ leitura obtida com o instrumento em calibração

$\mathrm{N}_{\mathrm{k}}=$ coeficiente de calibração determinado

\subsubsection{Determinação da tensão (kV) aplicada aos equipamentos de radiação $X$}

Para cada uma das diferentes técnicas de exames empregadas no radiodiagnostico, há um modo de operação e tensão aplicada próprios. Na TAB. 7 estão demonstradas alguns tipos de exames com suas faixas de operação e que servem de base para as implantações das qualidades nos laboratórios de calibração.

TABELA 7: Tipos de exames aplicados em clinicas de radiodiagnostico e suas respectivas faixas de tensão aplicada.

\begin{tabular}{ccc}
\hline Tipos de exames & $\begin{array}{c}\text { Tensão aplicada } \\
(\mathrm{kV})\end{array}$ & $\begin{array}{c}\text { Tensão utilizada neste } \\
\text { trabalho }(\mathrm{kV})\end{array}$ \\
\hline Radiologia convencional & 20 a 150 & - \\
Fluoroscopia & 50 a 150 & $50,70,90$ \\
Tomografia & 50 a 150 & - \\
Mamografia & 22 a 40 & - \\
\hline
\end{tabular}

O controle de qualidade é muito importante para a utilização de um sistema de radiodiagnóstico, principalmente em relação aos parâmetros que influenciam à determinação das qualidades do feixe de radiação, portanto, a exatidão da tensão aplicada ( $\mathrm{kV}$ ) e a corrente ( $\mathrm{mA}$ ) foram medidos utilizando-se um sistema invasivo Dynalyzer. Como uma confirmação destes parâmetros foram realizadas medidas com um sistema de medição de tensão, dose e tempo não invasivo (Diavolt), que é um detector de estado sólido e que de acordo com as recomendações da AIEA $^{(4)}$ e da IEC ${ }^{(17)}$, mede a grandeza Tensão de Pico Prática (PPV). Os valores reais de tensão deste equipamento foram determinados anteriormente por 
espectrometria ${ }^{(18)}$.

Os detectores semicondutores são pequenos equipamentos detectores de radiação de estado sólidos, práticos, e instantâneos. Conseguem amplificar um sinal proveniente de um baixo sinal de radiação e não se faz necessário corrigir as medidas pelo fator de temperatura e pressão ${ }^{(4,17)}$.

Os testes realizados foram:

- Teste de reprodutibilidade da tensão $(\mathrm{kV})$

- Teste de exatidão da tensão $(\mathrm{kV})$

O teste de reprodutibilidade avalia o desvio das medidas, entre o maior e menor valor encontrado em uma série de medidas. E, o teste de exatidão avalia o desvio entre a tensão aplicada e a tensão nominal (identificada no painel da máquina de raios $\mathrm{X}$ ).

\subsubsection{Dependência energética das câmaras de ionização utilizadas}

As câmaras de ionização utilizadas neste trabalho, tanto as duas planas como a de fluoroscopia foram avaliadas quanto a dependência energética no intervalo estudado neste trabalho. Esta avaliação indica o seu desempenho em determinadas faixas. $O$ fator que indica a dependência energética de uma câmara de ionização é o Kq (fator de qualidade), que é determinado em comparação ao valor de referência para a qualidade de radiação, que no caso de radiodiagnóstico é o RQR 5 (70 kV). 


\section{RESULTADOS}

\subsection{Desenvolvimentos de suportes}

Para a reprodutibilidade de posicionamento das câmaras tanto para o teste de estabilidade como para as medidas no feixe de radiação- $X$, foram projetados $\mathrm{e}$ confeccionados os seguintes suportes:

- Um suporte para o teste de estabilidade para as câmaras indicadas para Fluoroscopia;

- Um sistema de colimação para o equipamento de radiação-X Medicor/Neo Diagnomax, incluindo o posicionador em acrílico da câmara monitora, que pode ser visualizado na FIG. 26;

- Um suporte em acrílico para o posicionamento da câmara de fluoroscopia no feixe;

- Um suporte em acrílico para o teste de estabilidade da câmara PTW, 77335 .

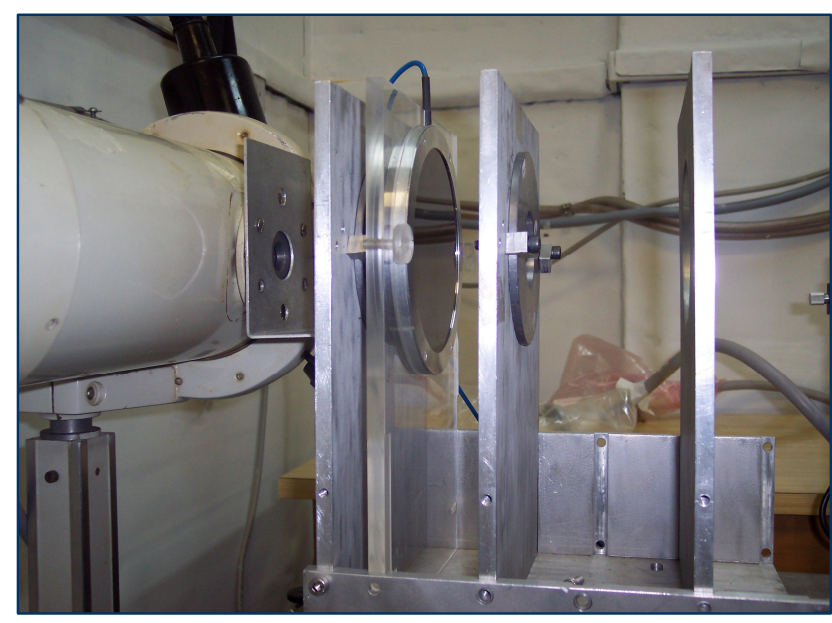

(A)

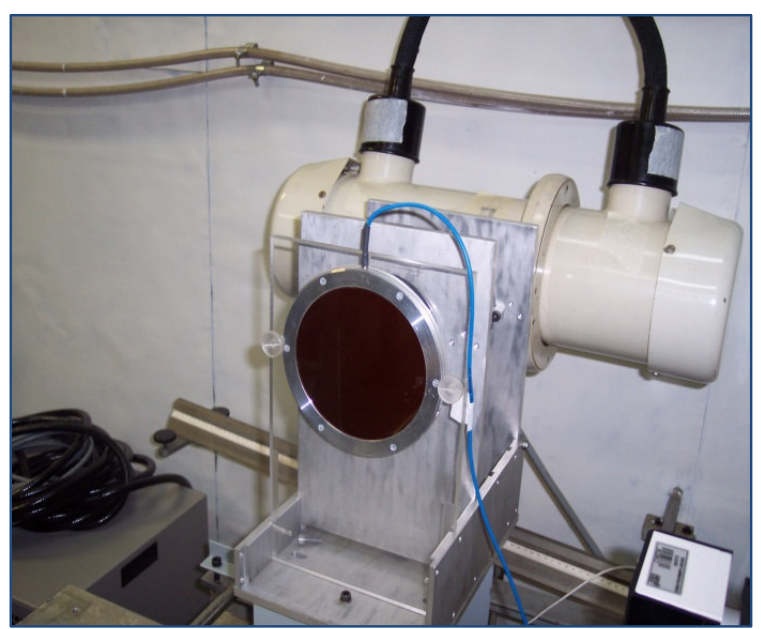

(B)

FIGURA 26: Sistema de colimação e suporte da câmara monitora desenvolvidos neste trabalho. (A) vista frontal e (B) vista lateral. 


\subsection{Estudo do comportamento das câmaras planas como câmaras}

\section{monitoras}

O estudo do comportamento das câmaras planas PTW 77335 para serem utilizadas como câmaras monitoras, foi iniciado pelos testes de repetibilidade e estabilidade a longo prazo. Para estas medidas foram desenvolvidos os suportes que garantiram o posicionamento reprodutível da fonte de controle em relação a câmara.

O teste de repetibilidade é definido como uma série de medidas seqüenciais em um intervalo de tempo pré-determinado, utilizando uma fonte controle, que neste caso foi de ${ }^{14} \mathrm{C}$. O teste de estabilidade a longo prazo é realizado pela análise dos resultados do teste de repetibilidade ao longo do tempo (semanas, meses ou anos). Os gráficos da FIG.27 demonstram o comportamento das câmaras para estes testes. Cada ponto representa a média de dez medidas. Notase que as duas câmaras apresentam uma variação dentro do limite máximo de aceitação de $2 \%$ em relação ao valor de referência ${ }^{(60,61)}$.
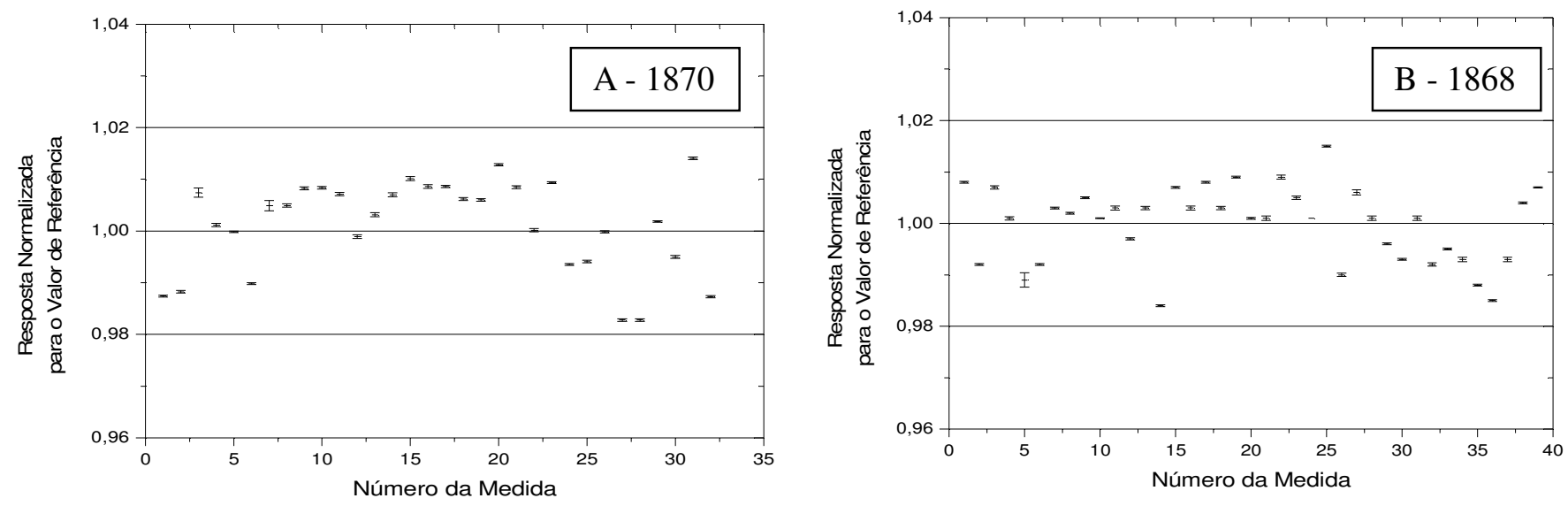

FIGURA 27: Comportamento das câmaras de ionização A e B para os testes de estabilidade a curto e longo prazo

As taxas do kerma do ar foram determinadas com a câmara de ionização de referência de placas paralelas com volume sensível de $1 \mathrm{~cm}^{3}$ da PTW junto com 
as câmaras de ionização utilizadas como monitoras (1870 e 1868), e seqüencialmente foram realizadas as medidas sem as câmaras monitoras. Os valores obtidos são mostrados na TAB. 8 para ambas as câmaras.

TABELA 8 - Valores obtidos de taxa de kerma no ar com e sem as câmaras planas no feixe de radiação.

\begin{tabular}{cccccc} 
& & & \multicolumn{3}{c}{$\begin{array}{c}\text { Taxa de kerma no ar } \\
(\mathrm{mG} / \mathrm{min})\end{array}$} \\
\cline { 4 - 6 } $\begin{array}{c}\text { Qualidade } \\
\text { da }\end{array}$ & $\begin{array}{c}\text { Tensão } \\
\text { nominal } \\
\text { radiação }\end{array}$ & $\begin{array}{c}\text { CSR } \\
(\mathrm{kV})\end{array}$ & $\begin{array}{c}\text { Sem câmara } \\
(\mathrm{mmAl})\end{array}$ & $\begin{array}{c}\text { Com a câmara Com a câmara } \\
\text { monitora }\end{array}$ & $\begin{array}{c}\text { monitora } \\
\text { monitora }\end{array}$ \\
\hline RQR 3 & 50 & 1,84 & 1,98 & 1,72 & $1870(\mathrm{~A})$ \\
RQR 5 & 70 & 2,44 & 4,66 & 4,23 & 4,27 \\
RQR 7 & 90 & 3,70 & 7,86 & 6,79 & 7,59 \\
\hline
\end{tabular}

A avaliação da variação da taxa de kerma no ar com e sem as câmaras planas posicionadas como câmaras monitoras demonstrou que a menor redução das taxas de kerma no ar foi apresentada com a câmara A (1870) no feixe, como pode ser visto na TAB.9. Neste caso, todos os valores apresentaram uma variação menor do que $10 \%{ }^{(62)}$.

TABELA 9: Variação da redução das taxas de kerma no ar, com as câmaras planas posicionadas em conjunto com a câmara de referência.

\begin{tabular}{ccc}
\hline Qualidade de radiação & $\begin{array}{c}\text { Câmara de ionização de } \\
1868(\mathrm{~B})\end{array}$ & $\begin{array}{c}\text { Câmara de ionização de } \\
1870(\mathrm{~A})\end{array}$ \\
\hline RQR 3 & $15 \%$ & $8,8 \%$ \\
RQR 5 & $10 \%$ & $9,1 \%$ \\
RQR 7 & $16 \%$ & $3,6 \%$ \\
\hline
\end{tabular}

$\mathrm{Na}$ seqüência foram determinados os coeficientes de calibração das câmaras de ionização planas A e B. Esta determinação foi realizada utilizando o sistema de referência já citado, nas qualidades de radiação já implantadas no LCI, de acordo com a primeira versão da norma IEC $61267^{(18,22)}$.

Os resultados obtidos são mostrados na TAB. 10. O comportamento da 
câmara A (1870) em relação a B (1868), mostra uma menor dependência energética no intervalo testado. Sendo esta última pouco influenciada pela flutuação do rendimento do equipamento de radiação $X$.

TABELA 10: Coeficiente de Calibração (Nk) e fator de qualidade $(\mathrm{Kq})$ para as câmaras planas PTW, $A$ e $B$, para as qualidades RQR3, RQR5 e RQR7.

\begin{tabular}{|c|c|c|c|c|c|c|}
\hline \multirow{2}{*}{$\begin{array}{l}\text { Qualidade } \\
\text { de } \\
\text { radiação }\end{array}$} & \multirow{2}{*}{$\begin{array}{l}\text { Tensão } \\
\text { aplicada } \\
\text { (kV) }\end{array}$} & \multirow{2}{*}{$\begin{array}{l}\text { Energia } \\
\text { Efetiva } \\
(\mathrm{keV})\end{array}$} & \multicolumn{2}{|l|}{ Câmara A } & \multicolumn{2}{|l|}{ Câmara B } \\
\hline & & & $\mathrm{Nk}(\mathrm{G} / \mathrm{C})$ & $\mathrm{Kq}$ & $\mathrm{Nk}(\mathrm{Gy} / \mathrm{C})$ & $\mathrm{Kq}$ \\
\hline$\overline{R Q R ~} 3$ & 50 & 32,0 & - & 0,931 & - & 0,715 \\
\hline RQR 5 & 70 & 39,2 & $7,36 \times 10^{4}$ & 1 & $6,42 \times 10^{4}$ & 1 \\
\hline RQR 7 & 90 & 46,0 & - & 0,937 & - & 0,877 \\
\hline
\end{tabular}

Embora as duas câmaras tenham apresentado uma boa estabilidade, a câmara $A$ apresentou um melhor comportamento no feixe de radiação $X$, com uma pequena dependência energética (FIG. 28) e pouca redução das taxas de kerma no ar. A dependência energética foi de $7 \%$ para a câmara $A$ e de $28,5 \%$ para a câmara B. Portanto, optou-se em utilizar a câmara A como a câmara monitora para este sistema.
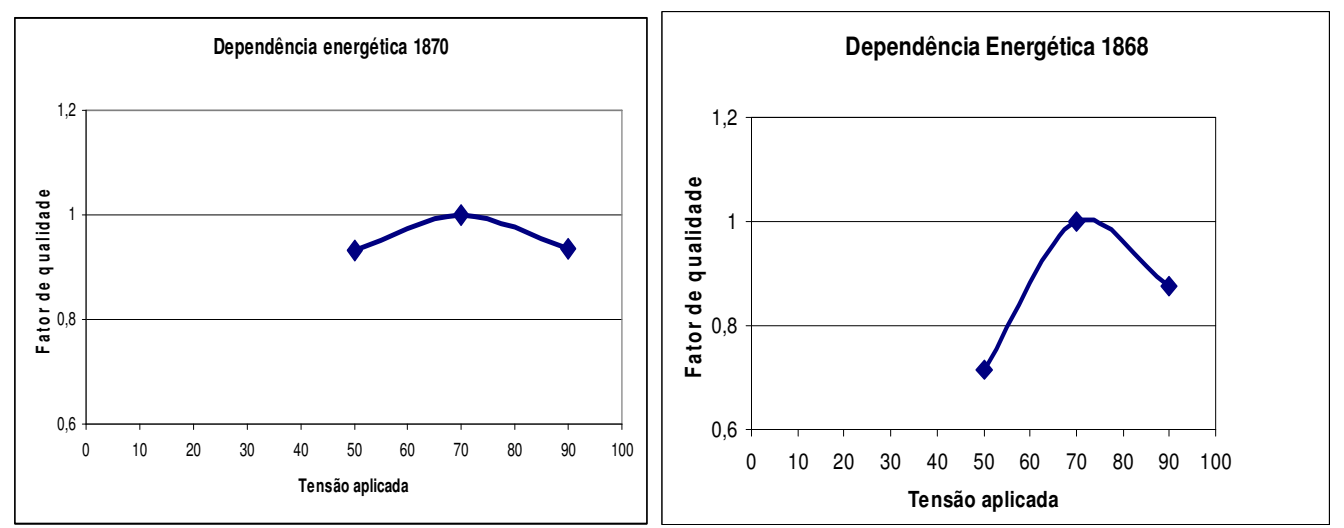

FIGURA 28: Dependência energética das câmaras de ionização planas 


\subsection{Controle de qualidade do sistema de radiação X Medicor}

Para o sistema de radiação $X$ utilizado neste trabalho foram analisados os parâmetros que influenciam a determinação das qualidades do feixe de radiação. Para a exatidão da tensão aplicada (kV) e da corrente (mA) foi utilizado um medidor invasivo Dynalizer já citado anteriormente. Como uma confirmação destes parâmetros foram realizadas medidas com um sistema de medição de tensão, dose e tempo não invasivo (Diavolt). Lembrando sempre que os valores reais de tensão foram obtidos anteriormente por espectrometria ${ }^{(18)}$. A TAB. 11 mostra os valores obtidos com estes diferentes métodos de medição.

TABELA 11: Valores de tensão obtidos pelos métodos invasivo e não invasivos.

\begin{tabular}{|c|c|c|c|c|c|c|}
\hline \multirow{2}{*}{$\begin{array}{l}\text { Tensão } \\
\text { Nominal } \\
(\mathrm{kV})\end{array}$} & \multirow{2}{*}{$\begin{array}{c}\text { Corrente } \\
\text { Aplicada } \\
\text { (mA) }\end{array}$} & \multirow{2}{*}{ Espectrometria* } & \multirow{2}{*}{ Dynalyzer** } & \multicolumn{3}{|c|}{ Diavolt * } \\
\hline & & & & PPV & kVp máx & kVp med \\
\hline 100 & máx & 88,7 & $87,1 \pm 0,18$ & $81,5 \pm 0,10$ & $89,3 \pm 0,18$ & $87,8 \pm 0,18$ \\
\hline 100 & $\min$ & 89,8 & $89,8 \pm 0,29$ & $87,8 \pm 0,29$ & $94,5 \pm 0,60$ & $91,8 \pm 0,18$ \\
\hline 90 & máx & 79,8 & $78,0 \pm 0,09$ & $73,8 \pm 0,09$ & $80,3 \pm 0,25$ & $79,1 \pm 0,10$ \\
\hline 90 & $\min$ & 80,1 & $80,3 \pm 0,24$ & $80,9 \pm 0,15$ & $85,8 \pm 0,26$ & $83,4 \pm 0,39$ \\
\hline 80 & máx & 69,2 & $68,7 \pm 0,04$ & $65,7 \pm 0,04$ & $70,5 \pm 0,12$ & $69,6 \pm 0,13$ \\
\hline 80 & $\min$ & 70,3 & $70,6 \pm 0,15$ & $72,6 \pm 0,05$ & $78,8 \pm 0,86$ & $75,9 \pm 0,30$ \\
\hline 71 & máx & 61,7 & $61,0 \pm 0,90$ & $61,0 \pm 0,90$ & $62,0 \pm 0,15$ & $62,0 \pm 0,11$ \\
\hline 71 & $\min$ & 62,9 & $62,9 \pm 0,05$ & $67,6 \pm 0,14$ & $72,0 \pm 0,40$ & $62,6 \pm 0,52$ \\
\hline 60 & máx & 50,9 & $50,5 \pm 0,08$ & $49,1 \pm 0,08$ & $52,2 \pm 0,07$ & $51,4 \pm 0,09$ \\
\hline 60 & $\min$ & 52,0 & $52,9 \pm 0,02$ & sr & $\mathrm{sr}$ & sr \\
\hline 50 & máx & 42,6 & $44,0 \pm 0,46$ & sr & sr & sr \\
\hline 50 & máx & 43,1 & $44,0 \pm 0,03$ & sr & $\mathrm{sr}$ & sr \\
\hline
\end{tabular}


Para a determinação da exatidão da tensão $(k V p)$ utilizou-se a fórmula dada a seguir.

$$
d(\%)=100 \cdot \frac{k V p_{\text {nom }}-k V p_{\text {med }}}{k V p_{\text {nom }}}
$$

A ANVISA ${ }^{(5)}$ determina que a variação máxima nos valores de tensão $(k V p)$ seja de até $10 \%$. Os valores obtidos para a exatidão com o instrumento invasivo e os não invasivos concordaram com a espectrometria já determinada, considerando que a espectrometria pode ser considerada um método primário de determinação da tensão aplicada a um sistema de radiação $X^{(18)}$. Este é um procedimento válido ${ }^{(63)}$, considerando-se que o espectrômetro pode ser calibrado utilizando-se os picos de emissão de uma fonte de ${ }^{241} \mathrm{Am}$ calibrada, não havendo a necessidade de encaminhá-lo periodicamente para um Laboratório de Calibração.

Em relação aos valores nominais, indicados pela máquina, foi encontrado um desvio mínimo de 10,7\% e máximo de 18,2\%, como pode ser observado na TAB. 12. Considerando que os valores obtidos na espectrometria são os valores nominais de referência, pela razão já exposta anteriormente, a variação máxima encontrada será de $8,1 \%$, no caso da medida do PPV com o Diavolt (TAB. 13) Para esta análise foram desconsiderados os valores obtidos para a corrente mínima, pois este equipamento apresentou uma grande instabilidade nesta posição, comprometendo a sua utilização para correntes mínimas. De qualquer modo, embora não seja possível fazer o teste de exatidão, dentro de um intervalo de medidas, os valores de corrente apresentados pelo Dynalyzer demonstraram uma reprodutibilidade máxima de $0,77 \%$. 
TABELA 12: Diferença percentual entre os valores de tensão aplicados ao tubo obtidos com diferentes medidores, para a corrente máxima aplicada em função do valor indicado no painel da máquina.

\begin{tabular}{|c|c|c|c|c|c|}
\hline $\begin{array}{l}\text { Tensão } \\
\text { nominal }\end{array}$ & Espectrometria & Dynalyzer & & Diavolt $\left({ }^{\circ}\right.$ & \\
\hline $\mathrm{kV}$ & (\%) & (\%) & PPV & kVp máx & $k V p$ med \\
\hline 100 & $\overline{11,3}$ & 12,9 & $\overline{18,5}$ & 10,7 & 12,2 \\
\hline 90 & 11,3 & 13,3 & 18,0 & 10,8 & 12,1 \\
\hline 80 & 13,5 & 14,1 & 17,9 & 11,9 & 13,0 \\
\hline 71 & 13,1 & 14,1 & 14,1 & 12,7 & 12,7 \\
\hline 60 & 15,2 & 15,8 & 18,2 & 13 & 14,3 \\
\hline 50 & 14,8 & 12,0 & sr & sr & sr \\
\hline
\end{tabular}

TABELA 13: Diferença percentual entre os valores de tensão aplicados ao tubo obtidos com diferentes medidores para a corrente máxima aplicada, em função do valor real determinado por espectrometria.

\begin{tabular}{cccccc}
\hline $\begin{array}{c}\text { Tensão } \\
\text { nominal } \\
\text { kV }\end{array}$ & $\begin{array}{c}\text { Tensão Real } \\
(\text { Espectrometria) } \\
(\mathrm{KV})\end{array}$ & $\begin{array}{c}\text { Dynalyzer } \\
(\%)\end{array}$ & PPV & kVp máx & kVp med \\
\hline 100 & 88,7 & 1,8 & 8,1 & $-0,68$ & 1,0 \\
90 & 79,8 & 2,3 & 7,5 & $-0,63$ & 0,88 \\
80 & 69,2 & 0,72 & 5,1 & $-1,88$ & $-0,58$ \\
71 & 61,7 & 1,1 & 1,1 & $-0,49$ & $-0,49$ \\
60 & 50,9 & 0,79 & 3,54 & $-2,55$ & $-0,98$ \\
50 & 42,6 & $-3,3$ & $s r$ & $s r$ & $s r$ \\
\hline
\end{tabular}




\subsection{Implantação das qualidades RQR de acordo com a revisão de}

norma IEC 61267

De acordo com a norma IEC $61267^{(17)}$ para se obter as qualidades recomendadas para fluoroscopia, inicialmente deve-se implantar as qualidades $R Q R$, que simulam os feixes que emergem do sistema de radiação $X$, e interagem com o paciente. As qualidades recomendadas vão de 40 até 150 kV. Neste trabalho foram implantadas as qualidades de feixe RQR 3, RQR 5 e RQR 7 que correspondem a 50, 70 e 90 kV, devido a uma limitação da máquina.

\subsubsection{Determinação da filtração adicional}

A determinação da filtração adicional para o estabelecimento de cada uma das qualidades foi realizada seguindo a metodologia sugerida pela norma IEC 61267 e já descrita no item 4.2.6. Para cada uma das qualidades RQR foi construída uma curva de atenuação demonstrada na FIG. 29. Pelo posicionamento do retângulo, foi encontrada a filtração adicional de 2,2 mmAl para a qualidade RQR 3, 2,0 mmAl para a RQR 5 e 2,5 mmAl para RQR7. 


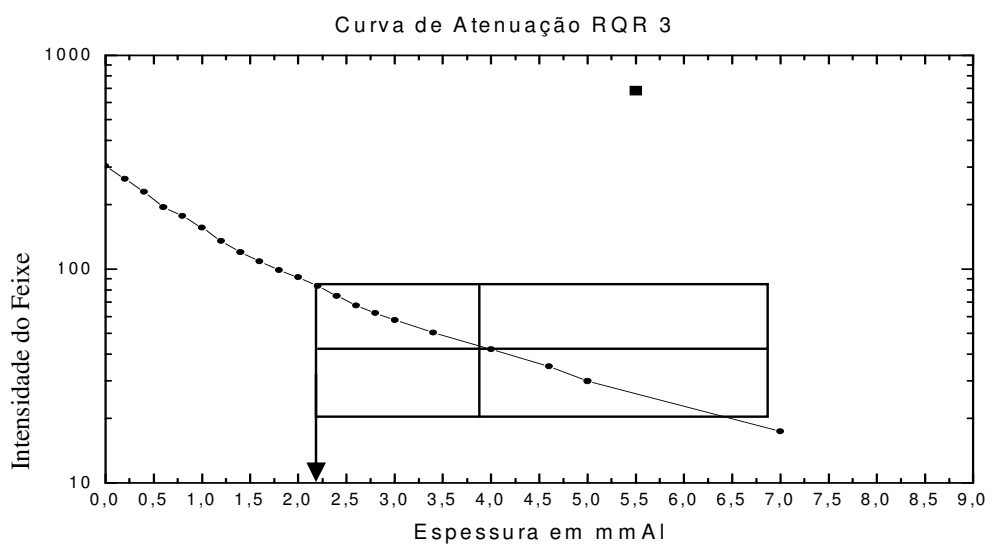

Curva de Atenuação RQR 5

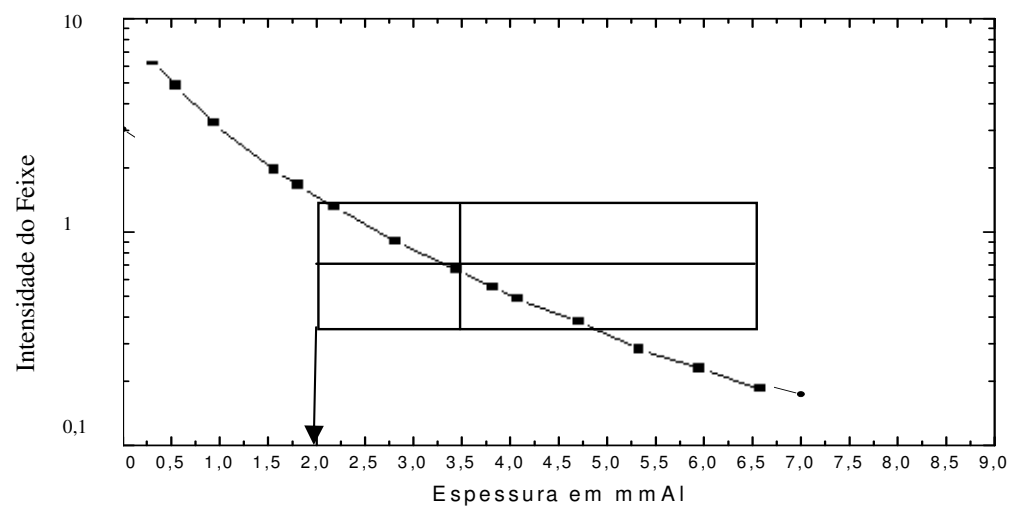

Curva de Atenuação RQR 7

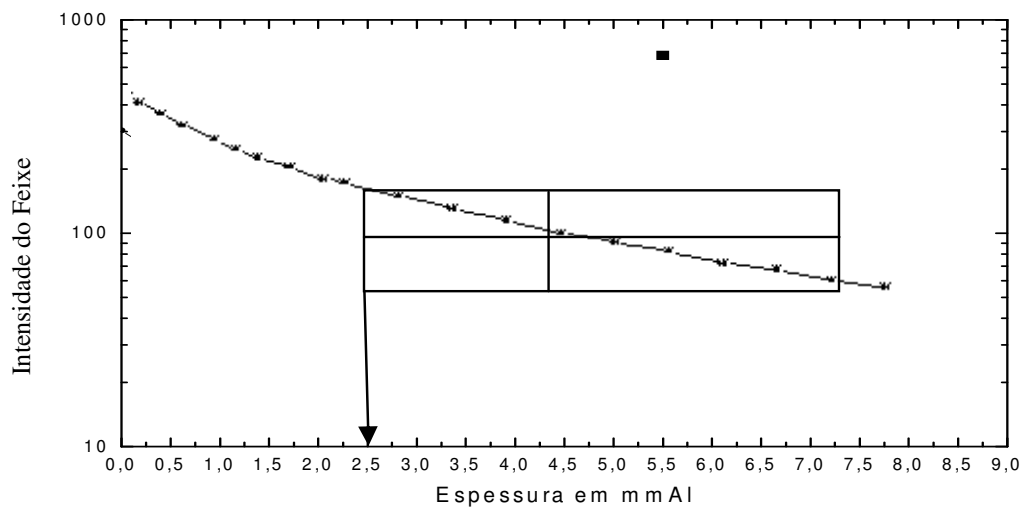

FIGURA 29: Curvas de atenuação para a determinação da filtração adicional para as qualidades RQR $3(50 \mathrm{kV})$, RQR $5(70 \mathrm{kV})$ e RQR $7(90 \mathrm{kV})$ (retângulo meramente ilustrativo). 
De acordo com a portaria 453 da $\mathrm{ANVISA}^{(5),}$ um sistema de radiodiagnóstico clínico precisa ter no mínimo uma filtração total de 2,5mmAl. Como a filtração inerente do tubo de raios $\mathrm{X}$ Medicor é igual a $0,8 \mathrm{mmAl}$, somado aos valores encontrado para a filtração adicional, todas estariam de acordo com a ANVISA.

\subsubsection{Determinação das Camadas Semi-redutoras, CSR}

A filtração adicional determinada foi, então, inserida na saída do feixe de radiação e foi realizada outra curva de atenuação para a determinação da Camada Semi Redutora, CSR. Os valores foram plotados e um ajuste polinomial de quarta ordem forneceu o valor correto da CSR, como demonstra a FIG. 30.

As qualidades (RQR) estarão implantadas corretamente, quando a razão entre os valores obtidos da intensidade do feixe sem atenuador, $\mathrm{K}_{0}$, e a intensidade do feixe após se acrescentar a camada de material com atenuador, $\mathrm{K}$, estiver entre 0,485 a 0,515. Para a qualidade RQR 3 a norma recomenda uma CSR de 1,78 mmAl, o que neste trabalho representa uma razão de 0,512, indicando que a qualidade já estaria implantada. Mas, com o ajuste polinomial, a CSR encontrada para que esta razão ficasse em 0,50 foi de $1,85 \mathrm{mmAl}$.

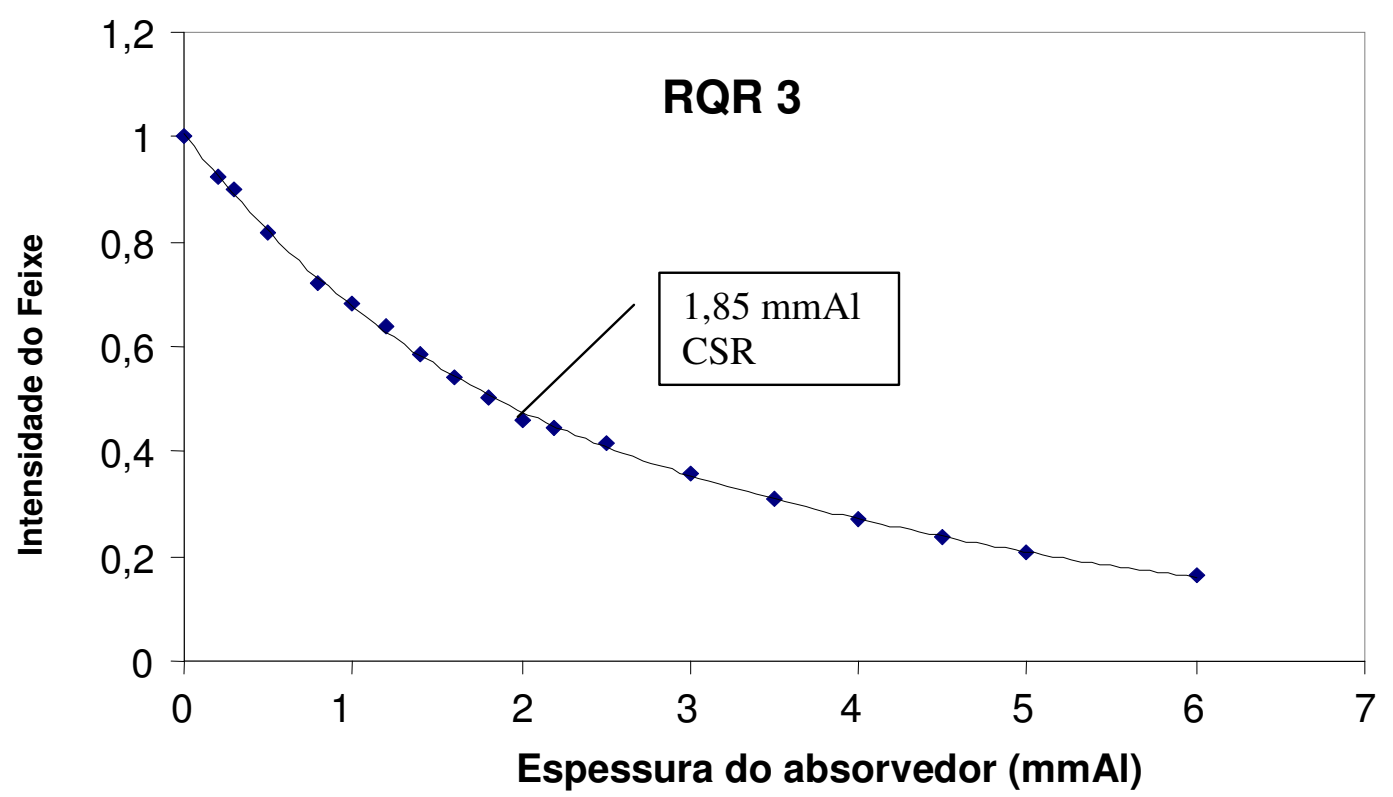

FIGURA 30: Curva de atenuação para a determinação da CSR relativa à qualidade RQR 3, com a filtração adicional de 2,2 mmAl. 
Para a qualidade RQR 5, procurou-se chegar a razão de 0,500 como no caso anterior e a CSR encontrada foi de 2,44 mmAl, como pode ser visto na FIG. 31 .

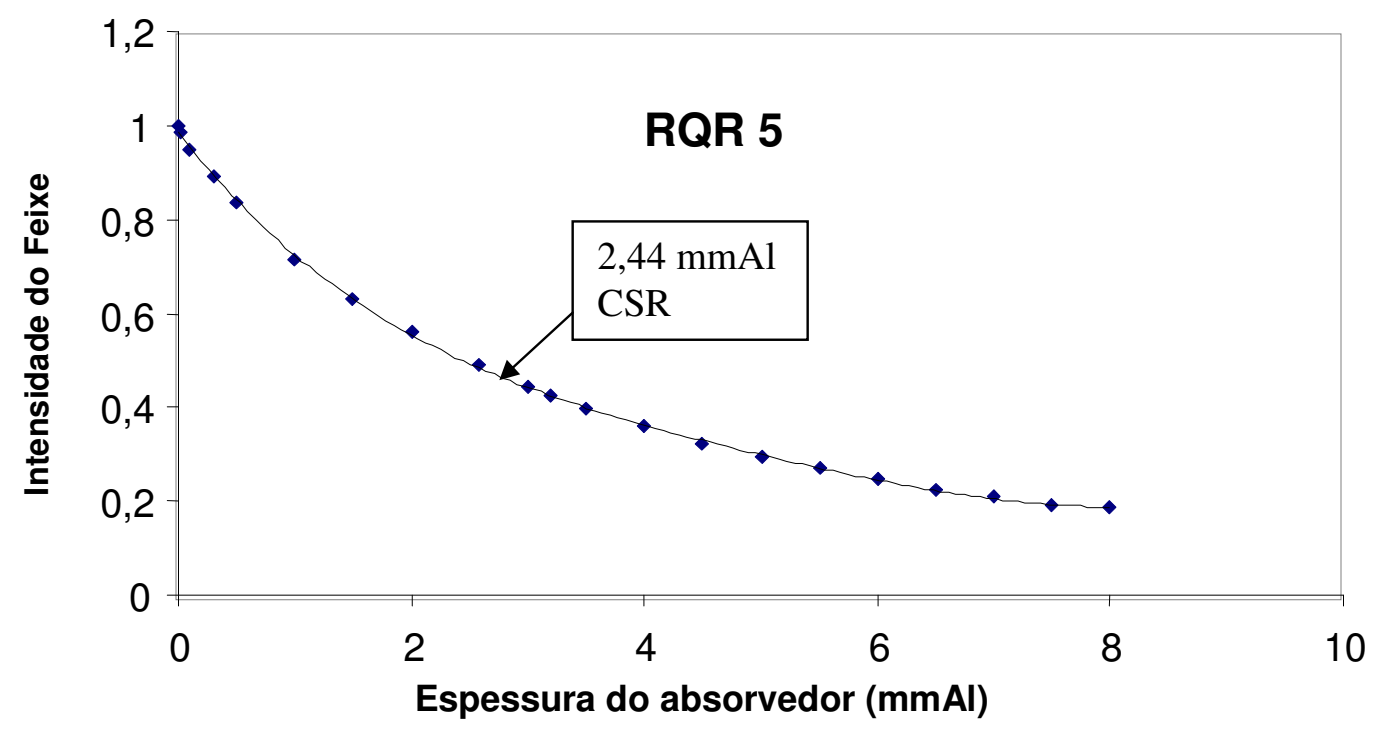

FIGURA 31: Curva de atenuação para a determinação da CSR relativa à qualidade RQR 5, com a filtração adicional de 2,0 mmAl.

A FIG. 32 demonstra a CSR encontrada para a qualidade de radiação $R Q R 7$, seguindo o mesmo procedimento para as qualidades anteriores. O valor encontrado foi 3,9 mmAl.

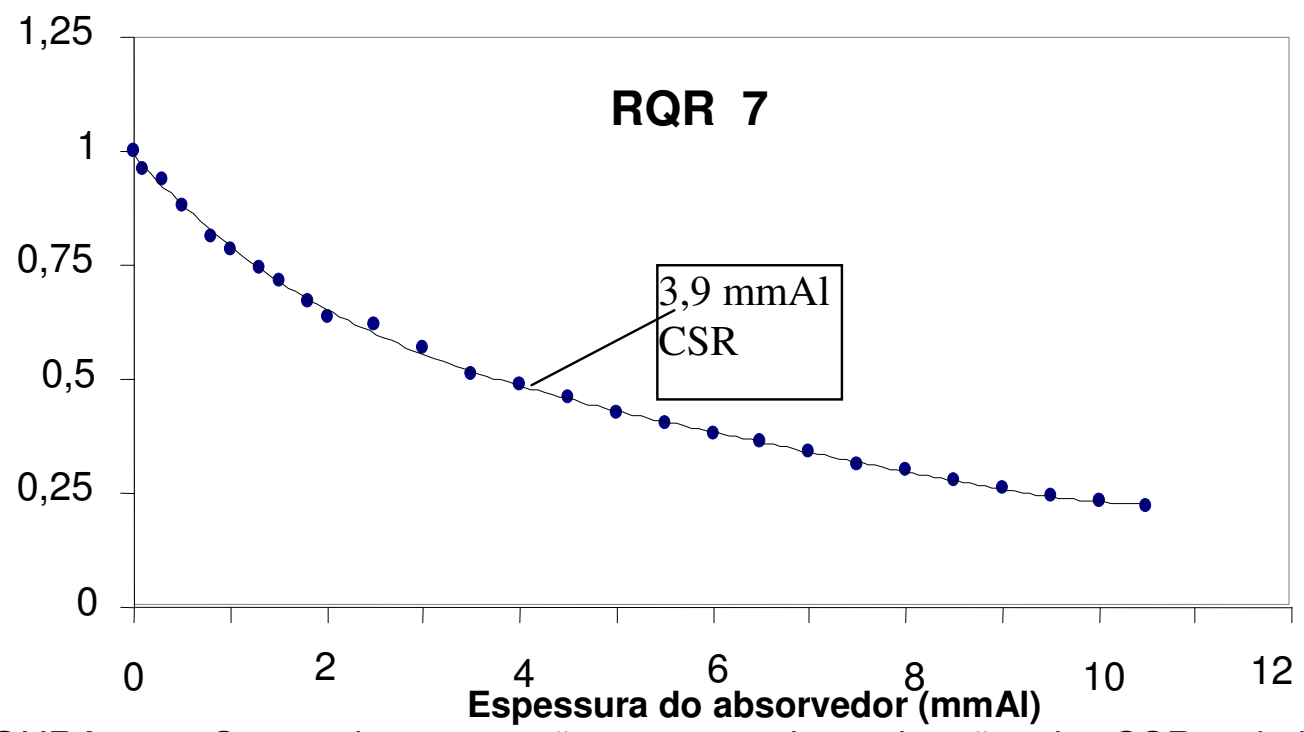

FIGURA 32: Curva de atenuação para a determinação da CSR relativa à qualidade RQR 7 com a 
Os valores encontrados estiveram de acordo com a norma em 6\% no seu pior caso (RQR 7). Baseando-se nos valores de CSR, foram encontrados, então, os valores de energia efetiva para cada qualidade correspondente ${ }^{(38)}$.

\subsubsection{Determinação das taxas de kerma no ar}

Para a determinação das taxas de kerma no ar, foi necessário se determinar os fatores de calibração da câmara de ionização de referência nas energias das qualidades novas, utilizando-se sua curva de dependência energética fornecida pelo laboratório padrão primário PTB. Todas as características dos feixes estabelecidos estão apresentadas na TAB. 14.

TABELA 14: Características dos feixes de radiação RQR implantados

\begin{tabular}{ccccccc}
\hline $\begin{array}{c}\text { Qualidade } \\
\text { da } \\
\text { radiação }\end{array}$ & $\begin{array}{c}\text { Tensão } \\
\text { aplicada } \\
(\mathrm{kV})\end{array}$ & $\begin{array}{c}\text { Filtração } \\
\text { adicional } \\
\text { mmAl) }\end{array}$ & $\begin{array}{c}\text { CSR } \\
(\mathrm{mmAl})\end{array}$ & $\begin{array}{c}\text { Coeficiente de } \\
\text { homogeneidade } \\
(\mathrm{h})\end{array}$ & $\begin{array}{c}\text { Energia } \\
\text { efetiva } \\
(\mathrm{keV})\end{array}$ & $\begin{array}{c}\text { Taxa de kerma } \\
\text { no ar } \\
(\mathrm{mGy} / \mathrm{min})\end{array}$ \\
\hline RQR 3 & 50 & 2,2 & 1,85 & 0,75 & 28,0 & 1,68 \\
RQR 5 & 70 & 2,0 & 2,5 & 0,70 & 30,0 & 4,51 \\
RQR 7 & 90 & 2,5 & 3,9 & 0,68 & 37,0 & 7,50 \\
\hline
\end{tabular}

\subsection{Controle de qualidade e calibração das câmaras de ionização de} fluoroscopia

Foram realizados os testes de estabilidade e fuga de corrente para as câmaras Radcal, modelo 10×5-60 que são indicadas para medidas em fluoroscopia, como descrito nos itens 4.2.2 e 4.2.3. Nos testes iniciais as câmaras apresentaram um bom desempenho. Na TAB. 15 estão apresentados os resultados encontrados com seus respectivos desvios padrões da média (incerteza do tipo A) . Neste caso, a fonte de controle utilizada foi de ${ }^{90} \mathrm{Sr}+{ }^{90} \mathrm{Y}$ com uma atividade de $0,3 \mathrm{mCi}$. Cada valor obtido representa a média de 10 medidas 
de 60s cada.

O teste de fuga foi realizado com a mesma fonte posicionada sobre a câmara de ionização plana, após o intervalo de $60 \mathrm{~s}$, ela foi retirada e os valores para 0, 600 e 1200s foram anotados. Todas as medidas foram corrigidas pelo fator de temperatura e pressão.

TABELA 15: Resultados dos testes de estabilidade e fuga de corrente das câmaras de ionização para fluoroscopia Radcal.

\begin{tabular}{c|c|c|c}
\hline \multicolumn{2}{c|}{ Câmara série 9785} & \multicolumn{2}{c}{ Câmara série 24931 } \\
\hline $\begin{array}{c}\text { Leitura } \\
(\mathrm{nC})^{*}\end{array}$ & Fuga & $\begin{array}{c}\text { Leitura } \\
(\mathrm{nC})^{*}\end{array}$ & Fuga \\
\hline $4,1 \pm 0,00022$ & 0,0030 & $5,7 \pm 0,00028$ & 0,00010 \\
\hline $4,2 \pm 0,00027$ & 0,0029 & $5,6 \pm 0,00029$ & 0,00135 \\
\hline $4,2 \pm 0,00073$ & 0,0006 & $5,6 \pm 0,0043$ & 0,06195 \\
\hline $4,2 \pm 0,00022$ & 0,0016 & $5,57 \pm 0,0196$ & 0 \\
\hline $4,2 \pm 0,00028$ & 0,0028 & $5,6 \pm 0,00023$ & 0 \\
\hline $4,2 \pm 0,00028$ & 0,0023 & $5,6 \pm 0,00034$ & $-0,00040$ \\
\hline $4,2 \pm 0,00041$ & 0,0020 & $5,6 \pm 0,0096$ & 0,00050 \\
\hline $4,2 \pm 0,00014$ & 0,0022 & $5,6 \pm 0,00024$ & 0,00050 \\
\hline
\end{tabular}

*unidade de escala do eletrômetro

A câmara de ionização a ser utilizada como referência neste trabalho para fluoroscopia é a de série 9785. Portanto, foi realizada a calibração dela nas qualidades $R Q R$, para ser utilizada na implantação das qualidades específicas de fluoroscopia $R Q C^{(17)}$. Foi utilizado o método de substituição e os coeficientes de calibração encontrados estão na TAB. 16. 
TABELA 16: Coeficientes de calibração e fatores de qualidade para a câmara de ionização Radcal, modelo 10×5-60, série 9785

\begin{tabular}{ccc}
\hline $\begin{array}{c}\text { Qualidade } \\
\text { de } \\
\text { radiação }\end{array}$ & $\begin{array}{c}\text { Coeficiente } \\
\text { de } \\
\text { Calibração } \\
N_{K}(\text { Gy/C) }\end{array}$ & $\begin{array}{c}\text { Fator } \\
\text { de } \\
\text { Qualidade } \\
(\mathrm{Kq})\end{array}$ \\
\hline RQR 3 & $5,34 \times 10^{5}$ & 0,939 \\
RQR 5 & $5,34 \times 10^{5}$ & 1,00 \\
RQR 7 & $5,34 \times 10^{5}$ & 1,109 \\
\hline
\end{tabular}

\subsection{Implantação das qualidades RQC de acordo a norma IEC $61267^{(17)}$}

De acordo com a norma IEC 61267, foram estabelecidas as qualidades específicas para fluoroscopia (RQC 3, RQC 5 e $\left.R Q C 8^{\ddagger}\right)$ seguindo a mesma metodologia utilizada para as qualidades RQR, com exceção da determinação da filtração adicional, que será a mesma neste caso. Para as determinações das qualidades RQC foram utilizados filtros de cobre, pois este material endurece o feixe de radiação $X$ eliminando os fótons de baixa energia. $O$ procedimento de implantação destas qualidades seguiu as seguintes etapas:

a. Colocar a filtração adicional determinada para as qualidades $R Q R$ na saída do feixe;

b. Acrescentar a filtração de cobre necessária para cada uma das qualidades RQC como determina a IEC 61267 e que estão apresentadas na TAB. 17;

c. Determinação da curva de atenuação para cada qualidade para se encontrar as respectivas CSR e suas energias efetivas. Os gráficos das curvas de atenuação para as qualidades RQC 3, 5 e 7/8, estão na FIG. 33.

\footnotetext{
$\ddagger$ O sistema de radiação-X Neo Diagnomax, no modo fluoroscopia, tem uma tensão de operação nominal entre 40 e $100 \mathrm{kV}$, mas operacionalmente há uma variação de aproximadamente - $10 \mathrm{kV}$, portanto, $100 \mathrm{kV}$ representa em torno de 93kV. Esta qualidade será denominada RQC 7/8.
} 

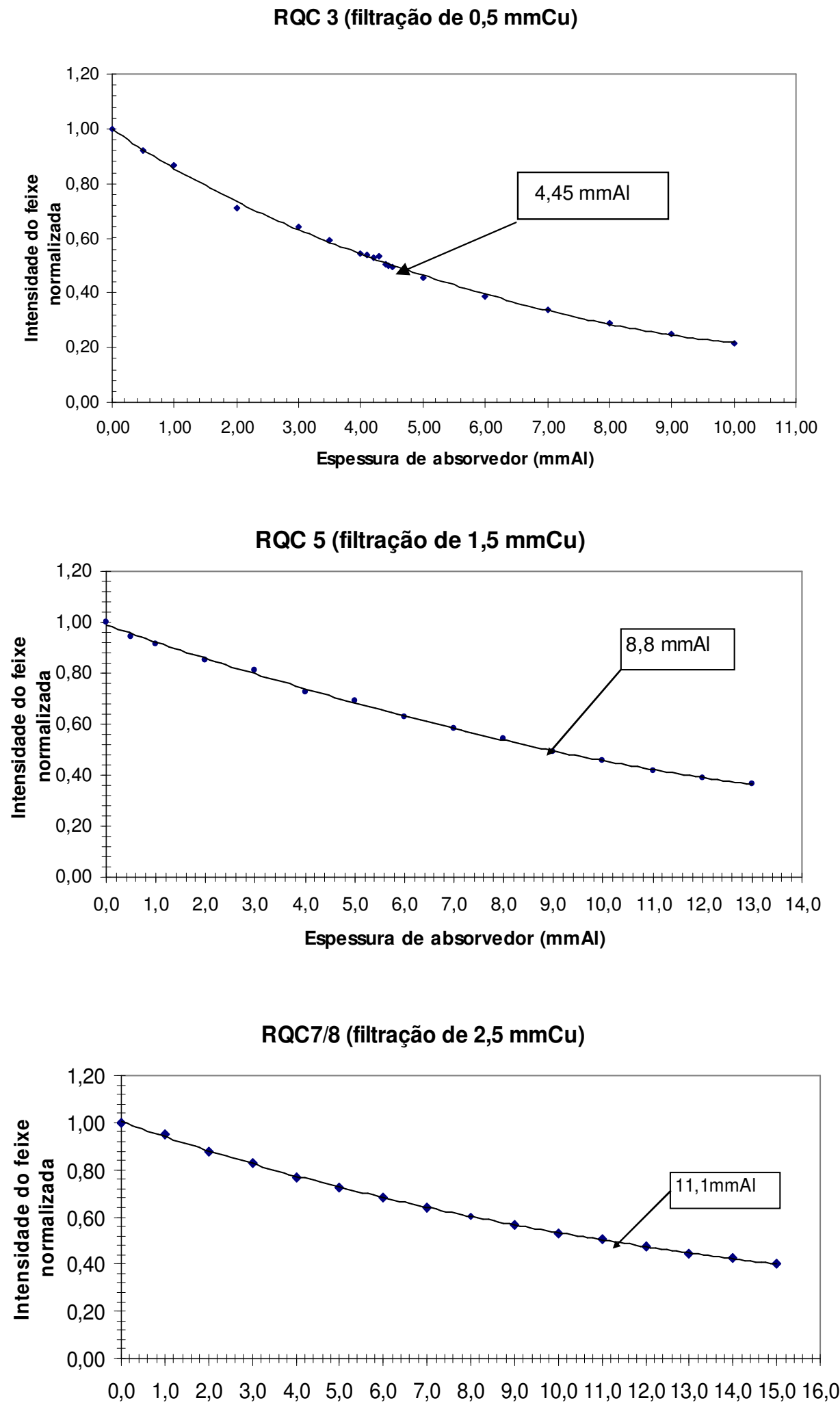

Espessura de absorvedor (mmAl)

FIGURA 33: Curvas de atenuação para as qualidades RQC 3, 5 e 7/8. 
Os valores de CSR encontrados estiveram muito próximos aos da norma IEC61267, com uma variação de 0, 4,5 e -3,6\% para RQC3, RQC5 e RQC 7/8, respectivamente. Lembrando que no caso da RQC 7/8 a tensão aplicada foi de aproximadamente $90 \mathrm{kV}$ e não $100 \mathrm{kV}$ como recomenda a norma, por uma limitação da máquina.

Conhecendo-se a CSR de cada feixe de radiação $X$, foi possível determinar-se $o$ valor de energia efetiva por meio de tabelas e fórmulas que relacionam os dois valores, considerando-se os coeficientes de atenuação $(\mu)$ do material utilizado para a determinação da camada semi-redutora ${ }^{(38)}$. Os valores encontrados estão na TAB. 16.

d. Determinação das taxas de kerma no ar para cada qualidade RQC, utilizando a câmara de referência para fluoroscopia e seus coeficientes de calibração determinados anteriormente (Nk e Kq).

Todas as características dos feixes estabelecidos estão apresentadas na TAB. 17.

TABELA 17: Características dos feixes de radiação RQC implantadas.

\begin{tabular}{|c|c|c|c|c|c|c|}
\hline \multirow{2}{*}{$\begin{array}{l}\text { Qualidade } \\
\qquad \text { da } \\
\text { radiação }\end{array}$} & \multirow{2}{*}{$\begin{array}{c}\text { Tensão } \\
\text { aplicada } \\
(\mathrm{kV})\end{array}$} & \multicolumn{2}{|c|}{ Filtração adicional } & \multirow{2}{*}{$\begin{array}{c}\text { CSR } \\
(\mathrm{mmAl})\end{array}$} & \multirow{2}{*}{$\begin{array}{c}\text { Energia } \\
\text { efetiva } \\
(\mathrm{keV})\end{array}$} & \multirow{2}{*}{$\begin{array}{c}\text { Taxa de } \\
\text { kerma no ar } \\
\text { (mGy/min) }\end{array}$} \\
\hline & & $(\mathrm{mmAl})$ & $(\mathrm{mmCu})$ & & & \\
\hline RQC 3 & 50 & 2,2 & 0,5 & 4,5 & 39,7 & 0,131 \\
\hline RQC 5 & 70 & 2,0 & 1,5 & 8,8 & 58,8 & 0,180 \\
\hline RQC 8 & 90 & 2,5 & 2,0 & 11,1 & 70,4 & 0,844 \\
\hline
\end{tabular}

\subsection{Determinação da homogeneidade do campo de radiação}

Após a colocação do novo sistema de colimadores no sistema NEODiagnomax, como descrito no item 5.1; o tamanho do campo de irradiação foi calculado, considerando que as câmaras de ionização de referência e em calibração devem estar totalmente dentro do campo durante a sua irradiação. $O$ último colimador apresenta um diâmetro de $4,8 \mathrm{~cm}$ e está posicionado a uma distância de $21 \mathrm{~cm}$ do ponto focal. $O$ tamanho do campo foi encontrado utilizando 0 
seguinte cálculo:

$$
X=A \times B / C
$$

Onde $\mathrm{X}$ é o tamanho do campo a ser determinado, A é a distância do foco até o objeto, o B é o diâmetro da colimação em centímetros e $C$ é a distância entre o ponto focal e o colimador. Portanto, o tamanho do campo a uma distância de $50 \mathrm{~cm}$ é igual a $11,42 \mathrm{~cm}$.

Após esta determinação, foram realizadas medidas com uma câmara de ionização marca PTW, modelo 31002/0, indicada para medidas em radioterapia, com volume de $0,125 \mathrm{~cm}^{3}$, com um eletrômetro na escala de $\mathrm{pC}$ (picoCoulomb), para determinação da homogeneidade do campo e confirmação do seu tamanho. Esta câmara foi utilizada devido ao seu pequeno tamanho, possibilitando uma varredura de toda a área selecionada, conforme esquema da FIG. 34, que também mostra a câmara de ionização posicionada no seu suporte.
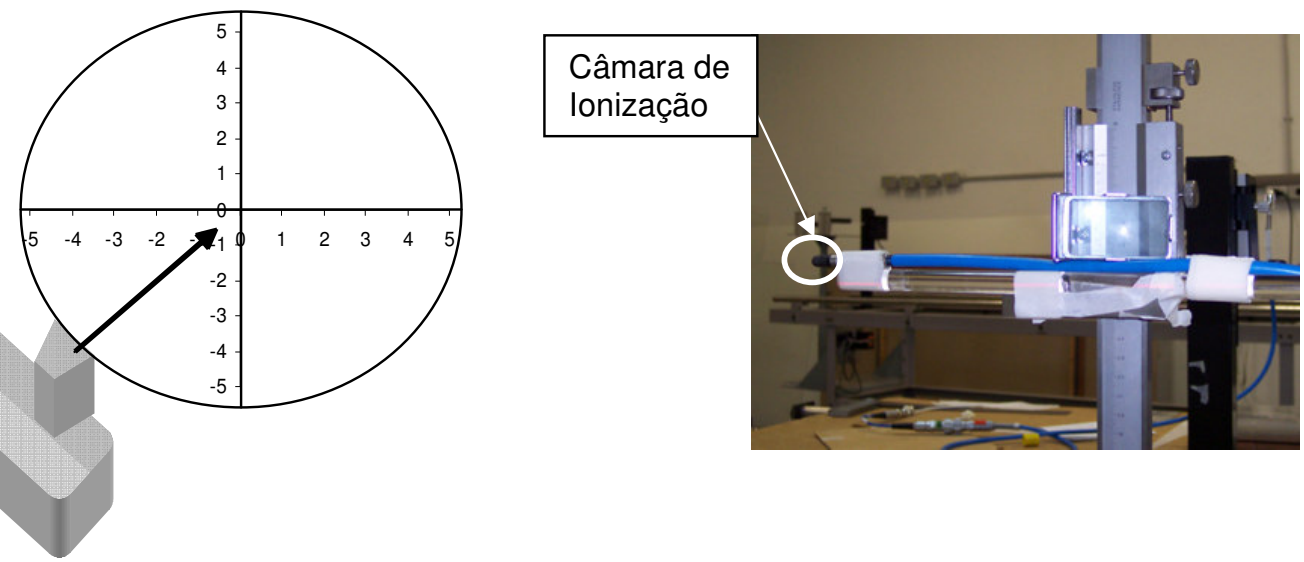

FIGURA 34: Esquema do campo de irradiação para estudo da homogeneidade Câmara de ionização marca PTW, modelo 31002/0, utilizada no estudo da homogeneidade do campo.

A câmara de ionização foi posicionada na frente do feixe, a uma distância de $50 \mathrm{~cm}$ do foco. O ponto de referência inicial (ponto zero) foi demarcado com um sistema laser (do tipo linha), o lado esquerdo do tubo foi apontado como negativo (-) e o lado direito como positivo (+). 
As medidas foram realizadas para as qualidades de radiação $R Q R$ 3, 5 e 7, ou seja, 50, 70 e $90 \mathrm{kV}$ respectivamente. Inicialmente foram feitas as medidas no sentido horizontal. Na seqüência foi realizada uma avaliação da homogeneidade vertical dos campos de radiação, para as mesmas qualidades. Na FIG. 35 estão os valores comparativos das duas situações.

Comparativo da homogeneidade

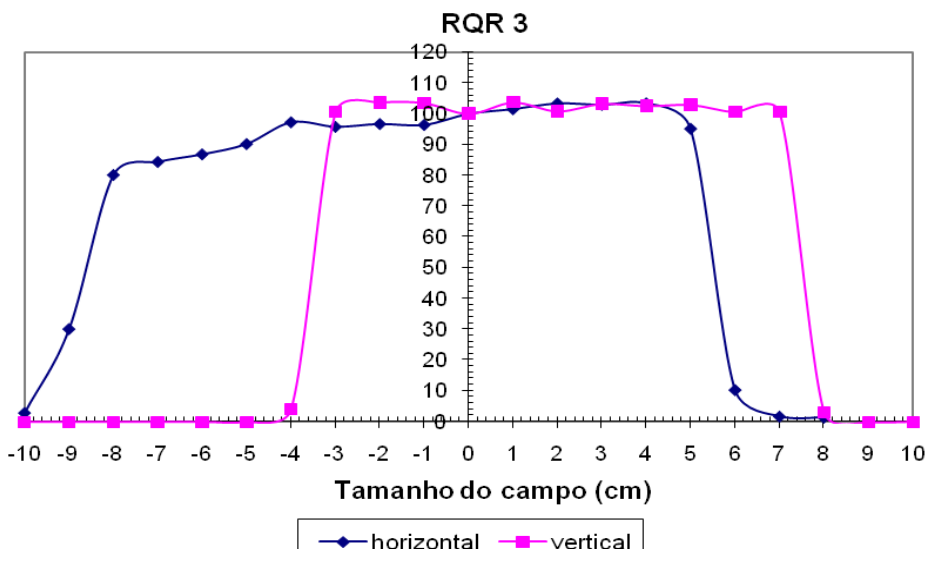

RQR 5

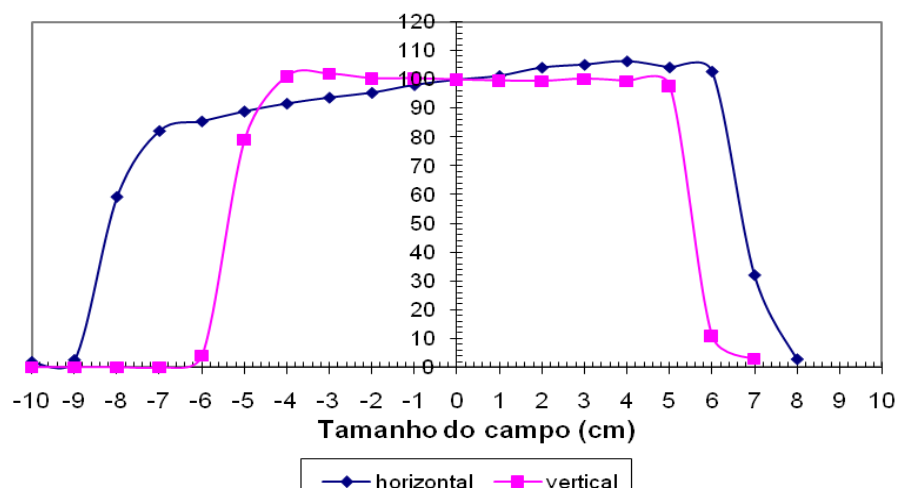

RQR 7

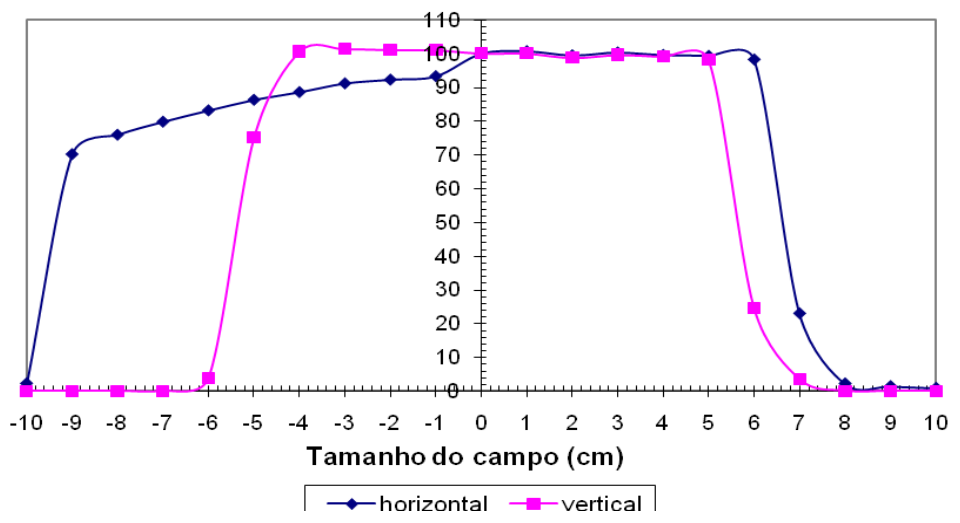

FIGURA 35: Analise comparativa da homogeneidade dos campos no sentido horizontal e vertical 
No sentido horizontal a homogeneidade se manteve acima de $90 \%$ para 50 e $70 \mathrm{kV}$ e, para $90 \mathrm{kV}$, este valor caiu para $86 \%$ em $10 \mathrm{~cm}$ No sentido vertical percebe-se que embora a homogeneidade seja maior que $99 \%$ em todos os casos, o campo está levemente deslocado para cima, o que não prejudica as irradiações, considerando que as câmaras de ionização são menores do que o tamanho do campo e são posicionadas sempre no centro do feixe. De qualquer modo, deve-se levar este fato em consideração ao se irradiar outras amostras ou os simuladores que podem ter uma dimensão maior. Um fator importante que se deve levar em conta é o Efeito Anódico. Este fenômeno acontece devido a angulação do anodo. A variação desta angulação depende do fabricante do aparelho, evidenciando o fluxo do feixe primário com maior intensidade do eletrodo negativo do equipamento (catodo) e com um fluxo de menor intensidade (abrindo um leque) na parte positiva do aparelho (anodo).

Este estudo mostrou que todos os campos utilizados no trabalho variaram entre 86 a 100\%, no tamanho de interesse, ou seja aprox. $10 \mathrm{~cm}$. O desvio máximo obtido entre o valor de referência (100\%) e o menor dentro de $10 \mathrm{~cm}$, foi de $14 \%$ no caso de $90 \mathrm{KV}$.

\subsection{Desenvolvimento e utilização dos simuladores para estimativa do}

\section{kerma de entrada e saída}

De acordo com o TRS 457 da IAEA e a IEC 61267, para a estimativa do kerma de entrada e de saída de pacientes, devem ser confeccionados simuladores específicos para cada aplicação de radiodiagnóstico. No caso da fluoroscopia, que é o foco deste trabalho, a recomendação é que se utilizem dois simuladores de acrílico preenchidos com água, sendo um com as dimensões de $300 \times 300 \times 200 \mathrm{~mm}$ (representando um paciente com um biotipo padrão) e um segundo de $300 \times 300 \times 100 \mathrm{~mm}$, que em conjunto com o primeiro representa um paciente com um biotipo maior. A FIG. 36 mostra um desenho com as dimensões dos simuladores desenvolvidos neste trabalho e uma foto dos dois posicionados no feixe de radiação. 

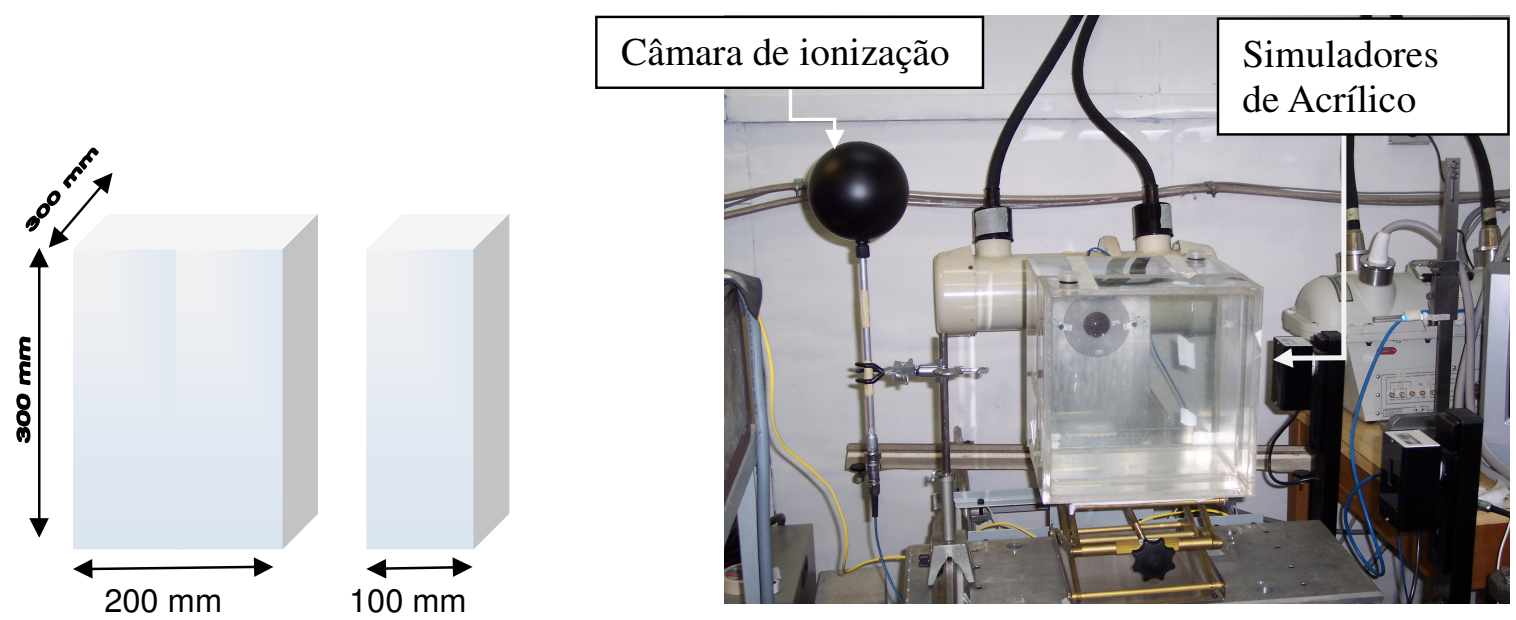

FIGURA 36: Simuladores de acrílico desenvolvidos nesse trabalho e posicionados no feixe de radiação.

\section{um simulador}

\subsubsection{Determinação do kerma na superfície de entrada usando}

O kerma na superfície de entrada, $\mathrm{K}_{\mathrm{e}}$, é definido como sendo o kerma no ar no eixo do feixe de raios $X$ no ponto onde ele entra no paciente ou no simulador. $A$ contribuição da radiação retroespalhada é incluída ${ }^{(47)}$. A sua determinação é um dos fatores mais importantes na fluoroscopia, sendo que o retroespalhamento que ocorre neste instante é danoso tanto ao paciente quanto ao corpo clinico, portanto é importante se levar em conta a distância foco-objeto, colimação, intensidade do feixe, distância do intensificador de imagem entre outros. Na FIG. 37 pode-se observar a influência da distância foco-objeto na dose (kerma) recebida.

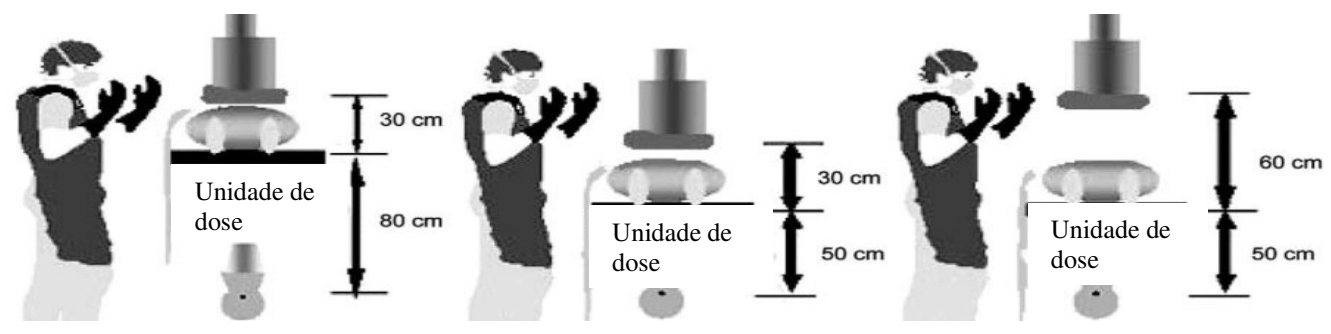

FIGURA 37: Influência da distância foco-objeto na dose recebida pelo paciente e corpo clínico ${ }^{(6)}$.

Para as medidas de kerma na superfície de entrada na radiologia de uma maneira geral, incluindo a fluoroscopia, são utilizados simuladores de tórax ou 
abdome no centro do feixe primário, a mesma distância utilizada rotineiramente.

Neste trabalho, a câmara de ionização $10 \times 5-60$ foi posicionada a $50 \mathrm{~cm}$ do ponto focal e na superfície de entrada do simulador preenchido com água, como demonstra a FIG. 38. Foram feitas as medidas do kerma na superfície de entrada, para todas as qualidades de radiação $R Q R$ implantadas. Foram realizadas três medidas de carga para cada qualidade e todas elas foram corrigidas para as condições ambientais. Inicialmente foi utilizado o simulador de $300 \mathrm{~mm} \times 200 \mathrm{~mm}$ (equivalente ao paciente padrão) e na seqüência foi adicionado o complemento de $300 \mathrm{~mm} \times 100 \mathrm{~mm}$, para a simulação de um paciente maior ${ }^{(4,17)}$. A FIG. 38 ilustra o arranjo de irradiação utilizado com a câmara de ionização posicionada na frente do simulador, no centro do campo de radiação.
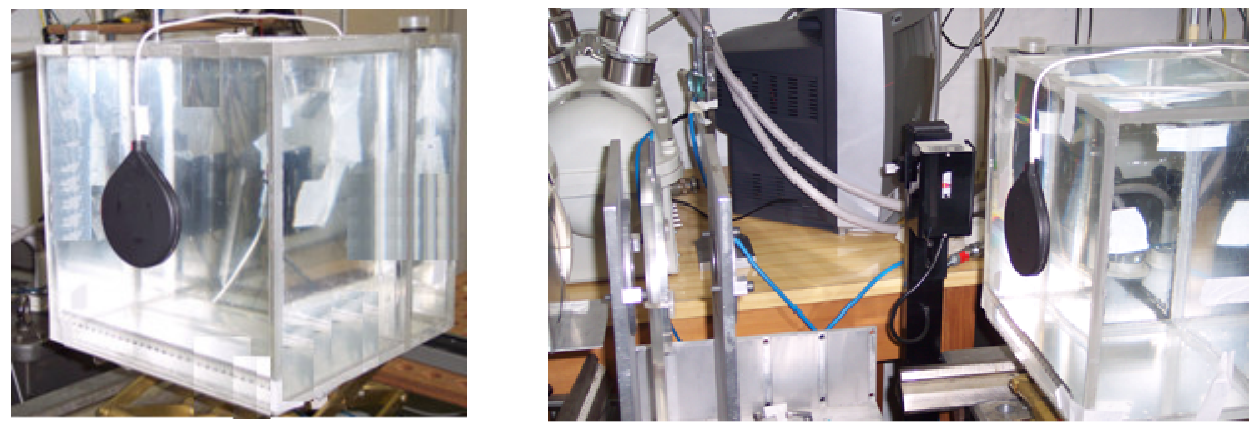

FIGURA 38: Câmara de ionização de referência para fluoroscopia Radcal, posicionada na frente dos simuladores que representam um paciente maior.

Num sistema de fluoroscopia, a colimação do feixe é muito importante, principalmente com relação ao retroespalhamento, portanto, neste trabalho, todas as medidas com o simulador foram realizadas tanto com o último colimador quanto sem a presença dele, que normalmente é posicionado após a câmara monitora, e possui diâmetro de $4,8 \mathrm{~cm}$.

$\mathrm{O} \mathrm{K}_{\mathrm{e}}$ também pode ser determinado a partir das medidas do kerma no ar incidente, $\mathrm{K}_{\mathrm{i}}$, que é o kerma no ar no eixo central do feixe incidente à distância foco-superfície da pele, isto é, no plano de entrada da pele e inclui apenas o feixe primário incidente no paciente ou simulador e nenhuma radiação 
retroespalhada ${ }^{(47)}$. A relação entre as duas grandezas está descrita no TRS 457 da $\operatorname{AIEA}^{(4)}$ e é dada pela equação:

$$
\mathrm{K}_{\mathrm{e}}=\mathrm{K}_{\mathrm{i} \cdot \mathrm{B}}
$$

Onde B é o fator de retroespalhamento, que pode ser encontrado em diversas fontes na literatura. Neste caso utilizaremos os fatores recomendados pelo TRS 457. A sua aplicação depende da CSR, filtração e tipo e tamanho do simulador ${ }^{(4)}$.

Os valores de $\mathrm{K}_{\mathrm{i}}(\mathrm{Gy} / \mathrm{min})$ foram determinados de acordo com o item 5.4.3 usando com referência a câmara monitora. Na TAB. 18 estão os valores encontrados com e sem a colimação do feixe.

TABELA 18: Valores do kerma no ar incidente, $\mathrm{K}_{\mathrm{i}}$, medidos com a câmara monitora

\begin{tabular}{cc}
\hline Qualidade de radiação & $\begin{array}{c}\mathrm{K}_{\mathrm{i}} \\
\text { colimado } \\
\text { (Gy/min) }\end{array}$ \\
\hline RQR 3 & $3,24 \times 10^{-3}$ \\
RQR 5 & $8,37 \times 10^{-3}$ \\
RQR 7 & $1,23 \times 10^{-2}$ \\
\hline
\end{tabular}

$\mathrm{Na}$ seqüência foram medidos os valores de $\mathrm{K}_{e}$ utilizando o simulador desenvolvido para este trabalho. Os valores obtidos foram comparados com aqueles calculados pela utilização dos fatores de retroespalhamento, $B$, fornecidos pela TRS 457. Os valores encontrados estão na TAB. 19. 
TABELA 19: Valores de kerma na superfície de entrada, $K_{e}$, medidos e obtidos pela aplicação da equação $\mathrm{K}_{\mathrm{e}}=\mathrm{K}_{\mathrm{i}} \mathrm{B}$, em $\mathrm{Gy} / \mathrm{min}$.

\begin{tabular}{c|c|c|c}
\hline $\begin{array}{c}\text { Qualidade } \\
\text { de } \\
\text { Radiação }\end{array}$ & $\begin{array}{c}\mathrm{K}_{\mathrm{e} \text { medido }} \\
\text { não colimado }\end{array}$ & $\begin{array}{c}\mathrm{K}_{\mathrm{e} \text { medido }} \\
\text { colimado }\end{array}$ & $\mathrm{K}_{\mathrm{e}}=\mathrm{Ki} \times \mathrm{B}$ \\
\hline RQR 3 & $4,25 \times 10^{-3}$ & $4,09 \times 10^{-3}$ & $4,08 \times 10^{-3}$ \\
RQR 5 & $1,19 \times 10^{-2}$ & $1,18 \times 10^{-2}$ & $1,12 \times 10^{-2}$ \\
RQR 7 & $2,10 \times 10^{-2}$ & $1,98 \times 10^{-2}$ & $1,72 \times 10^{-2}$ \\
\hline
\end{tabular}

Os fatores de retroespalhamento, B, obtidos experimentalmente pela razão do $\mathrm{K}_{\mathrm{e}}$ pelo $\mathrm{K}_{\mathrm{i}}$, foram comparados pelos fornecidos pela TRS 457 e foi encontrada uma diferença de até $18,6 \%$, para o feixe não colimado (TAB.20). O que demonstra a validade de se calibrar as câmaras de ionização numa condição adequada para seu uso, para minimizar os possíveis erros.

TABELA 20: Comparação entre os fatores de retroespalhamento, $\mathrm{B}$, obtidos e os fornecidos pela TRS 457.

\begin{tabular}{ccccc}
\hline $\begin{array}{c}\text { Qualidade de } \\
\text { radiação }\end{array}$ & $\begin{array}{c}\text { Colimação do } \\
\text { feixe }\end{array}$ & $\begin{array}{c}\text { B } \\
\text { medido }\end{array}$ & $\begin{array}{c}\text { B } \\
\text { (TRS-457) }\end{array}$ & $\begin{array}{c}\text { Diferença } \\
\text { percentual }\end{array}$ \\
\hline RQR 3 & sim & 1,26 & 1,26 & $0 \%$ \\
RQR 3 & não & 1,34 & 1,26 & $5,97 \%$ \\
\hline RQR 5 & sim & 1,41 & 1,34 & $4,96 \%$ \\
RQR 5 & não & 1,50 & 1,34 & $10,67 \%$ \\
\hline RQR 7 & sim & 1,61 & 1,40 & $13,04 \%$ \\
RQR 7 & não & 1,72 & 1,40 & $18,60 \%$ \\
\hline
\end{tabular}




\subsubsection{Determinação do kerma de saída do simulador}

Para a avaliação do kerma de saída, foram feitas medidas com a câmara de ionização posicionada atrás do simulador de acrílico. Estas medidas são importantes para se estimar a quantidade de dose que sai do paciente e interage com o intensificador de imagem. Todas as medidas foram realizadas em função da resposta da câmara monitora $(\mathrm{nC})$. Foram realizadas medidas com e sem o colimador posicionado depois da câmara monitora. Os valores encontrados são mostrados na TAB. 21.

TABELA 21: Kerma de saída para as qualidades RQR, em função da resposta da câmara monitora $(\mathrm{nC})$.

\begin{tabular}{cccc}
\hline $\begin{array}{c}\text { Qualidade de } \\
\text { radiação }\end{array}$ & $\begin{array}{c}\text { Kerma de saída } \\
\text { (mGy/nC) }\end{array}$ & $\begin{array}{c}\text { Diferença } \\
\text { percentual }\end{array}$ & $\begin{array}{c}\text { Colimação do } \\
\text { feixe }\end{array}$ \\
\hline RQR 3 & 0,174 & $6,9 \%$ & sim \\
RQR 3 & 0,186 & & não \\
RQR 5 & 0,151 & $24 \%$ & sim \\
RQR 5 & 0,187 & & não \\
RQR 7 & 0,138 & $5,8 \%$ & sim \\
RQR 7 & 0,146 & & não \\
\hline
\end{tabular}

A avaliação do kerma de saída para os feixes colimados e não colimados mostrou uma variação muito maior em relação ao de entrada. Para a medida dos feixes colimados utilizou-se um colimador de $4,8 \mathrm{~cm}$ após a câmara monitora e os feixes não colimados $^{\S}$ foram obtidos apenas com o colimador de $4,0 \mathrm{~cm}$ que fica na posição anterior a câmara monitora. $O$ arranjo utilizado nestas medidas pode ser visto na FIG. 39.

\footnotetext{
${ }^{\S}$ Para todas as medidas de entrada e saída, o diâmetro foi o mesmo informado no texto acima.
} 

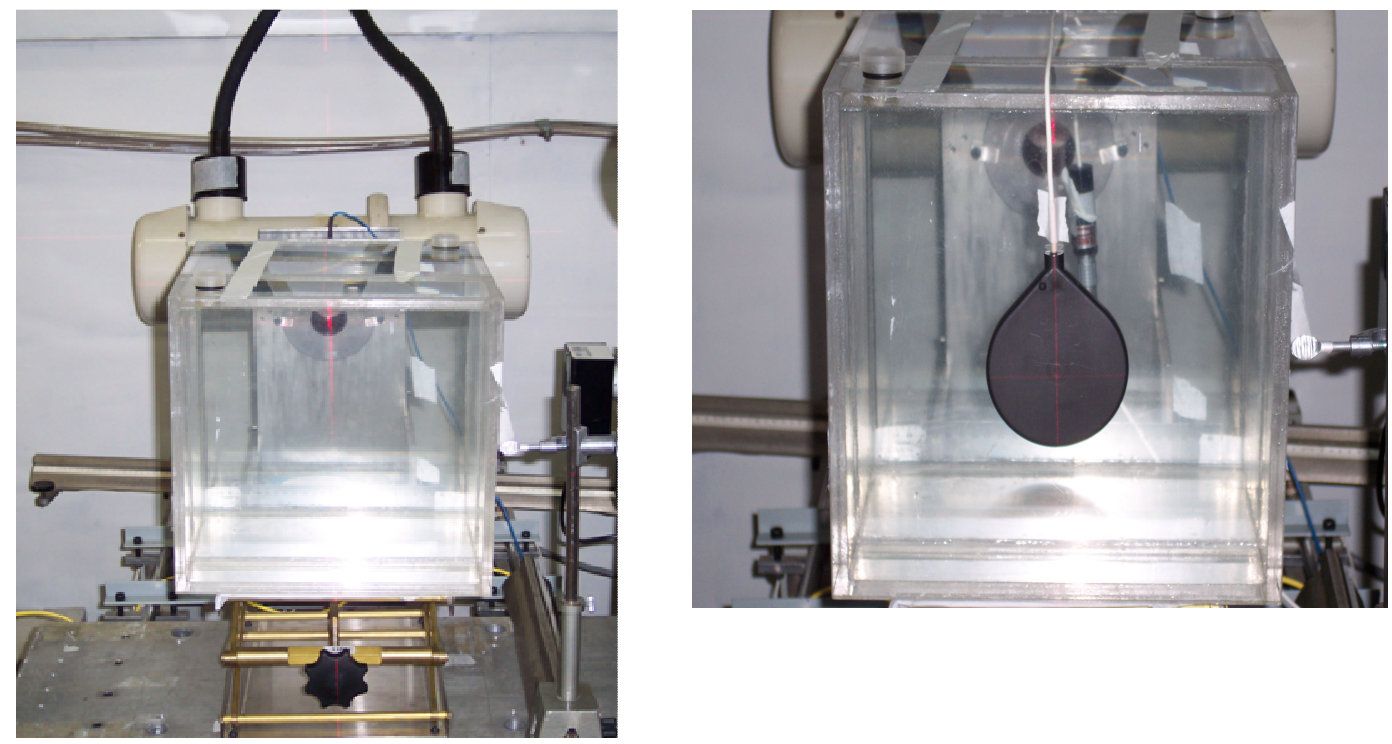

FIGURA 39: Arranjo utilizado para as medidas de kerma de saída, com a câmara de ionização de referência posicionada atrás do simulador.

Corrigindo os valores para a resposta da câmara monitora, pode-se comparar as taxas de kerma de saída para feixes colimados e não colimados, como pode ser observado na TAB. 22.

TABELA 22: Taxas de kerma de saída, em Gy/min, para feixes colimados e sem colimação.

\begin{tabular}{ccc}
\hline $\begin{array}{c}\text { Qualidade } \\
\text { de } \\
\text { radiação }\end{array}$ & \multicolumn{2}{c}{ Taxas de kerma de saída } \\
\cline { 2 - 3 } (Gy/min) \\
\hline RQR 3 & Feixe colimado & Feixe não colimado \\
RQR 5 & $3,44 \times 10^{-5}$ & $5,02 \times 10^{-5}$ \\
RQR 7 & $8,79 \times 10^{-6}$ & $1,27 \times 10^{-5}$ \\
& $7,62 \times 10^{-7}$ & $1,17 \times 10^{-6}$ \\
\hline
\end{tabular}




\subsubsection{Determinação das taxas de kerma na superfície de entrada simulando um paciente maior}

Um arranjo de calibração e dosimetria em um Laboratório de Calibração pode ter todas as suas condições de uso controladas e reprodutíveis. Em um arranjo clínico já não e tão fácil manter as suas condições reprodutíveis, pois há uma série de fatores que devem ser considerados, por exemplo:

- Técnica diagnóstica a ser aplicada;

- Tamanho do paciente;

- Variações no tamanho de campo;

- Outros

O código de prática (TRS 457) recomenda que para a simulação de um paciente maior devem ser unidos os dois simuladores como já descrito anteriormente: o de $300 \mathrm{~mm} \times 200 \mathrm{~mm}$ e o complemento de $300 \mathrm{~mm} \times 100 \mathrm{~mm}$.

O procedimento de medida e avaliação foi o mesmo realizado no item 5.8.1. Os valores de $K_{i}$ para os feixes colimados e não colimados e os fatores de retroespalhamento, $\mathrm{B}$, medidos e a sua diferença percentual em relação aos fornecidos pelo AIEA (TRS 457) estão apresentados na TAB.23.

TABELA 23: Valores de kerma no ar incidente, $\mathrm{K}_{\mathrm{i}}$, fatores de retroespalhamento, $\mathrm{B}$, medidos e os fornecidos pelo TRS 457.

\begin{tabular}{|c|c|c|c|c|c|c|}
\hline \multirow{2}{*}{$\begin{array}{l}\text { Qualidade } \\
\text { de radiação }\end{array}$} & \multirow{2}{*}{$\begin{array}{c}\mathrm{K}_{\mathrm{i}} \\
(\mathrm{mG} / \mathrm{min})\end{array}$} & \multicolumn{2}{|c|}{$\mathrm{B}$ medido } & \multirow[t]{2}{*}{$\begin{array}{c}\mathrm{B} \\
\mathrm{TRS}-457\end{array}$} & \multicolumn{2}{|c|}{$\begin{array}{c}\text { Diferença } \\
\text { percentual (\%) }\end{array}$} \\
\hline & & $\begin{array}{c}\text { não } \\
\text { colimado }\end{array}$ & colimado & & $\begin{array}{l}\text { não } \\
\text { colim. }\end{array}$ & colim. \\
\hline RQR 3 & $3,50 \times 10^{-3}$ & 1,38 & 1,31 & 1,26 & 8,7 & 3,8 \\
\hline RQR 5 & $8,29 \times 10^{-3}$ & 1,51 & 1,46 & 1,34 & 11,3 & 8,21 \\
\hline RQR 7 & $1,23 \times 10^{-2}$ & 1,79 & 1,67 & 1,40 & 21,8 & 16,1 \\
\hline
\end{tabular}


Utilizando os fatores de retroespalhamento fornecidos pelo AIEA (TRS 457), determinou-se os valores de $K_{e}$ neste caso e foram comparados com os valores de $\mathrm{K}_{\mathrm{e}}$ medidos, como mostra a TAB. 24 .

Tabela 24: Valores de kerma na superfície de entrada, $\mathrm{K}_{\mathrm{e}}$, medido e utilizando calculo fornecido pelo TRS 457.

\begin{tabular}{cccc}
\hline $\begin{array}{c}\text { Qualidade de } \\
\text { Radiação }\end{array}$ & $\begin{array}{c}\mathrm{K}_{\mathrm{e} \text { medido }} \\
\text { colimado }\end{array}$ & $\begin{array}{c}\mathrm{K}_{\mathrm{e} \text { medido }} \\
\text { não colimado }\end{array}$ & $\mathrm{K}_{\mathrm{e}}=\mathrm{Ki} . \mathrm{B}$ \\
\hline RQR 3 & $4,59 \times 10^{-3}$ & $4,84 \times 10^{-3}$ & $4,41 \times 10^{-3}$ \\
RQR 5 & $1,21 \times 10^{-2}$ & $1,25 \times 10^{-2}$ & $1,11 \times 10^{-2}$ \\
RQR 7 & $2,05 \times 10^{-2}$ & $2,19 \times 10^{-2}$ & $1,72 \times 10^{-2}$ \\
\hline
\end{tabular}

O comportamento dos valores encontrados foram muito próximos daqueles encontrados para um paciente padrão.

$\mathrm{Na}$ TAB. 25 encontra-se uma comparação entre os valores obtidos para os feixes colimados e não colimados. Nota-se que existe uma diferença significativa quando os feixes não estão adequadamente colimados (até 9,94\%).

TABELA 25: Diferença percentual encontrada entre os valores de $\mathrm{K}_{\mathrm{e}}$ em feixes colimados e não colimados

\begin{tabular}{c|c}
\hline Qualidade Implantada & Diferença percentual \\
\hline RQR 3 & $9,94 \%$ \\
RQR 5 & $3,15 \%$ \\
RQR 7 & $0,11 \%$ \\
\hline
\end{tabular}




\subsubsection{Determinação das taxas de kerma de saída simulando}

\section{um paciente maior}

Para a avaliação do kerma de saída, foram feitas medidas com a câmara de ionização posicionada atrás do simulador de acrílico. Estas medidas são importantes para se estimar a quantidade de dose que sai do paciente e interage com o intensificador de imagem. A exemplo do item 5.8.2, todas as medidas foram realizadas em função da resposta da câmara monitora $(\mathrm{nC})$. Foram feitas medidas com e sem o colimador posicionado depois da câmara monitora. Os valores encontrados são mostrados na TAB. 26.

TABELA 26: Valores de kerma de saída em comparação com o kerma na superfície de entrada, $\mathrm{K}_{\mathrm{e}}$.

\begin{tabular}{ccccc}
\hline $\begin{array}{c}\text { Qualidade da } \\
\text { radiação }\end{array}$ & $\begin{array}{c}\text { Kerma de } \\
\text { saída medido } \\
(\mathrm{mGy} / \mathrm{min})\end{array}$ & $\begin{array}{c}\mathrm{K}_{\mathrm{e}} \text { medido } \\
(\mathrm{mGy} / \mathrm{min})\end{array}$ & $\begin{array}{c}\text { Quantidade } \\
\text { absorvida } \\
(\%)\end{array}$ & $\begin{array}{c}\text { Colimação do } \\
\text { feixe }\end{array}$ \\
\hline RQR 3 & $7,62 \times 10^{-7}$ & $3,19 \times 10^{-3}$ & 99,99 & sim \\
& $1,17 \times 10^{-6}$ & $3,21 \times 10^{-3}$ & 99,99 & não \\
RQR 5 & $8,79 \times 10^{-6}$ & $7,75 \times 10^{-3}$ & 99,98 & sim \\
& $1,27 \times 10^{-5}$ & $7,95 \times 10^{-3}$ & 99,98 & não \\
RQR 7 & $3,44 \times 10^{-5}$ & $1,19 \times 10^{-2}$ & 99,97 & sim \\
& $5,02 \times 10^{-5}$ & $1,22 \times 10^{-2}$ & 99,97 & não \\
\hline
\end{tabular}

O resultado mostra que há uma tendência decrescente da quantidade de radiação absorvida pelo simulador. Quanto maior a energia do feixe, menor é a absorção pelo simulador ou paciente. Isso ocorre provavelmente pela interação dos fótons de baixa energia com o material. O RQR 3 representa uma energia efetiva de $28 \mathrm{keV}$ enquanto o RQR 7 possui $37 \mathrm{keV}$. Neste intervalo a quantidade de radiação absorvida pelo simulador variou 0, 03\%. 


\subsubsection{Medidas de radiação espalhada para uma situação extrema (simulador maior)}

Estas medidas foram feitas considerando condições extremas, pois, as medidas foram realizadas com o simulador de dimensões $300 \mathrm{~mm} \times 200 \mathrm{~mm}$ em conjunto com o simulador de $300 \mathrm{~mm} \times 100 \mathrm{~mm}$ (simulando um paciente maior). Estes valores de radiação espalhada são importantes para a simulação de uma condição real de trabalho clínico, e pode ser utilizada na estimativa da dose (gray) no corpo clínico.

As medidas foram tomadas com uma câmara de ionização de referência para proteção radiológica, marca PTW, modelo 32002, com volume de $1000 \mathrm{~mL}$ na presença dos simuladores. Com o simulador posicionado a $50 \mathrm{~cm}$ do ponto focal, e a câmara posicionada a $40 \mathrm{~cm}$ perpendicularmente ao feixe central, o que representava aproximadamente $20 \mathrm{~cm}$ até 0 simulador. Com este arranjo, foram tomadas três medidas para cada uma das seis posições da câmara em relação ao simulador: anterior, meio e posterior para cada lado. Sendo que a câmara foi mantida sempre paralela ao simulador. Com este procedimento fez se uma varredura em torno do simulador, levando em conta a movimentação do corpo clinico ao redor do paciente. $O$ fator de calibração $\left(\mathrm{N}_{\mathrm{K}}\right)$ e fator de qualidade $(\mathrm{Kq})$, da câmara de ionização utilizada possui rastreabilidade ao laboratório de dosimetria primário alemão PTB. Utilizando estes valores as taxas de kerma no ar para os feixes espalhados foram determinados. A FIG. 40a e b mostram o arranjo e posicionamento da câmara em relação ao simulador.
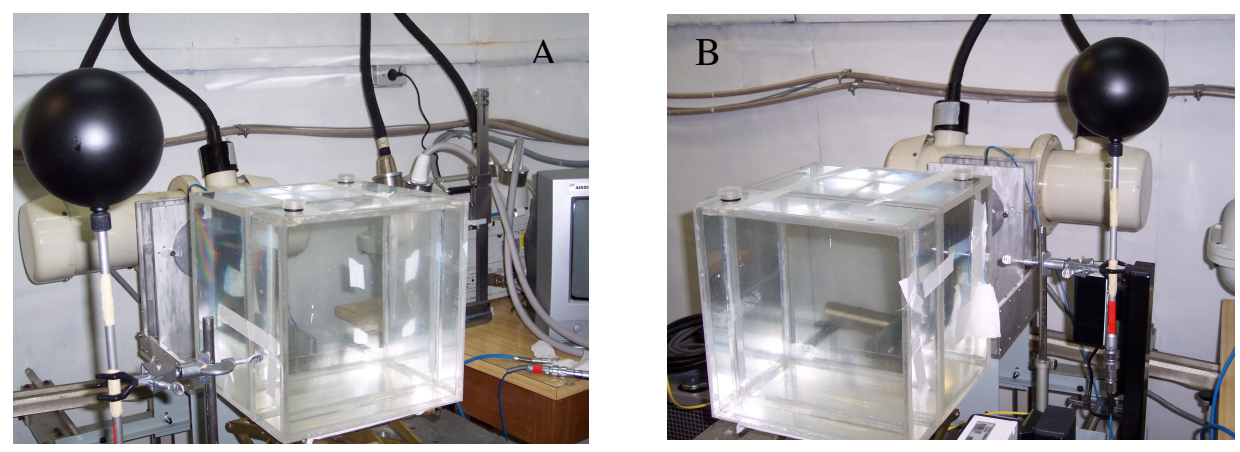

FIGURA 40: Câmara utilizada para medir a radiação espalhada posicionada no lado esquerdo (A) e no lado direito (B) do simulador.

Analisando os valores encontrados percebeu-se a influência do efeito 
anódico com maior ou menor exposição do corpo clínico. Este fato acontece, pois, o lado do eletrodo negativo (-) apresenta uma intensidade do feixe menor, porém o seu limiar não é tão definido. O lado do eletrodo positivo (+) possui uma intensidade do feixe maior, mais homogêneo e tem o seu limiar bem definido. Na FIG. 41 pode verificar um esquema das irradiações realizadas e os valores encontrados para a qualidade RQR3.

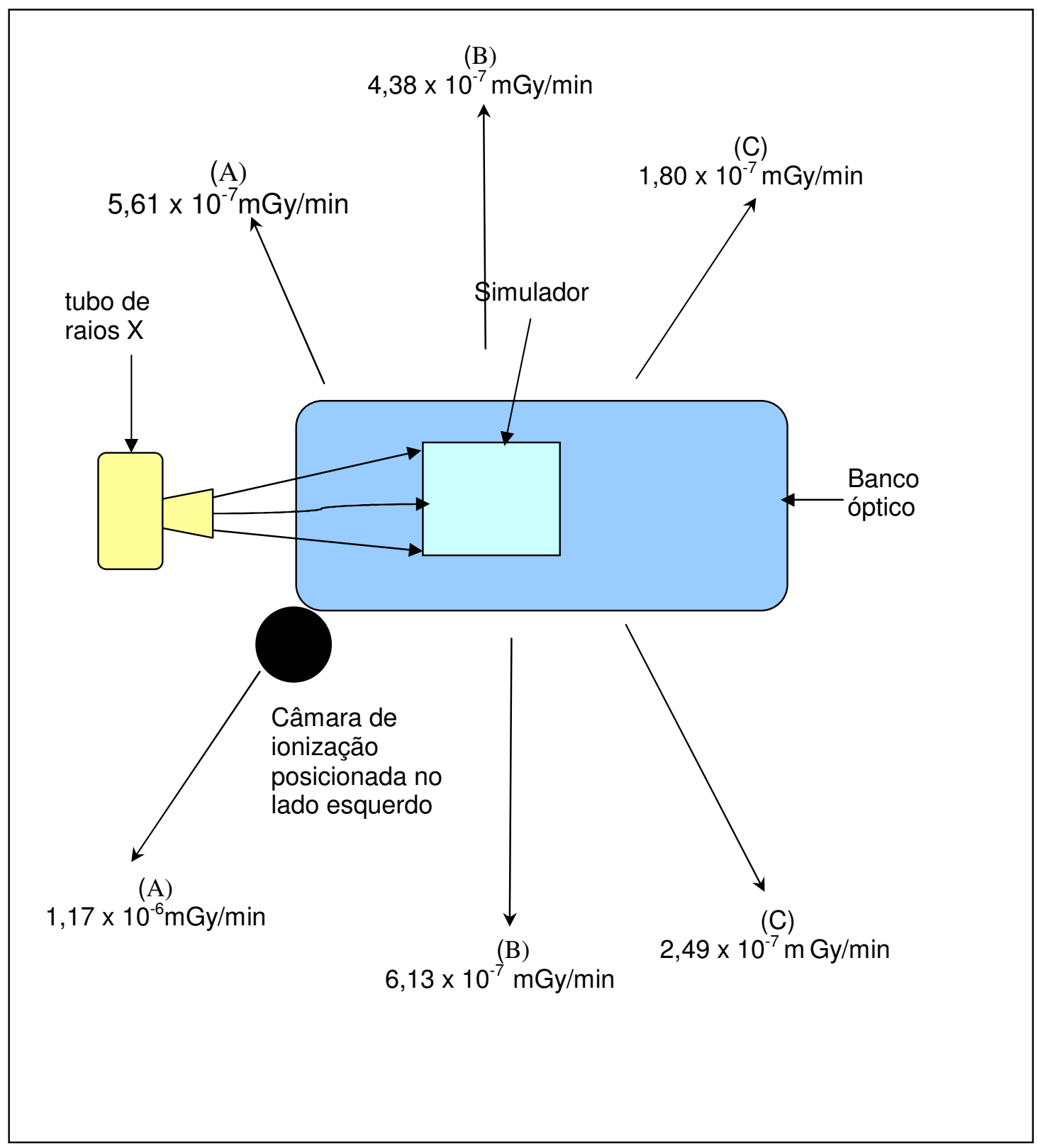

FIGURA 41: Representação do arranjo utilizado para a determinação da radiação espalhada em posições diferentes em torno do simulador (RQR 3). As letras entre parênteses representam a posição da câmara de ionização durante as medidas. 
A figura representa a movimentação da câmara de ionização utilizada para radioproteção, para simular a dose recebida pelo corpo clínico em cada ponto estratégico. A letra $A$, representa a posição mais próxima ao tronco superior e cabeça, a letra B simula a posição do corpo clínico próximo ao abdômen do paciente e a letra $\mathrm{C}$ a uma posição próxima a pelve e membros inferiores. $\mathrm{A}$ avaliação do teste mostrou que no ponto mais próximo (como era esperado) há uma maior contribuição. Em uma situação real o médico e auxiliares estariam protegidos pelos equipamentos de proteção pessoal (EPI) e a posição do tubo também seria diferente já que o nosso trabalho foi realizado nas condições de um laboratório.

Neste trabalho com o intuito de alcançar todos os parâmetros de influência em radiodiagnóstico, foram realizadas medidas de espalhamento e kerma incidente na posição do corpo clínico. Os valores são apresentados em mGy/min e se encontram da TAB. 27. Analisando estes valores, podemos concluir que, se este equipamento fosse utilizado rotineiramente em exames fluoroscópicos, seria recomendável que o corpo clínico trabalhasse do lado direito do tubo, para se evitar maiores contribuições de espalhamento.

TABELA 27: Valores de taxa de kerma incidente para a radiação espalhada ao redor do simulador maior, representando uma situação extrema.

\begin{tabular}{cccc}
\hline $\begin{array}{c}\text { Qualidade de } \\
\text { radiação }\end{array}$ & $\begin{array}{c}\text { Taxa de Kerma } \\
\text { (mGy/min) } \\
\text { lado direito }\end{array}$ & $\begin{array}{c}\text { Taxa de Kerma } \\
\text { (mGy/min) } \\
\text { lado esquerdo }\end{array}$ & $\begin{array}{c}\text { Posicionamento da } \\
\text { câmara de } \\
\text { ionização }\end{array}$ \\
\hline RQR 3 & $5,61 \times 10^{-7}$ & $1,17 \times 10^{-6}$ & $\mathrm{~A}$ \\
& $4,38 \times 10^{-7}$ & $6,13 \times 10^{-7}$ & $\mathrm{~B}$ \\
& $1,80 \times 10^{-7}$ & $2,49 \times 10^{-7}$ & $\mathrm{C}$ \\
RQR 5 & $2,72 \times 10^{-6}$ & $5,73 \times 10^{-6}$ & $\mathrm{~A}$ \\
& $2,04 \times 10^{-6}$ & $4,86 \times 10^{-6}$ & $\mathrm{~B}$ \\
& $1,01 \times 10^{-6}$ & $1,42 \times 10^{-6}$ & $\mathrm{C}$ \\
RQR 7 & $7,18 \times 10^{-6}$ & $1,34 \times 10^{-5}$ & $\mathrm{~A}$ \\
& $5,90 \times 10^{-6}$ & $8,02 \times 10^{-6}$ & $\mathrm{~B}$ \\
& $2,88 \times 10^{-6}$ & $3,97 \times 10^{-6}$ & $\mathrm{C}$ \\
\hline
\end{tabular}


Os resultados encontrados para o lado direito do tubo demonstram uma contribuição menor da taxa de kerma no ar para a radiação espalhada. A maior contribuição ao corpo clínico encontra-se no lado esquerdo, na posição A para o RQR 7, no valor de $1,34 \times 10^{-5} \mathrm{mGy} / \mathrm{min}$. A diferença percentual máxima entre os dois lados foi de $58,0 \%$, na posição $B$ para a qualidade RQR 5 .

Este estudo mostrou que a importância do efeito anódico para as técnicas que utilizam a fluoroscopia e procedimentos intervencionistas, pois o corpo clínico apresenta-se muito próximo do paciente e conseqüentemente haverá espalhamento interagindo.

O gráfico (FIG. 42) mostra com mais clareza a disposição das doses de espalhamento ao redor do simulador de $300 \mathrm{~mm} \times 200 \mathrm{~mm}$ com a união do simulador $300 \mathrm{~mm} \times 100 \mathrm{~mm}$. Percebe-se claramente que o lado esquerdo apresenta valores superiores ao lado direito. Portanto é importante este estudo para se obter a melhor posição de trabalho durante um procedimento

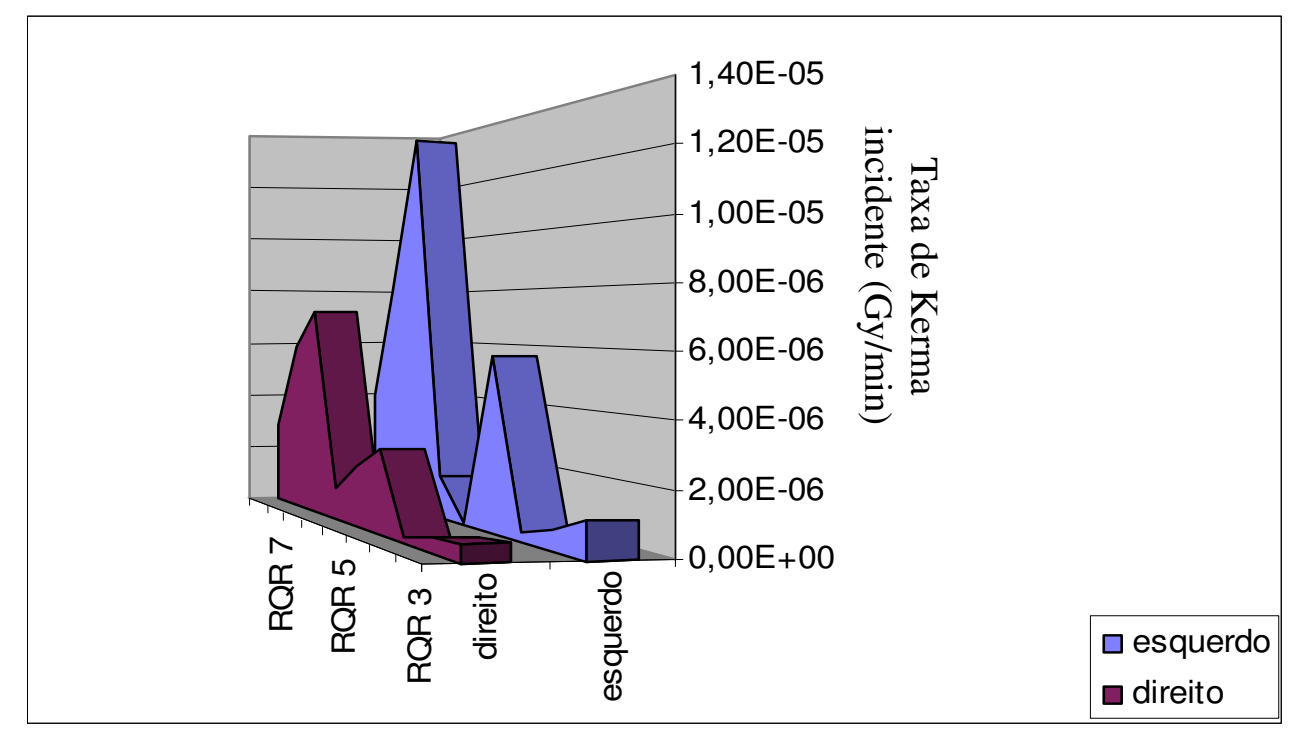

FIGURA 42: Diferença entre os valores de taxa de kerma no ar para as o lado esquerdo e o lado direito, mantendo as mesmas posições do simulador. 


\section{CONCLUSÕES}

Apesar do desenvolvimento do trabalho ter apresentado algumas dificuldades para ser realizado, por se tratar de um equipamento clínico, cuja instabilidade da corrente aplicada é grande, os resultados obtidos se mostraram satisfatórios. Inicialmente, se estudou o desempenho de uma câmara de ionização plana para fazer a função de câmara monitora, avaliando a sua estabilidade a curto e longo prazo e o seu comportamento no feixe de radiação $X$. Na seqüência, foram projetados e fabricados os suportes para todas as câmaras utilizadas neste trabalho, além de um sistema de colimadores e um suporte de acrílico especialmente desenvolvido para a câmara de transmissão. Este sistema mostrou praticidade, pois se mantêm fixos a geometria da câmara e o posicionamento dos filtros sem a necessidade de recursos auxiliares. A avaliação da câmara de ionização específica para fluoroscopia foi realizada e esta também mostrou ter um bom comportamento, sendo que seus coeficientes de calibração foram determinados. As qualidades recomendadas pela norma IEC para fluoroscopia foram implantadas com pequena variação em relação aos valores sugeridos. Todas as características destas qualidades foram estabelecidas. Um programa de controle de qualidade do sistema utilizado foi implantado, considerando que a sua principal característica, por ser um sistema clínico, é a grande variação dos fatores de influência (tensão e corrente). Este programa permitiu a identificação de problemas antes não percebidos. Foram implantadas as qualidades de radiação RQR3, RQR5 e RQR7 e as específicas para a fluoroscopia RQC3, RQC5 e RQC7 seguindo as recomendações da norma IEC 61267. Todas as características dos feixes foram determinadas, desde a sua CSR até as taxas de kerma no ar. A homogeneidade dos campos utilizados no trabalho variou entre 86 a $100 \%$, no tamanho de interesse, ou seja, aproximadamente. $10 \mathrm{~cm}$. O desvio máximo obtido entre o valor de referência (100\%) e o menor dentro de $10 \mathrm{~cm}$, foi de $14 \%$ no caso de 90 KV. Para a determinação de dose de entrada e saída do paciente e de radiação espalhada na posição do corpo clínico, foram construídos simuladores de acrílico. Foram determinados os valores de kerma incidente, kerma na superfície de entrada, kerma de saída, tanto para o simulador representando um paciente 
padrão e como para o simulador representando um paciente maior. Todas as medidas foram realizadas com e sem a colimação posicionada entre a câmara monitora e o simulador e os resultados encontrados mostram uma diferença de até $18 \%$, comprovando a importância da colimação nos procedimentos fluoroscópicos e intervencionistas.

Além destas medidas, foram determinadas as taxas de kerma incidente na posição do corpo clínico, demonstrando que o lado direito deste sistema de radiação $X$ é o mais indicado para o posicionamento do corpo clínico, demonstrando a importância deste estudo.

Neste trabalho foi desenvolvido um procedimento que poderá ser aplicado aos instrumentos medidores de radiação que são empregados em controle de qualidade em sistemas fluoroscópicos. O método de calibração que atualmente é realizado no ar poderá ser realizado mais próximo da sua situação de uso, incluindo as medidas com o simulador. 


\section{REFERÊNCIAS}

1. LINTON, O. W. Medical application of x-rays: a century of radiation 18951995. Beam Line, summer 1995, p. 25-34, 1995.

2. CÉREBRO E MENTE : revista eletrônica de divulgação científica e neurociências <http://www.cerebromente.org.br/n20/history/neuroimage2> Data de pesquisa: 13 de outubro 2008.

3. OKUNO, E. Radiação Efeitos, Riscos e Benefícios . Ed Harbra., , São Paulo - SP,1988, 1998 (revisão).

4. INTERNATIONAL ATOMIC ENERGY AGENCY. Dosimetry in Diagnostic Radiology. An International Code of Practice. (IAEA). TRS 457; Vienna, 2007.

5. MINISTÉRIO DA SAÚDE. Portaria 453. Diretrizes de proteção radiológica em radiodiagnóstico médico e odontológico. Diário Oficial da União, Brasília, 02 de junho de 1998.

6. HIRSHFELD, J. W.,JR, BALTER, S, BRINKER J A. et al, ACCF/AHA/HRS/SCAl Clinical Competence Statement on Physician Knowledge to Optimize Patient Safety and Image Quality in Fluoroscopically Guided Invasive Cardiovascular Procedures: A Report of the American College of Cardiology. Foundation/American Heart Association/American College of Physicians Task Force on Clinical Competence and Training; Circulation. n. 111, p. 511 - 532. Feb 2005

7. DREXLER, G. Diagnostic reference levels in the 1990 and 1996 recommendations of the ICRP. Radiation Protection and Dosimetry, v. 80, n. 1-3, p.7-10, 1998.

8. GRAY, J.E., ARCHER, B.R., BUTLER, P.F., HOBBS, B.B., METTLER, F.A. PIZZUTIELLO, R.J., SCHUELER, B.A. STRAUSS, K.J., SULEIMAN, O.H., YAFFE, M.J. Reference values for diagnostic radiology: application and impact. Radiology. v. 235 (2) p. 354-358, 2005.

9. REGULLA, D.F., EDER, H. Patient exposure in medical $X$-ray imaging in Europe. Radiation Protection Dosimetry. v. 114(1-3), p 11-25 Sp. Iss. SI, 2005. 
10. OLIVEIRA, M., NOGUEIRA, M.S., GUEDES, E., ANDRADE, M.C., PEIXOTO,J.E., SILVA,V.L.S., BORGES, J.C. Avaliação da Qualidade da Imagem versus Doses em Serviços de Mamografia de Belo Horizonte. Anais do IX Congresso Brasileiro de Física Medica, Maio de 2004, Rio de Janeiro, Brasil, 2004.

11.ZENÓBIO, M.A.F., SILVA, T.A. Metodologia para Medida da Dose Absorvida em Pacientes Submetidos a Exames Tomográficos para 0 Planejamento de Implantes Dentais. Anais do IX Congresso Brasileiro de Física Medica, Maio de 2004, Rio de Janeiro, Brasil, 2004.

12. LIMA, A.A.; CARVALHO, A.C.P. AZEVEDO, A. C. P. Avaliação dos padrões de dose em radiologia pediátrica. Radiololigia Brasileira, São Paulo, v. 37, n. 4, Aug. 2004. Disponível em: <http://www.scielo.br/scielo doi: 10.1590/S0100-39842004000400011. >. Acesso em: 04 Apr. 2008

13. OLIVEIRA, L.C.G. Estimativa do kerma no ar na superfície de entrada em exames mamográficos. 2007. Dissertação (Mestrado)- Universidade Federal do Rio de Janeiro. Rio de Janeiro.

14. HARRISON, R.M. Backscatter Factor for Diagnostic Radiology (1-4 mmAl HVL). Physics in Medicine and Biology, v .27, n 12, p.1465-1474, 1982.

15. KLEVENHAGEN, S.C. Experimentally basckscatter factors for X-rays generated at voltages between 16 and $140 \mathrm{kV}$. Physics in Medicine and Biology, v. 34, n 12, p.1871-1882, 1989.

16. GROSSWENDT, B. Dependence of the photon basckscatter for water on irradiation field size and source to-phantom distances between 1.5 and 10 cm. Physics in Medicine and Biology, v 38, p. 305-310, 1993.

17. INTERNATIONAL ELECTROTECHNICAL COMMISSION. Medical diagnostic $X$-ray equipment radiation conditions for use in determination of characteristics. (IEC 61267). Revision 2005.

18.POTIENS, M.P.A. Metodologia dosimétrica e sistema de referência para radiação X nível diagnóstico.: 1999. Tese (Doutorado) - Instituto de Pesquisas Energéticas e Nucleares/Univ. de São Paulo, São Paulo.

19. GOVERNO DO ESTADO DE SÃO PAULO. Decreto n.o 12.342, Livro V: Normas Básicas de Proteção Contra Radiação e Riscos Elétricos. São Paulo, setembro, 1978. 
20. INTERNATIONAL COMMISSION ON RADIOLOGICAL PROTECTION. Quantitative Basis for Developing a Unified Index of Harm, (ICRP REPORT). no 45, 1985.

21. GOVERNO DO ESTADO DE SÃO PAULO. Resolução SS-625. Norma Técnica que se Dispõe sobre o uso de Fontes de Radiação lonizante no Âmbito do Estado de São Paulo. D.O.E.; SEÇÃO I; SÃO PAULO $14 / 12 / 94$.

22. INTERNATIONAL ELECTROTECHNICAL COMMISSION. IEC 1267. Medical diagnostic X-ray equipment Radiation conditions for use in determination of characteristics. 1994.

23. EUROPEAN COMMISSION, 1996. European guidelines on quality criteria for diagnostic radiographic images. Luxembourg, 1996.

24. AMERICAN ASSOCIATION OF PHYSICISTS IN MEDICINE. Managing the use of Fluoroscopy in Medical Institutions. Report of Task Group VI of the Radiation Protection Committee, AAPM report no. 58, Madison, USA, 1998.

25. ACUERDO REGIONAL DE COOPERACÍON PARA LA PROTECÍON DE LA CIENCIA Y TECNOLOGÍA NUCLEARES EN AMERICA LATINA. Guia Reguladora de Seguridad para La Prática de Rayos $X$ Diagnósticos (Simples y Fluoroscopia). ARCAL, Cusco, Peru ,2000.

26. LAMMOGLIA P. Elaboração e Implementação de Testes de Controle de Qualidade em Equipamentos de Angiografia por Subtração Digital. 2001; Dissertação (MESTRADO) - Instituto de Pesquisas Energéticas e Nucleares/Universidade de São Paulo. São Paulo.

27. SOCIEDAD ESPAÑOLA DE FÍSICA MÉDICA. Protocolo Español de Control de Calidad em Radiodiagnóstico. Revisión (SEFM). 1, 2002.

28. AGÊNCIA NACIONAL DE VIGILÂNCIA SANITÁRIA. RE $n$ o 64: Guia de procedimentos para segurança e qualidade de imagem em radiodiagnóstico médico, (ANVISA), Orientação técnica, 2003.

29. AGÊNCIA NACIONAL DE VIGILÂNCIA SANITÁRIA. RE $n^{\circ}$ 1016: Radiodiagnóstico Médico - Segurança e Desempenho de Equipamentos, (ANVISA), Orientação Técnica, 2006. 
30. ASSOCIAÇÃO BRASILEIRA DE NORMAS TÉCNICAS. Equipamento eletromédico parte 2-43: Requisitos particulares para a segurança de equipamento de raios $X$ para procedimentos intervencionistas. Rio de Janeiro: ABNT, 2004. (NBR- IEC 60601-2-43)

31. TAHA, O. Perspectivas para o ensino em radiologia. Radiologia Brasileira, São Paulo, v. 41, n. 1, Feb. 20. Acesso 14 Apr. 2009 $<$ http://www.scielo.br/scielo. $>$. doi:

$10.1590 /$ S0100984200800010000208 .

32. CONSELHO REGIONAL DE MEDICINA DO ESTADO SÃO PAULO <http:www.cremesp.org.br/library/modeulos/centro de dados/arquivos/ especialidades>. 30 jan 2009.

33. INTERNATIONAL ELECTROTECHNICAL COMMISSION. Particular requirements for the safety of $X$-ray equipment for interventional procedures. Medical electrical equipment, part 2-43. Geneva:, 2000; (IEC Report 60601).

34. KROHMER, J.S. Radiography and Fluoroscopy, 1920 to the Present. RadioGraphics, vol.9, n.6, p.1129-1153, 1989.

35. PICKER INTERNATIONAL AND SOME HISTORY <http://www.obultrasound.net/picker.html>, Acesso, 5 nov 2008.

36. MISTRETTA, C.A et all. X-ray Digital Subtraction Angiography to Magnetic Ressonance Digital Subtraction Angiography Using Three Dimensional Tricks. Historical Perspective and Computer Simulations: A Review. Investigative Radiology. V.33 (9): p 496-505, 1998

37. BUSHBERG, J.T., SEIBERT, J.A., LEIDHOLDT JR., E.M., BOONE, J.M. The essential physics of medical imaging. Minneapolis, Minnesota, USA. Williams \& Wilkins, 1994.

38. KHAN, F.M. The physics of radiation therapy. Minneapolis, Minnesota, USA. Williams \& Wilkins, 1984.

39. BITELLI.T. Física e Dosimetria das Radiações. $2^{\circ}$ Ed, Ateneu. São Paulo, Rio de Janeiro, Ribeirão Preto. 2006.

40. COMISSÃO NACINAL DE ENERGIA ATÔMICA. (CNEN) $<$ http://www.cnen.gov.br/ensino/apostilas/PIC.pdf> Acesso, 15 de maio 2009. 
41. TECNOLOGIA RADIOLOGICA: revista eletrônica de divulgação de novas técnicas e informações em radiodiagnóstico.

$<$ http://www.tecnologiaradiologica.com/materia fisica rx.htm>, Acesso, 15 de maio 2009.

42. WORLD HEALTH ORGANIZATION. <http://www.who.int/en/.> Acesso, 07 de outubro 2008.

43. INTERNATIONAL ATOMIC ENERGY AGENCY.Measurement Uncertainty. A Practical Guide for Secondary Standards Dosimetry Laboratories. (IAEA).(Vienna) May. 2008.

44. INSTITUTO NACIONAL DE METROLOGIA, NORMALIZAÇÃO E QUALIDADE INDUSTRIAL, Vocabulário Internacional de Termos Fundamentais e Gerais de Metrologia. Portaria INMETRO no 029 de (INMETRO) 1995. $5^{\text {a }}$ Edição, Editora SENAI, Rio de Janeiro, 2007

45. COMISSAO NACIONAL DE ENERGIA NUCLEAR.-Diretrizes Básicas de Proteção Radiológica . JANEIRO, 2005. (CNEN-NN-3.01).

46. INTERNATIONAL COMMISSION ON RADIATION UNITS AND MEASUREMENTS. Fundamental quantities and units for ionizing radiation. ICRU Report 60.Bethesda, MD, 1998.

47. LABORATÓRIO NACIONAL DE METROLOGIA DAS RADIAÇÕES IONIZANTES. Grandezas e unidades para radiações ionizantes: Recomendações e Definições. (LNMRI), Rio de Janeiro, dezembro 2002.

48. INTERNATIONAL COMMISSION ON RADIATION UNITS AND MEASUREMENTS - Measurement of Dose Equivalents from External Photon and Electron Radiations - (ICRU), 1992. (ICRU Report 47).

49. PARIZOTI, A. Otimização de Imagens e Proteção Radiológica em Fluoroscopia. 2008. Dissertação (Mestrado) - Departamento de Física e Matemática - FFCLRP/USP, Ribeirão Preto, São Paulo.

50. BOAG, J.W. Ionization Chambers. In: KASE, K.R.; BJÄRNGARD, B.E; ATTIX, A.H. The dosimetry of ionizing radiation, New York, NY: Academic, v.2, p 169-243, 1987.

51. BURNS D.T.,BÜERMANN,L. Free-air ionization chambers. Metrologia. n 46 p 9-23, 2009. 
52. CAMPOS, C. A. A.L. Construção, calibração e testes de uma câmara de ionização para medidas de exposição na região de 40 a $1250 \mathrm{keV}$. 1982. Dissertação (Mestrado) - Univ. Estadual do Rio de Janeiro. Rio de Janeiro.

53. MASSEY, J.R. Manual of dosimetry in radiotherapy. (Vienna) International Atomic Energy Agency, 1971 (Technical Report Series no. 110).

54. INTERNACIONAL ATOMIC ENERGY AGENCY. Absorbed dose determination in photon and electron beams, IAEA, (Vienna), 1987. (Technical Reports Series no 277).

55. INTERNACIONAL ATOMIC ENERGY AGENCY. The use of plane parallel ionization chambers in high energy electron and photons beams, (Vienna) IAEA, 1997. (Technical Reports Series no 381).

56. RADCAL CORPORATION. MANUAL OF INSTRUCTIONS, Monrovia. CA. 2005. shttp://www.radcal.com.htm $>$.

57. PYCHLAU H AND PYCHLAU, P . Ein Diagnostik-Dosimeter- Grundform und Abwandlung Deutsche Röntgenkongr. Beiheft. Fortschr. Röntgenstr, V 100, p 177-180, 1964.

58. CARLSSON, C. Integral Absorbed Doses in Roentgen Diagnostic Procedures. I. Acta radiologica: therapy, physics, biology. $v 177, \mathrm{p}$ 310-326, 1965.

59. LARSSON, P. Calibration of ionization chambers for measuring air kerma integrated over beam area in diagnostic radiology. Linköping, Sweden, 2006. Linköping University Medical Dissertations No. 970, 2006 .

60. INTERNATIONAL ELECTROTECHNICAL COMMISSION.. Medical electrical equipment - Dosimeters with ionization chambers and/or semi-conductor detectors as used in X-ray diagnostic imaging. IEC 61674, Geneva, 1997.

61. MIRANDA, J. A. ; POTIENS, M. P. A. Controle de Qualidade de Câmaras de lonização Planas utilizadas como Câmaras Monitoras em Feixes de Radiodiagnóstico. Revista Brasileira de Física Médica, v. 1, n. 1, p. 1519, 2005. 
62. MIRANDA, J. A. ; POTIENS, M. P. A. . Evaluation of the utilization of flat ionization chambers as monitor chamber. In: 12th INTERNATIONAL CONGRESS OF THE INTERNATIONAL RADIATION PROTECTION ASSOCIATION, Outubro, 2008, Buenos Aires. Proceedings... Buenos Aires, 2008.

63. GREEN, S.; PALETHORPE, J.E.; PEACH, D.E.; BRADLEY, D.A. Development of a calibration facility for test instrumentation in diagnostic radiology. Radiation Protection Dosimetry, v. 67, n.1, p.41-46, 1996. 